Water Mass Distribution and Polar Front Structure in the Southwestern

\title{
Barents Sea
}

by

Carolyn Louise Harris

\section{B.A. Wellesley College}

(1990)

Submitted in partial fulfillment of the

requirements for the degree of

MASTER OF SCIENCE

at the

MASSACHUSETTS INSTITUTE OF TECHNOLOGY

and the

WOODS HOLE OCEANOGRAPHIC INSTITUTION

May 1996

(c) Carolyn Louise Harris 1996

The author hereby grants to MIT and to WHOI permission to repraduce W. H. O. I. and to distribute copies of this thesis document in whole or in part.

Signature of Author ........

Joint Program in Physical Oceanography Massachusetts Institute of Technology

Woods Hole Oceanographic Institution

April 26, 1996

Certified by ....... 4 . $\ldots, \ldots, \ldots, \ldots$

Albert J. Plueddemann Associate Scientist Thesis Supervisor

Accepted by

Chair, Joint Committee for Physical Oceanography Massachusetts Institute of Technology Woods Hole Oceanographic Institution 


\title{
WATER MASS DISTRIBUTION AND POLAR FRONT STRUCTURE IN THE SOUTHWESTERN BARENTS SEA
}

\author{
by \\ Carolyn Louise Harris \\ Submitted in partial fulfillment of the requirements for the degree of \\ Master of Science at the Massachusetts Institute of Technology \\ and the Woods Hole Oceanographic Institution \\ April 26, 1996
}

\begin{abstract}
The water mass distribution in the southwestern Barents Sea, the thermohaline structure of the western Barents Sea Polar Front, and the formation of local water masses are described based on an analysis of historical hydrographic data and a recent process-oriented field experiment. This study concentrated on the frontal region between Bjørnøya and Hopen Island where Arctic water is found on the Spitzbergen Bank and Atlantic Water in the Bear Island Trough and Hopen Trench. Distributions of Atlantic, Arctic, and Polar Front waters are consistent with topographic control of Atlantic water circulation. Seasonal buoyancy forcing disrupts the topographic control in the surface layer, altering the frontal structure, and affecting local water mass formation. In the winter, the topographic control is firmly established and both sides of the front are vertically well-mixed. Winter cooling creates sea-ice over Spitzbergen Bank and convectively formed Modified Atlantic Water in the Bear Island Trough and Hopen Trench. In the summer, heating melts the sea-ice, producing a surface meltwater pool that can cross the polar front, disrupting topographic control and substantially increasing the vertical thermohaline gradients in the frontal region. The meltwater pool produces the largest geostrophic shear in the region.
\end{abstract}




\section{Acknowledgements}

I am very grateful to my advisor, Al Plueddemann, for his patience, support, and helpful advice during my first few years in the Joint Program. I also thank the other members of my thesis committee, Ken Brink, Glenn Flierl, Glen Gawarkiewicz, and Breck Owens, for their helpful suggestions on this work. Glen Gawarkiewicz, in particular, provided many useful suggestions during the development of this work.

Some figures in this work were produced with source code contributed by Derek Fong, Rich Signell, Jay Austin, Jamie Pringle, as well as contributors to the ftp.mathworks.com site, including Rich Pawlowicz. Rich Pawlowicz also provided the initial code to read the NODC-A data. Audrey Rogerson provided help with formatting the document and Joanna Muench helped me overcome Adobe Illustrator's learning curve. Derek Fong and Miles Sundermeyer gave very helpful comments on an early draft of this thesis.

A number of people gave me wonderful support during the course of this work. They include Ann Moses, Cheryl Greengrove, Julie Pallant, and Deb McCulloch, who kept me on my feet (or bike), Craig Lee and Joanna Muench, who included me in many sustaining discussions and dinners, and my classmates, Jay Austin, Natalia Beliakova, Derek Fong, François Primeau, Jamie Pringle, Miles Sundermeyer, Brian Racine, and Bill Williams, who helped me in innumerable ways to get this far. Special thanks is extended to Derek Fong for all of his advice, scientific help, computer code, and especially the many slices of homemade pizza which sustained me while writing this work.

Support for this work was provided by a Department of Defense National Defense Science and Engineering Graduate Fellowship and Office of Naval Research grant N0001490-J-1359. 


\section{Contents}

$\begin{array}{ll}\text { Abstract } & 3\end{array}$

$\begin{array}{ll}\text { Acknowledgements } & 5\end{array}$

1 Background $\quad 13$

1.1 Regional context . . . . . . . . . . . . . . . . . . . 13

1.2 Recent process studies . . . . . . . . . . . . . . . . 18

1.3 Outline of present study . . . . . . . . . . . . . . . . . . . . . 20

2 Water mass distribution and polar front structure 23

2.1 Introduction . . . . . . . . . . . . . . . . . . . . 23

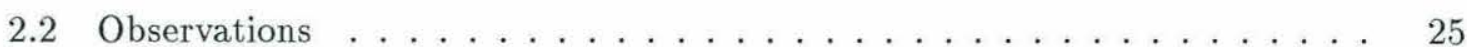

2.3 Results. . . . . . . . . . . . . . . . . . . . . 27

2.3.1 Subsurface water mass distributions . . . . . . . . . . . . . 28

2.3.2 Surface water mass distributions . . . . . . . . . . . . 36

2.3.3 Frontal structure and temporal variability . . . . . . . . . . . . . 40

2.4 Discussion . . . . . . . . . . . . . . . . . . . . 47 
2.4 .1 Water mass definitions . . . . . . . . . . . . . . 47

2.4 .2 Local water mass formation . . . . . . . . . . . . . . . . . 51

2.4.3 Seasonal frontal structure . . . . . . . . . . . . . . 56

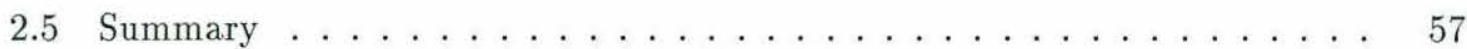

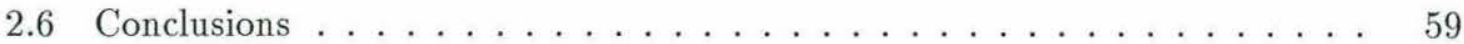

$\begin{array}{ll}\text { Bibliography } & 63\end{array}$

$\begin{array}{ll}\text { Appendices } & 67\end{array}$

A Supplementary information $\quad 67$

B NODC-B cross-front transect data $\quad 71$ 


\section{List of Figures}

1.1 Western Barents Sea map . . . . . . . . . . . . . . . 15

2.1 Location of observations . . . . . . . . . . . . . . . . 25

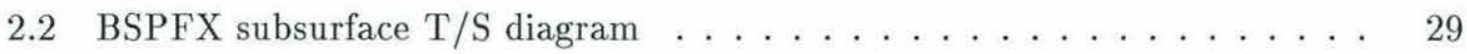

2.3 NODC subsurface $\mathrm{T} / \mathrm{S}$ diagram . . . . . . . . . . . . . . 30

2.4 NODC subsurface parent water mass geographical distributions . . . . . . . 31

2.5 NODC subsurface mixed water mass geographical distributions . . . . . . 32

2.6 NODC subsurface cross-bank water mass distributions . . . . . . . . . . . 34

2.7 BSPFX subsurface cross-bank water mass distributions . . . . . . . . 35

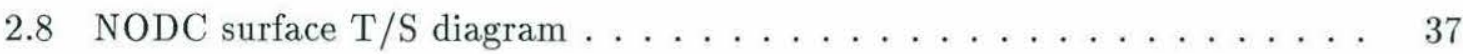

2.9 NODC surface water mass geographical distributions . . . . . . . . . 38

2.10 Surface layer unclassified water geographic distribution by salinity . . . . 39

2.11 Surface layer unclassified water . . . . . . . . . . . . . 41

2.12 Frontal region vertical thermohaline contrasts . . . . . . . . . . . . 43

2.13 NODC horizontal density contrasts . . . . . . . . . . . . . . 47

2.14 NODC cross-slope salinity transects . . . . . . . . . . . . 50 


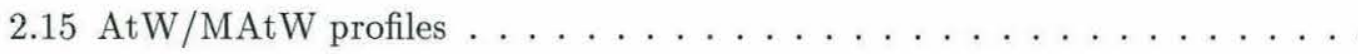

2.16 Schematic water mass modifications in $\mathrm{T} / \mathrm{S}$ space . . . . . . . . . 58

A.1 Noontime surface insolation . . . . . . . . . . . . . . 68

A.2 BSPFX CTD casts in $\mathrm{T} / \mathrm{S}$ space $\ldots \ldots \ldots \ldots \ldots$

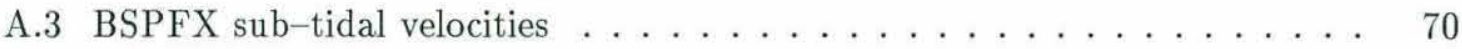

B.1 Key for NODC-B transect locations . . . . . . . . . . . . 72

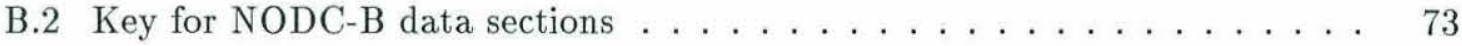

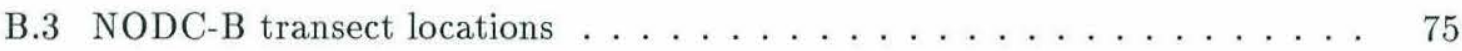

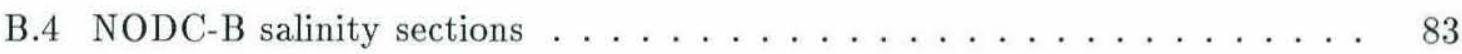

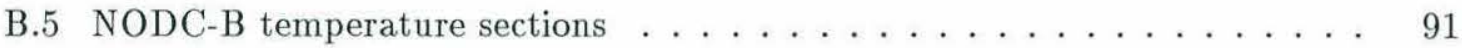

B.6 NODC-B density transects . . . . . . . . . . . . . . . . . 99 


\section{List of Tables}

2.1 Water mass definitions . . . . . . . . . . . . . . . . . 28

2.2 Monthly distribution of NODC-B cross-front transects . . . . . . . . . 42

2.3 Horizontal thermohaline contrasts, NODC-B and BSPFX . . . . . . . 45

A.1 Monthly surface heat flux . . . . . . . . . . . . . 67 


\section{Chapter 1}

\section{Background}

\subsection{Regional context}

The Barents Sea is a shallow marginal sea of the Arctic Ocean with connections to the Norwegian Sea to the west and the Kara Sea to the east. This study focuses on the western Barents Sea, a region where the water mass distribution is dominated by the Barents Sea Polar Front, the boundary between Atlantic water and Arctic water and an important site of water mass modification. The possibility of dense water or Arctic halocline water formation has attracted physical oceanographers to study the region for decades [Nansen, 1906; Aagaard et al., 1981; Aagaard et al., 1985; Steele et al., 1995], and biological oceanographers have long been interested in the high primary productivity near the polar front [Loeng, 1991]. Despite the interest in the region, little is known about the dynamics of the polar front or the factors controlling the variability of thermohaline properties in the frontal region.

This literature review describes the Barents Sea circulation, interannual water mass variability, dense water formation, ice cover, atmospheric forcing, and tides. The summary of the physical conditions in the Barents Sea is not intended to be comprehensive, but rather to describe those aspects which contribute most directly to the results presented 
in Chapter 2. The southwest Barents Sea is the primary focus, but other regions of the Barents are mentioned where relevant.

The general physical conditions in the Barents Sea have been described by Loeng [1991] and Pfirman et al. [1994]. The Barents Sea is rather shallow with a mean depth of $230 \mathrm{~m}$. The maximum depth of about $500 \mathrm{~m}$ occurs in the southwest Bear Island Trough (Figure 1.1). The main currents include the south or southwestward flowing Persey and East Spitzbergen Currents, which join to form the Bjørnøya (Bear Island) Current, and the northeastward flowing Norwegian Atlantic Current-Nordkapp Current. The Norwegian Atlantic Current-Nordkapp Current system transports North Atlantic water into the Barents while the Persey and East Spitzbergen currents transport water of Arctic origin. The Barents Sea Polar Front, the dominant large-scale feature of the central Barents, occurs at the junction of the Atlantic and Arctic waters. Observations of the surface temperature expression of the front along the southern flank of Spitzbergen Bank suggest that the front is topographically trapped [Johannessen and Foster, 1978]. Geostrophic calculations near Spitzbergen Bank referenced to $50 \mathrm{~m}$ depth indicate southwestward flow in the Arctic region north of the front and northeastward flow in the Atlantic region south of the front [Loeng, 1991]. The Atlantic water geostrophic flow is important to note because more recent studies, discussed below, indicate that a barotropic Atlantic water flow is superimposed on the geostrophic current and the net flow of Atlantic water near Spitzbergen Bank is actually in the opposite direction from the geostrophic flow [Parsons et al., 1996; Gawarkiewicz and Plueddemann, 1995].

In addition to its source in the Nordkapp Current, Atlantic water enters the Barents Sea from the north. This subsurface water mass, discussed in greater detail in Pfirman et al. [1994], enters the Barents after flowing along the western side of Spitzbergen and passing through Fram Strait. The temperature and salinity characteristics of this water mass are colder and fresher than the Atlantic water found in the southwestern Barents Sea due to the effects of processes along the different paths traversed by these currents. The northern Barents Atlantic water mass will be mentioned again in Chapter 2 after considering the water mass distributions in the southwestern Barents Sea. 


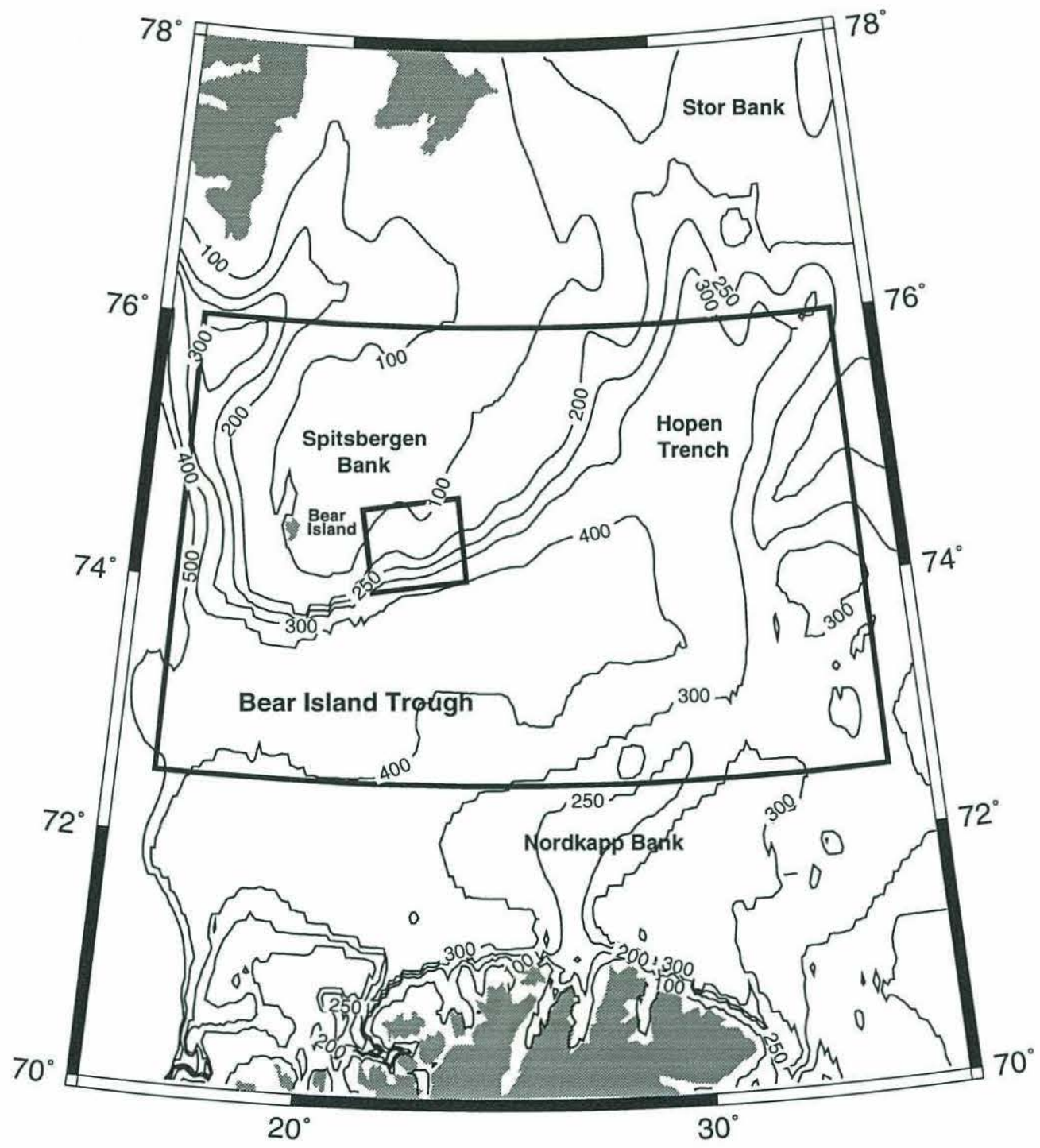

Figure 1.1: Map of the western Barents Sea. The bathymetry is from the ETOPO5 dataset; depth contours are shown in meters. The region containing the NODC-A data is shown by the large box. The Barents Sea Polar Front Experiment region is shown by the small box. 
The Atlantic water interannual variability has been calculated for observations in the Fugløya-Bjørnøya section from 1964-1979 [Blindheim and Loeng, 1981]. The observations were taken in the same season each year, therefore avoiding much of the seasonal fluctuation. Year to year fluctuations of up to $1.3^{\circ} \mathrm{C}$ occurred in the mean temperature field and up to $0.08 \%$ in the mean salinity field in the 100-200 m layer. Surface fluctuations $(0-50 \mathrm{~m})$ were stronger; up to twice as large as those in the 100-200 m layer. While year to year fluctuations decreased with depth, the longer term trends ( $\geq 3$ years) were approximately equal at all depths. The long term variability was attributed to variations in inflow volume and/or inflow thermohaline properties while the enhanced year to year variability in the surface layer was attributed to local processes. Advective changes thus appear to be important on longer time scales than local processes. Although the long term variability increases the uncertainties in categorizing water masses in the region, results presented in Chapter 2 show that the water masses defined by Loeng [1991] capture the core of the historical thermohaline distribution, especially below the surface layer.

The possibility of the Barents serving as a dense water source for the Arctic Ocean has been of great interest. Sea-ice formation causes brine rejection which forms dense water $\left(\sigma_{t} \leq 28.42 \mathrm{~kg} / \mathrm{m}^{3}\right)$ over the Storfjord off Svalbard Bank in the western Barents and along the coast of Novaya Zemlya in the eastern Barents [Midttun, 1985]. For comparison, the Arctic Ocean Deep Water has a density of $\sigma_{0}=28.09 \mathrm{~kg} / \mathrm{m}^{3}$ [Aagaard et al., 1985]. Other water types are also formed in the Barents. For example, slightly less dense convected water is formed by atmospheric cooling over Sentral Bank [Midttun, 1989]. Steele et al. [1995] reported formation of Arctic Halocline Water in the marginal ice zone of the northwest Barents. These observations support the concept that the Barents Sea is a region of active water mass modification. The present study will show that although a convective water mass similar to that found on Sentral Bank is formed in the southwest Barents Sea along the polar front, no significant amount of Arctic Ocean Deep Water nor Arctic Halocline Water is produced by the processes operating in the polar front region.

Important factors in water mass modification in the western Barents include the ice cover and heat flux. The geographic extent of ice cover varies little from year to year in 
the western Barents but it varies significantly, by hundreds of kilometers, in the eastern Barents [Midttun, 1989]. The southwestern Barents remains ice-free throughout the year because the surface heat flux is not strong enough to cool the Atlantic water sufficiently to form sea-ice. The maximum extent of the ice in the western Barents Sea is thus related to the location of the polar front. In contrast, the northern Barents is ice-covered much of the year. For example, at $76^{\circ} 30^{\prime} \mathrm{N}$, the southern tip of Spitzbergen is ice-free only from June through November [NCDC, 1990; Vinje, 1977]. Little multi-year sea-ice is observed in the Barents suggesting that most of the ice cover is locally formed rather than advected from the Arctic [Vinje, 1985]. The ice thickness is typically $40-150 \mathrm{~cm}$ between Bjørnøya and Hopen Island from January to May, with larger values in the north [Vinje, 1985]. In the summer, the sea-ice melts and mixes with Arctic water to form a surface low salinity water mass. This meltwater mass is produced north of the front, but it sometimes crosses into the Atlantic water region, capping the polar front. In Chapter 2, a connection will be hypothesized between the characteristics of the locally formed Modified Atlantic Water, and the amount of meltwater present in the frontal region.

The atmosphere-ocean heat flux has been calculated by Häkkinen and Cavalieri [1989] from observations taken during 1979. The results show this high-latitude sea has a short season of surface heating. In the region near Bjørnøya, net surface heating occurs only during the months of June-August. Averaged over an entire year, the Barents experiences a net surface heat loss, which is balanced by advection of warm currents from the south. The largest surface heat flux near Bjørnøya, $-440 \mathrm{~W} / \mathrm{m}^{2}$, occurs during February. The surface heat fluxes from the northern Barents are small compared to the southern Barents because the northern waters are colder to begin with, reducing the sensible heat loss, and because ice cover, once formed, insulates the water from additional heat loss. The heat flux calculated by Häkkinen and Cavalieri [1989] is applied to the hydrographic data in Chapter 2.

Tidal motions are strong near Spitzbergen Bank. Tidal velocities up to $100 \mathrm{~cm} / \mathrm{s}$ west of Bjørnøya on Spitzbergen Bank have been predicted by a model [Kowalik and Proshutinsky, 1995]. The shallow Spitzbergen Bank and strong tidal forcing produce a tidal mixing front whose location coincides with the $100 \mathrm{~m}$ isobath to the south and west of Bjørnøya. 
This tidal mixing front, which contains well-mixed waters, is relevant in Chapter 2 where vertical and horizontal stratification near the Bjørnøya is presented. Since the purpose of presenting the stratification is to characterize the polar front, an attempt has been made to exclude hydrographic stations positioned inside the tidal front from the analysis.

\section{$1.2 \quad$ Recent process studies}

Two specific studies are described because their results provided much of the motivation for the present work. The two studies are the Barents Sea Polar Front Experiment, [Parsons et al., 1996] and the numerical model of circulation in the southwest Barents described by Gawarkiewicz and Plueddemann [1995].

The Barents Sea Polar Front Experiment (BSPFX), a coordinated physical oceanography and acoustic field study, was conducted during three weeks of August 1992. The experiment took place about $60 \mathrm{~km}$ east of Bjørnøya in a $80 \times 70 \mathrm{~km}$ region on the southern slope of Spitzbergen Bank. Details of the experiment are discussed in Parsons et al. [1996]. A CTD survey provided hydrographic information for the BSPFX region and a shipboard Acoustic Doppler Current Profiler (ADCP) provided current measurements during the experiment. Current data were also obtained from three current meter moorings located in the northeast, northwest, and southwest corners of the survey region.

The $10 \times 10 \mathrm{~km}$ resolution hydrographic survey captured the frontal structure and demonstrated that the subsurface contributions of variations in temperature and salinity to the density field at the front were compensating, resulting in an average cross-front

density gradient of only $0.05 \mathrm{~kg} / \mathrm{m}^{3}$. The current measurements were dominated by strong tidal flows; the dominant tidal constituents $\left(\mathrm{M}_{2}, \mathrm{~S}_{2}\right.$, and $\left.\mathrm{K}_{1}\right)$ combined to create currents up to $50 \mathrm{~cm} / \mathrm{s}$. Sub-tidal flows were obtained from the current meter data by averaging over the deployment period [Parsons et al., 1996]. Sub-tidal flows were obtained from the shipboard ADCP data by a harmonic fitting technique [Candela et al., 1992]. Details of the application of this technique to the BSPFX ADCP data are reported in Harris et al. [1995]. The current meter and ADCP sub-tidal velocities showed little or no depth-averaged 
flow over the shelf. Along the entire southern portion of the survey region, however, the depth-averaged sub-tidal velocities indicated an along-isobath flow of Atlantic water of approximately $10 \mathrm{~cm} / \mathrm{s}$ to the west (see Appendix A, Figure A.3). The BSPFX geostrophic velocities referenced to $50 \mathrm{~m}$ depth showed eastward flow along the front, agreeing with previous circulation schemes (e.g., Loeng [1991]). Assuming, however, that the BSPFX sub-tidal flow represented the long-term mean flow implied that a different dynamical process must dominate the circulation.

Motivated by observations from the BSPFX experiment, Gawarkiewicz and Plueddemann [1995] used a numerical model to examine the thermohaline structure of the polar front. Their results showed that a barotropic inflow of North Atlantic water would conserve potential vorticity by flowing along isobaths, which implies that Atlantic water must flow around Bear Island Trough and recirculate into the Norwegian Sea. Other than this recirculation, topographically controlled Atlantic water can exit the trough only where the isobaths bifurcate to provide multiple flow paths, such as at the Sentral Bank-Nordkapp Bank Sill. This sill has an approximate depth of $250 \mathrm{~m}$ and, downstream of this sill, the $250 \mathrm{~m}$ isobath continues unbroken around the rest of Bear Island Trough. One implication of these results is that Atlantic water over isobaths shallower than $250 \mathrm{~m}$ exits Bear Island Trough at the Nordkapp Bank-Sentral Bank Sill. A second implication is that downstream of the sill, including the polar front region, the Atlantic water remains trapped to isobaths deeper than $250 \mathrm{~m}$. Hence, the polar front is trapped to the $250 \mathrm{~m}$ isobath.

Additional evidence supports the Atlantic water topographic control theory. For example, direct current measurements across the Bear Island Trough [Blindheim, 1989] show westward velocities at all depths between $73^{\circ} 30^{\prime} \mathrm{N}$ and Bjørnøya, a region including the recirculating Atlantic water. Simulations from a density driven three-dimensional primitive equation model show a recirculation of Atlantic water in the Bear Island Trough [Slagstad et al., 1990]. To maintain consistency with the accepted northeastward Atlantic water flow, many of these earlier results were considered unexplainable or were attributed to other phenomena, such as dense water outflow. More recently, Pfirman et al. [1994] reported an Atlantic water return flow along the eastern flank of Spitzbergen Bank based on a water 
mass core analysis. Finally, in a study of the production of dense water that feeds the overflows across the Greenland-Scotland Ridge, Mauritzen [1993] suggested that Atlantic water recirculation in the Barents Sea is part of the pre-conditioning for later deep convection in the Greenland Sea. Her results not only support the recirculation hypothesis, they also suggest that processes active along the recirculation path have implications beyond the regional circulation by affecting Greenland Sea deep convection.

\subsection{Outline of present study}

This literature synthesis has presented the Barents Sea as a region with large variability, a strong atmospheric heat flux, large tidal currents and active water mass formation processes, including convection, sea-ice formation and meltwater dynamics. A relatively simple, barotropic, topographic control theory of Atlantic water for the southwest Barents has been summarized.

Despite consistency with these previous results and good agreement with thermohaline characteristics observed during the BSPFX, the topographic control theory does not explain some principle frontal features clearly present in the observations. In particular, the theory lacks the summertime surface meltwater layer which, on occasion, disrupts the topographic control of Atlantic water in the surface layer by crossing the polar front. This work addresses four principal questions relating to the Atlantic water circulation, polar front thermohaline structure, and water mass modification:

- Is there evidence in the historical hydrographic data that the recirculating Atlantic water remains trapped to the $250 \mathrm{~m}$ isobath throughout the western Barents Sea?

- Under what conditions does the topographic control of Atlantic Water break down in the surface layer?

- What water mass modifications occur due to the proximity and thermohaline structure of water masses in the polar front region?

- What is the structure of the meltwater pool and what is its role in water mass modifications? 
Chapter 2 addresses these questions. Historical hydrographic data are analyzed to provide a framework integrating the current Atlantic water circulation theory with the observed water mass distributions and thermohaline frontal structure. Water mass modifications and seasonal processes local to the polar front are incorporated into the framework. Additional information about the observations and processes discussed in this study is included in the Appendices. 


\section{Chapter 2}

\section{Water mass distribution and polar front structure}

\section{$2.1 \quad$ Introduction}

The Barents Sea is a shallow Arctic shelf sea influenced by both Arctic and Atlantic water masses. The Barents Sea Polar Front, the boundary between the Atlantic and Arctic waters, is an active site of water mass modification. Motivated by results from the Barents Sea Polar Front Experiment (BSPFX), a recent modelling study presented a circulation scheme for the southwestern Barents Sea in which a westward, barotropic flow of Atlantic

water was trapped to isobaths deeper than $250 \mathrm{~m}$ along the polar front [Gawarkiewicz and Plueddemann, 1995]. Such a circulation scheme contrasts with the generally accepted view of eastward Atlantic water flow [Loeng, 1991].

Despite this contrast, the topographic control theory is appealing for a number of reasons. The theory is simple, it is dynamically based, and it agrees with the BSPFX observations at $80 \mathrm{~m}$ depth. The theory does not, however, fit the observations equally well at all depths. In particular, the barotropic model assumption is inconsistent with the surface meltwater layer present in the observations. Further, although it agrees with the 
BSPFX observations at $80 \mathrm{~m}$ depth, the model may not represent the mean circulation because the BSPFX experiment lasted for only three weeks, and we have little information on how temporally or spatially characteristic the BSPFX data really are.

Historical data from the National Oceanographic Data Center (NODC) archives can be used to consider frontal structure issues in a broader context. This study tests predictions of water mass distributions based on the topographic control theory over a broad time and space span at the surface and at depth with the conclusion that geographic distributions of defined water masses are consistent with the topographic control theory. Since the historical data show occasional disruption of the topographic control of Atlantic Water in the surface layer, this study then analyzes the historical data to determine the conditions under which the topographic control of Atlantic Water breaks down. In particular, the effects of seasonality on the frontal structure are examined by considering the lateral and vertical gradients of temperature, salinity, and density. In the winter, the frontal region is found to have very small vertical gradients at all depths. In the summer, the presence of a meltwater pool alters the surface structure in the frontal region by producing significant vertical gradients in temperature, salinity, and density. Water mass modifications which occur in the polar front region are examined and the results show that in addition to the two major Atlantic and Arctic water masses, two other water masses are present in the region; Polar Front Water, previously described by Loeng [1991] and Parsons et al. [1996] and Modified Atlantic Water, which forms via convection during late winter or early spring. The surface meltwater pool, which forms annually in the late spring and summer from melted sea-ice mixed with Arctic Water, is hypothesized to play a key role in both the surface disruption of topographic control at the polar front and in the formation of Modified Atlantic Water.

The observational basis for this analysis is described in Section 2.2 and the results are presented in Section 2.3. A more extended discussion of the results is presented in Section 2.4. The results are summarized in Section 2.5 and conclusions from this work are presented in Section 2.6. 


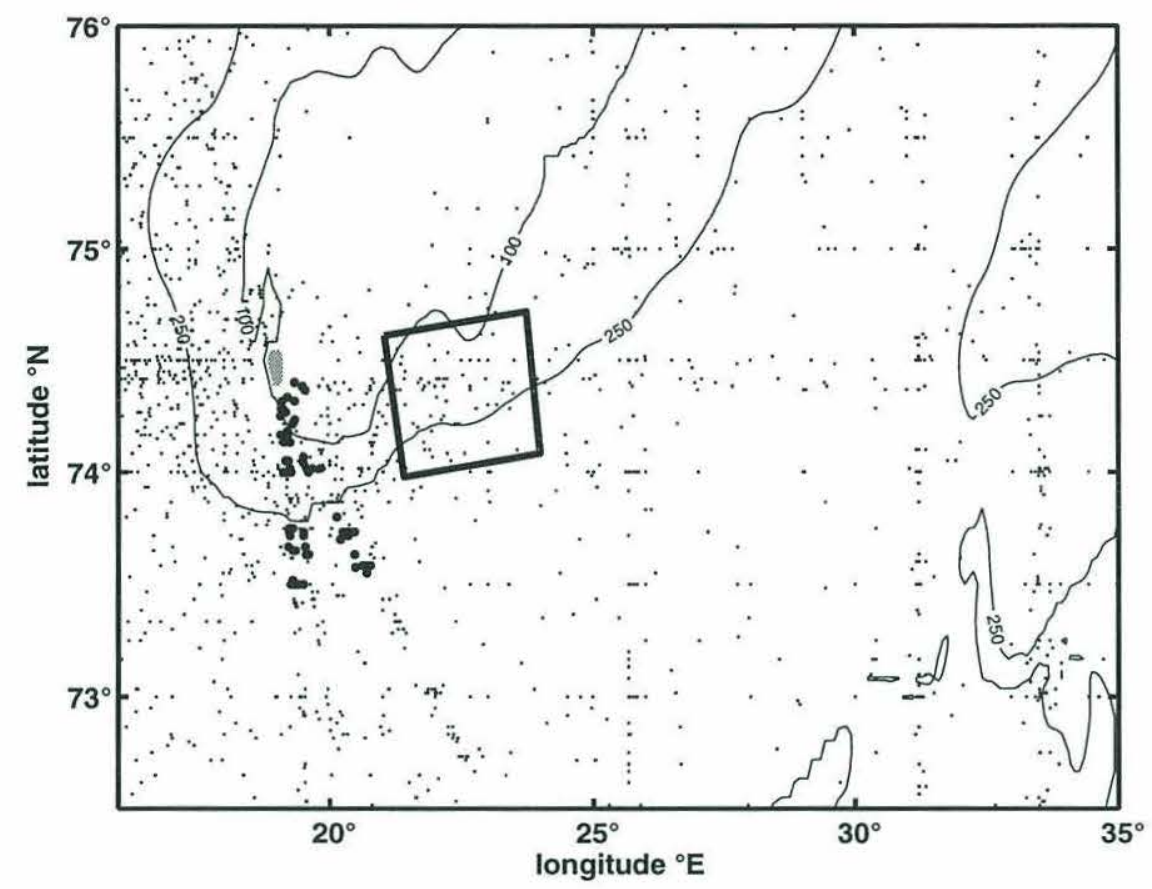

Figure 2.1: The entire figure represents the region for which NODC-A data were extracted (see Figure 1.1). The bathymetry is from the ETOPO5 dataset; contours at 100 and $250 \mathrm{~m}$ are shown. Bear Island appears shaded near $74^{\circ} 30^{\prime} \mathrm{N} 19^{\circ} \mathrm{E}$. Locations of individual NODCA casts are shown by the small black dots. The locations of the NODC-B data are shown as large black dots near Bear Island. The Barents Sea Polar Front Experiment region is shown by the dark box to the east of Bear Island.

\subsection{Observations}

The BSPFX experiment region spanned a $80 \times 70 \mathrm{~km}$ section of Spitzbergen Bank about $60 \mathrm{~km}$ east of Bear Island (Figure 2.1). The 3-week experiment took place in August 1992. The minimum water depth in the region was about $100 \mathrm{~m}$ and the maximum about $450 \mathrm{~m}$. The hydrographic survey included cross-slope transects occupied with CTD stations which provided $10 \mathrm{~km}$ resolution in both the along-front and across-front directions. Each of the transects was occupied multiple times, but due to the potential complications of the abrupt topography of Finger Canyon in the western part of the survey region, only 10 transects from the eastern part of the study region are included in this analysis. Further details of the experiment appear in Parsons et al. [1996]. 
Historical data from the NODC archives were used to extend the temporal and spatial coverage of the temperature and salinity data. Two NODC data sets are used: the Global Ocean Temperature and Salinity Profiles $[N O D C, 1991]$ and the Oceanographic Station Profile Time Series $[N O D C, 1993]$. Hereinafter, the former data set will be referred to as NODC-A and the latter as NODC-B. The NODC-A data were restricted to the region $72.5-76.0^{\circ} \mathrm{N}$ and $16.0-35.0^{\circ} \mathrm{E}$ (Figure 2.1). In order to focus on repeated transects which spanned the polar front region, the subset of NODC-B data named NA-12 was used and this subset was further restricted to the region $72.5-75^{\circ} \mathrm{N}, 19-22^{\circ} \mathrm{E}$. In an effort to utilize only data collected with post-World War II measurement technologies, data prior to 1950 were ignored in both NODC data sets.

This analysis used the NODC data sets for two distinct purposes. First, the geographic distributions of water masses defined by temperature and salinity characteristics were examined. The widest possible temporal and spatial resolution was obtained by including both NODC-A and NODC-B data in this part of the analysis. Second, the thermohaline structure of the frontal region was examined. Individual realizations of transects crossing the polar front were obtained from the NODC-B data for this part of the analysis.

Cross-frontal sections were extracted from the NODC-B data in the following way. The records were first sorted by cruise number and then each cruise was sorted by time. The cruises were separated into cross-front transects and any transect with fewer than 3 cross-front stations was ignored as were individual stations which did not form a simple transect across the frontal region. A few casts contained clearly anomalous data and these data were removed. The resulting data set contained two repeated cross-front transects; one apparently along the Fugløya-Bjørnøya line and the other trending southeast of Bear Island. Both lines are to the west of the BSPFX region (Figure 2.1). Individual transects are shown in Appendix B.

A number of caveats should be kept in mind when working with the NODC data, which span several decades and technologies. First, although all data are reported to be observed rather than interpolated values, data are often reported only at standard depths, i.e., $0,10,20,50,100 \mathrm{~m}$, etc. Inflection points are generally missing when data are reported 
in this way and therefore gradients estimated from such data are expected to be smaller than the true gradients. Second, Blindheim and Loeng [1981] found the region to have large interannual variability, making large scatter inevitable in the results. Third, the data are biased toward summertime observations, probably a result of the unpleasant realities of making wintertime oceanographic measurements in a sub-Arctic sea. Finally, the maximum resolution of the data set is $0.01 \mathrm{psu}$ for salinity and $0.01^{\circ} \mathrm{C}$ for temperature, limiting the precision of the results. Although the use of electrical conductivity techniques gives a theoretical accuracy for salinity of $0.002 \%$ [Levitus, 1982], the accuracy of the NODC data set is difficult to determine and it is believed the accuracy of the worst data points may be as poor as $0.1^{\circ} \mathrm{C}$ and 0.1 psu. Previous work has found Arctic NODC data to be noisy, but consistent with other data sets when averaged appropriately [Aagaard et al., 1985].

\section{$2.3 \quad$ Results}

The results from the analysis are described in this section. First, the geographic distributions of the subsurface $(>50 \mathrm{~m})$ water masses are presented and found consistent with the topographic control theory. Next, the surface $(0-50 \mathrm{~m})$ geographic distributions are shown using the same water mass definitions. While the geographic distributions of the defined water masses in the surface layer are also consistent with the topographic control theory, nearly half of the surface layer data are outside the water mass definitions, mainly due to seasonal changes. The seasonal changes in surface water masses reported here and in the literature provide motivation to examine the thermohaline frontal structure and its temporal variability. The vertical structure of the temperature, salinity and density fields is examined, showing that the polar front region is vertically well-mixed in wintertime but has significant vertical stratification in the summertime, mainly due to the meltwater pool. The horizontal density gradients demonstrate that the summertime meltwater pool contains the main geostrophic shear in the polar front region. The BSPFX observations are analyzed separately and compared with the NODC results, demonstrating that the BSPFX data generally represent typical summertime conditions at the polar front. 


\begin{tabular}{lrr} 
Water Mass & $\mathrm{T}\left({ }^{\circ} \mathrm{C}\right)$ & $\mathrm{S}(\mathrm{psu})$ \\
\hline & & \\
Atlantic & $1.0-8.0$ & $35.00-35.20$ \\
Arctic & $\leq 0.0$ & $34.30-34.80$ \\
Polar Front & $1.0-2.0$ & $34.80-35.00$ \\
& $-0.5-1.0$ & $34.80-34.95$ \\
Modified Atlantic & $<1.0$ & $34.95-35.10$ \\
\hline
\end{tabular}

Table 2.1: Southwestern Barents Sea water mass definitions. See also Figure 2.2.

\subsubsection{Subsurface water mass distributions}

The geographic distributions of subsurface water masses are now described. The topographic control theory suggests that given a barotropic Nordkapp Current, the polar front will be located at the same isobath as the Nordkapp Bank-Sentral Bank sill depth, about $250 \mathrm{~m}$. To test this theory with the available data, water mass definitions were chosen and the geographic distributions of these water masses were analyzed. From the topographic control theory we expect to find Atlantic water only where the bottom depth is greater than $250 \mathrm{~m}$ and Arctic water only where the bottom depth is less than $250 \mathrm{~m}$. Polar Front water should be located in between the Atlantic and Arctic water masses.

The water mass definitions used for this part of the analysis are listed in Table 2.1. The definitions, which closely follow [Loeng, 1991], were not intended to be all-inclusive but rather were chosen to incorporate the dominant water masses in the region. Note that some water masses important to the broader circulation of the Barents Sea (e.g., Coastal Water) are intentionally excluded by restricting the geographic region in order to focus on the polar front. The choice of water mass definitions is discussed in Section 2.4.

A temperature/salinity (T/S) diagram for subsurface $(>50 \mathrm{~m})$ BSPFX data is shown in Figure 2.2. Water mass definitions are also shown. The observed Atlantic Water core occupies a narrow region in T/S space while the Polar Front Water and Arctic Water distributions are slightly more diffuse. No Modified Atlantic Water was found during this summertime experiment. 


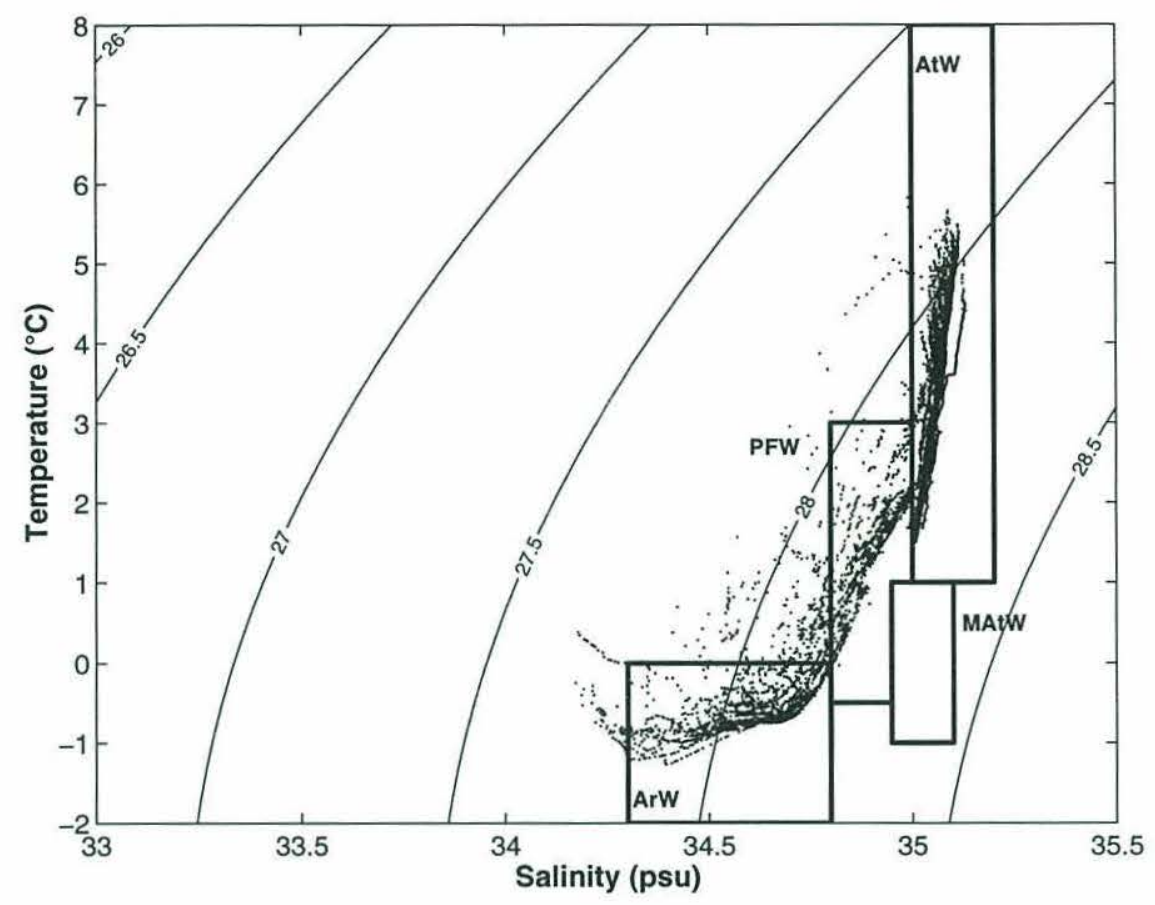

Figure 2.2: Temperature/salinity diagram for BSPFX CTD data deeper than $50 \mathrm{~m}$. Density $\left(\sigma_{t}\right)$ contours, referenced to $50 \mathrm{db}$, are superimposed along with water mass definitions. The two parent water masses are Atlantic Water (AtW) and Arctic Water (ArW) and the two locally formed water masses are Polar Front Water (PFW) and Modified Atlantic Water (MAtW). Labels designating the Polar Front and Modified Atlantic water mass definitions are displayed outside their respective boxes. Water mass definitions are identical to Table 2.1.

The same water mass definitions applied to the NODC data are shown in Figure 2.3. The historical data fill the water mass definition boxes more evenly than the BSPFX data, resulting in less concentrated $\mathrm{T} / \mathrm{S}$ core regions. The historical data also occupy a significantly greater range in $\mathrm{T} / \mathrm{S}$ space outside the water mass boxes, a result attributed to the greater geographical and temporal range of the NODC data and the large interannual variability reported for the Barents [Blindheim and Loeng, 1981].

The geographic extent of the Atlantic and Arctic water masses is shown in Figure 2.4. Based on these distributions, the following two points can be made. First, around Spitzbergen Bank, the subsurface Atlantic Water is found mostly in waters deeper than $250 \mathrm{~m}$ (Figure 2.4a). Second, the subsurface Arctic Water distribution extends into waters deeper than the shelfbreak (roughly the $100 \mathrm{~m}$ isobath) but tends to remain shelfward of 


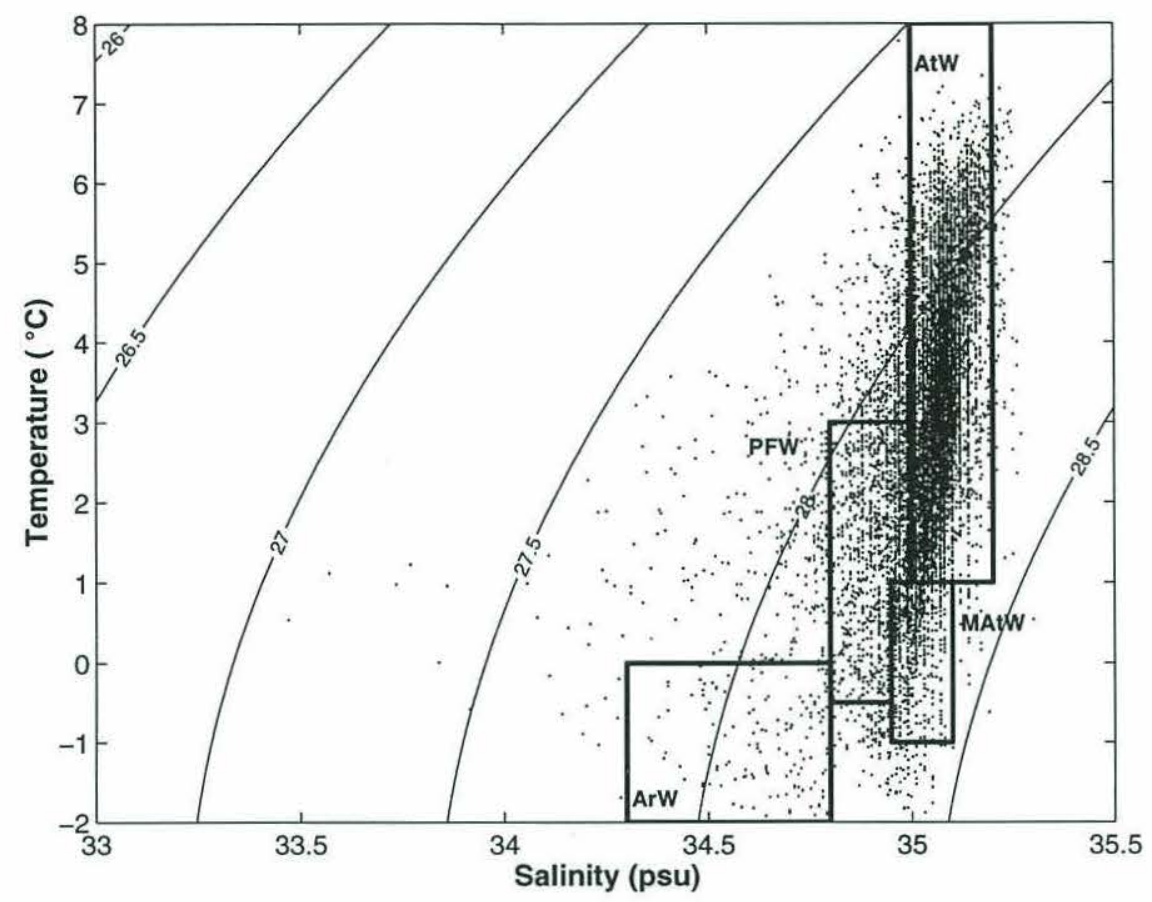

Figure 2.3: T/S diagram for the combined NODC-A and NODC-B data sets. Water mass definitions are the same as Figure 2.2 and Table 2.1.

the $250 \mathrm{~m}$ isobath (Figure $2.4 \mathrm{~b}$ ). Both results are consistent with the topographic control theory. The second result also demonstrates that the Arctic Water boundary is not coincident with the tidal front on Spitzbergen Bank. Kowalik and Proshutinsky [1995] calculated the location of the tidal front with a numerical model and found the tidal front located at the $100 \mathrm{~m}$ isobath in the immediate vicinity of Bjørnøya, but shallower, between the $50 \mathrm{~m}$ and $100 \mathrm{~m}$ isobaths, north or east of the island. Note that Arctic Water does not appear on the shallowest parts of Spitzbergen Bank in Figure 2.4b because observations above $50 \mathrm{~m}$ depth are not included in the figure.

The subsurface distributions of locally produced Polar Front Water and Modified Atlantic Water from the NODC data are shown in Figure 2.5. Again, only data deeper than $50 \mathrm{~m}$ depth are shown. The distribution of Polar Front Water (Figure 2.5a) is less straightforward than either parent water mass (see Figure 2.4). While Polar Front Water is found predominantly between the 100 and $250 \mathrm{~m}$ isobaths, there is considerable scatter of this water mass in the Hopen Trench as well as near the opening to the Norwegian Sea. 
a. Atlantic Water

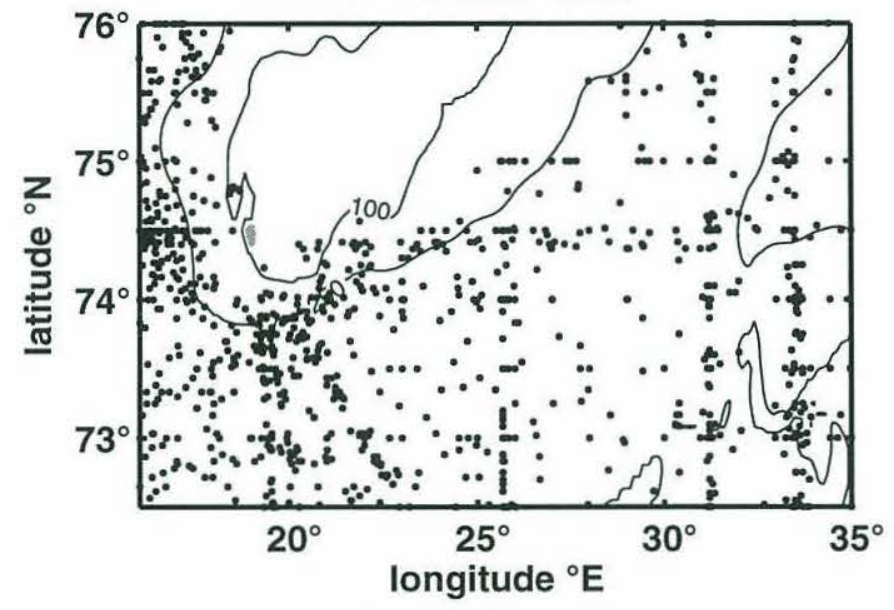

b. Arctic Water

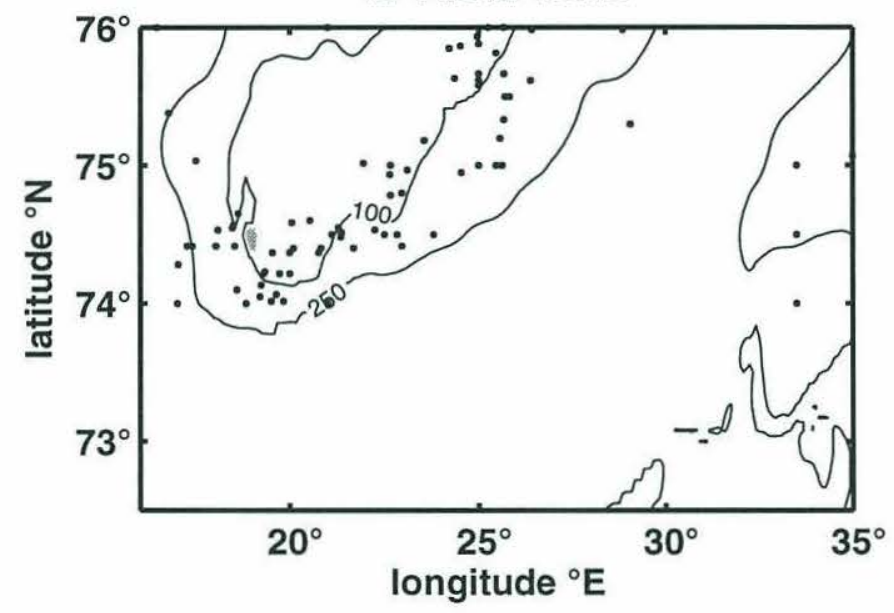

Figure 2.4: Geographic distributions of subsurface (>50 m) (a) Atlantic Water and (b) Arctic Water in the southwestern Barents Sea. The data are superimposed on a topographic map from the ETOPO5 bathymetry with contours showing the 0,100 , and $250 \mathrm{~m}$ isobaths. Water masses are defined in Table 2.1. 


\section{a. Polar Front Water}

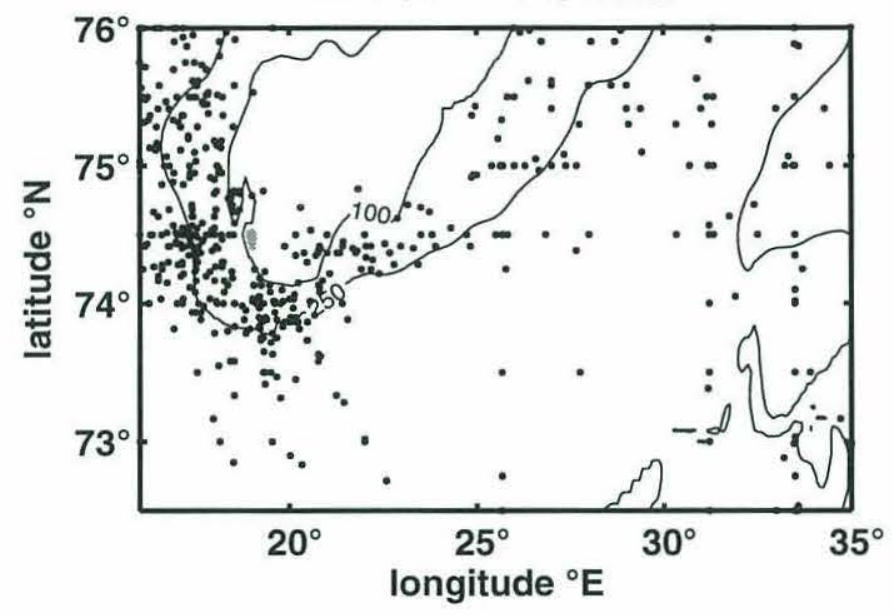

b. Modified Atlantic Water

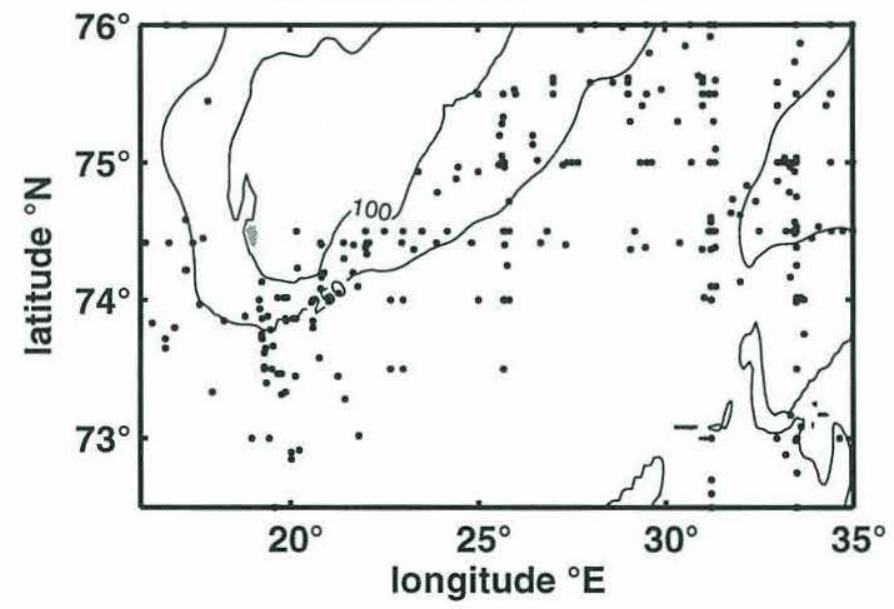

Figure 2.5: Geographical distributions of subsurface (>50 m) (a) Polar Front Water and (b) Modified Atlantic Water. Water masses are defined in Table 2.1. Topography is the same as Figure 2.4. 
The scatter in this figure is likely due to eddy activity and will be discussed further in Section 2.4.

The distribution of the second locally formed water mass, Modified Atlantic Water is shown in Figure 2.5b. Modified Atlantic Water is found on the southeast slope of Spitzbergen Bank, predominantly between the $100 \mathrm{~m}$ isobath and the deepest part of Bear Island Channel, and on the shallow Sentral Bank to the east. The distribution on the southern flank of Spitzbergen Bank in particular suggests that Modified Atlantic Water is formed in conjunction with processes at the polar front. Its distribution and formation via convection will be discussed further in Section 2.4, where order of magnitude calculations will show that the observed surface heat flux and the amount of fresh water liberated by sea-ice melting are consistent with the amounts required to transform Atlantic Water into Modified Atlantic Water.

The southern slope of Spitzbergen Bank has rapidly changing topography with respect to the large scale of Figures 2.4 and 2.5. While these figures allow a gross view of the water mass distributions from all the NODC data, the NODC-B and BSPFX crossfrontal transects permit a closer view of the water mass distributions with respect to the topography of the flank of Spitzbergen Bank.

The percentage of the water column $(>50 \mathrm{~m}$ ) occupied by each water mass type is calculated for each transect as a function of cross-slope distance. The mean percentages for the NODC-B data are displayed in Figure 2.6. In order to account for water which has been warmed by solar radiation as well as water which results from ice melt, the definition of Arctic Water was expanded from the definition in Table 2.1 to include all water with $\mathrm{S}<34.8$ psu. This modification only alters the results within an offshelf distance of $55 \mathrm{~km}$. The NODC-B data show the prevalence of Arctic Water on the shallow shelf and Atlantic Water deeper in the trough (Figure 2.6). Unfortunately, a lack of data around $60 \mathrm{~km}$ off the shelf precludes verification of the hypothesized concentration of Polar Front Water at mid-slope. 


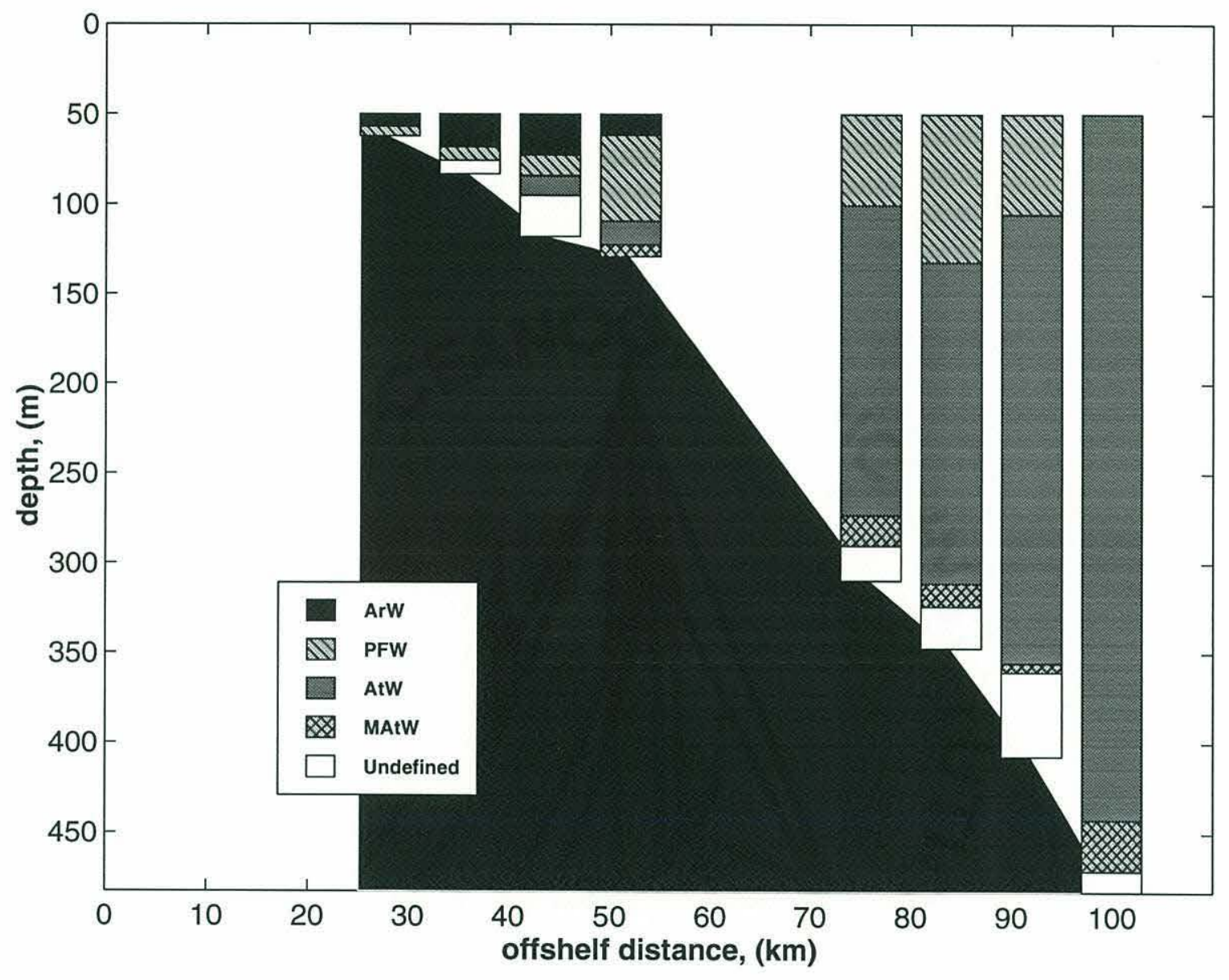

Figure 2.6: The relative importance of each water mass as a function of cross-bank distance is shown for subsurface (>50 m) NODC-B data. The vertical location of water masses within the water column is meaningless in this presentation and only the relative height is important. The data have been averaged into $8 \mathrm{~km}$ bins in the horizontal and any bin with fewer than 5 casts is not displayed; a lack of data around $60 \mathrm{~km}$ is the cause of the gap in the figure. The bathymetry are averaged from bottom depths recorded with each cast. Water mass definitions are identical to Table 2.1 except the Arctic Water definition is expanded to include all water with $\mathrm{S}<34.8$. 


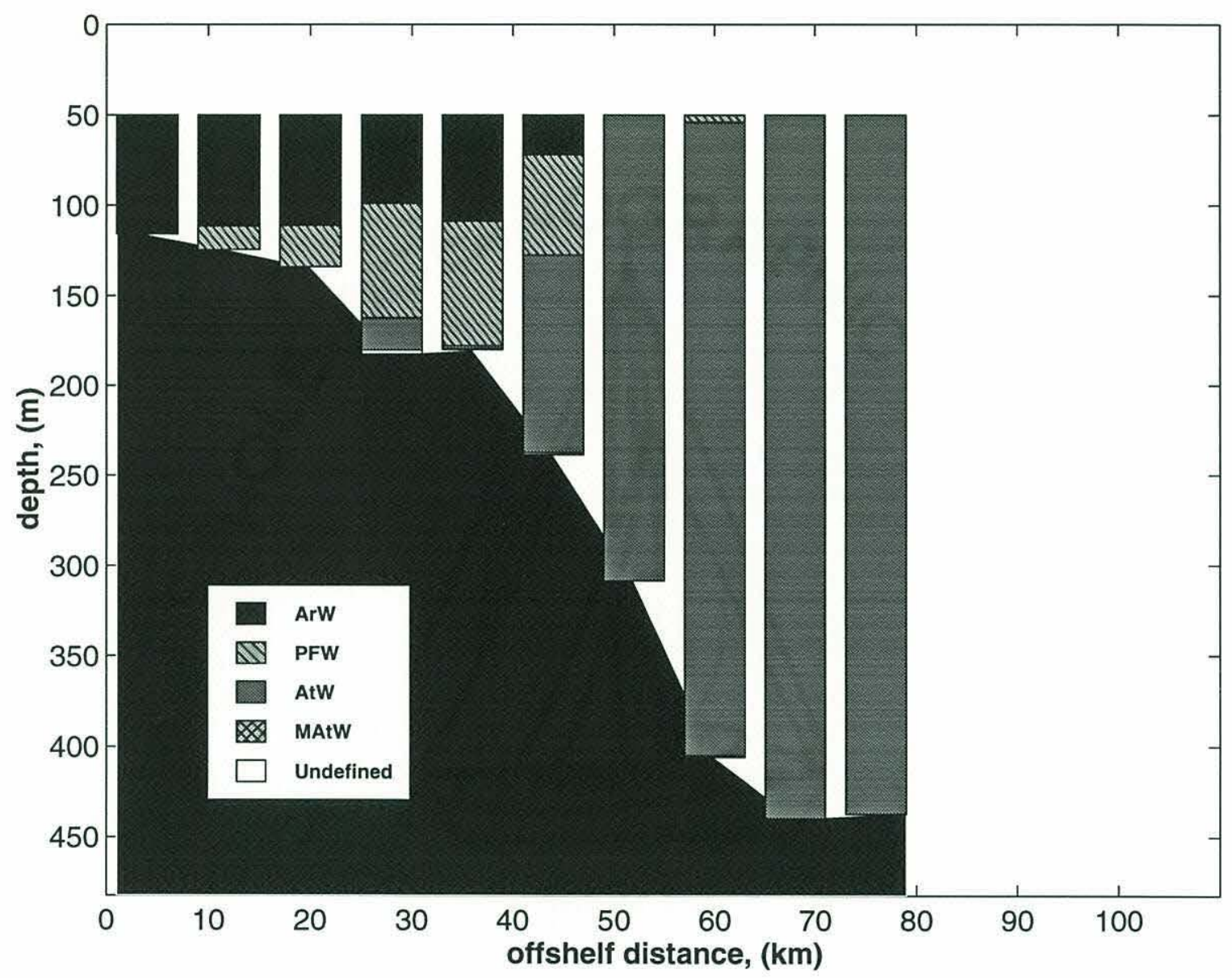

Figure 2.7: The relative importance of each water mass as a function of cross-bank distance is shown for subsurface $(>50 \mathrm{~m}$ ) BSPFX data. See Figure 2.6 for further details. 
The results of the same analysis applied to the BSPFX data are displayed in Figure 2.7. Arctic Water is shown concentrated on the shallow shelf and Atlantic Water dominates the water column where depths are greater than $250 \mathrm{~m}$. The main core of Polar Front Water between the Arctic and Atlantic waters is visible shelfward of the $250 \mathrm{~m}$ isobath in this figure.

In summary, the subsurface distributions of Atlantic, Arctic, and Polar Front waters are consistent with expectations from the topographic control theory. The subsurface distribution of Modified Atlantic Water suggests that its formation is linked with processes in the polar front region.

\subsubsection{Surface water mass distributions}

Not shown in the previous geographical distributions (Figures 2.2-2.4) are the data from the surface layer, 0-50 $\mathrm{m}$ depth. These data cover a much wider region in $\mathrm{T} / \mathrm{S}$ space, extending as warm as $10^{\circ} \mathrm{C}$ and as fresh as $32 \mathrm{psu}$ in the NODC data. This wide range makes the coverage in T/S space quite sparse. Consequently, it is difficult to clearly define water masses in the surface layer. To illustrate this greater variability in T/S space, the NODC $0-50 \mathrm{~m}$ surface layer T/S characteristics are shown in Figure 2.8. Only $55 \%$ of the surface layer data are contained within one of the water mass definitions (see Table 2.1) compared with $90 \%$ of the data below $50 \mathrm{~m}$ depth.

The geographical distributions of the water masses in the surface layer, 0-50 m, are shown in Figure 2.9. These figures display the location of only those data which fall into one of the water mass boxes defined in Table 2.1. As noted above, this is about $55 \%$ of the surface data. These figures are quite similar to the subsurface water mass geographical distributions shown in Figures 2.4 and 2.5, indicating that the topographic control theory remains valid in the surface layer within the context of the original water mass definitions. What is left unclear from these figures is how the unclassified $45 \%$ of the surface waters are distributed, and, more importantly, what their sources are. 


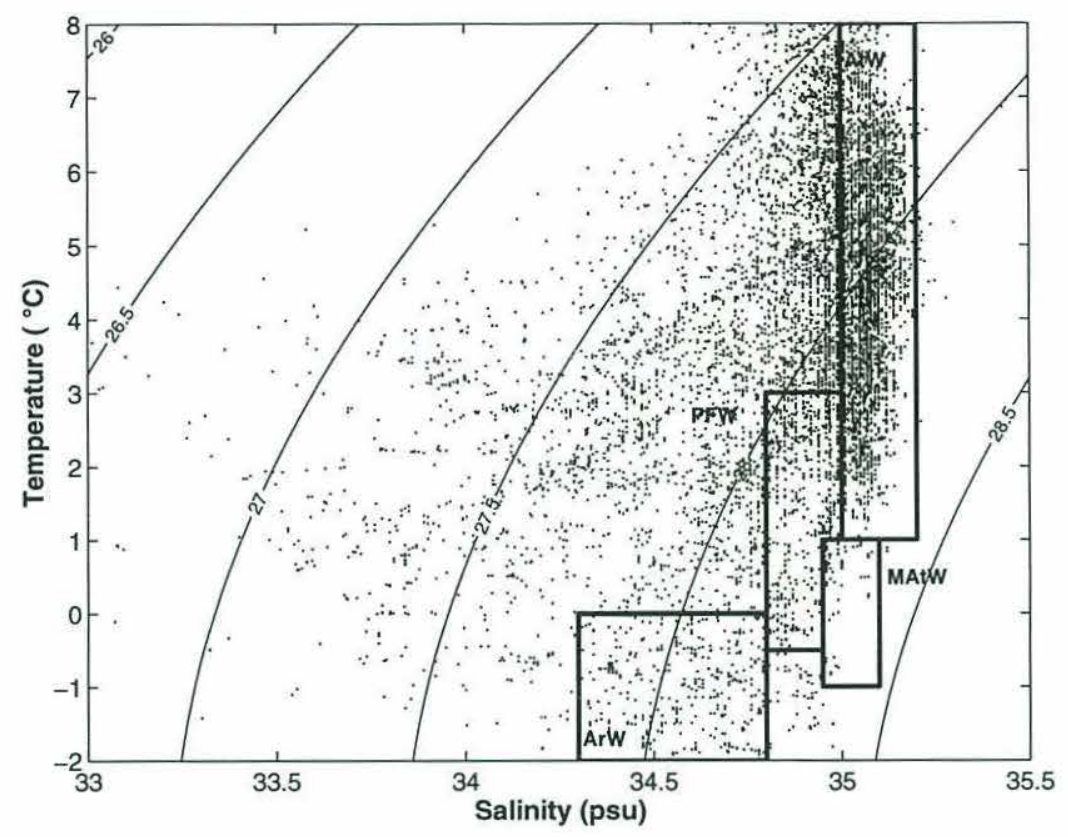

Figure 2.8: T/S diagram for the surface $(0-50 \mathrm{~m})$ combined NODC-A and NODC-B data sets. Water mass definitions are the same as in Table 2.1.

The processes that are candidates for creating the unclassified surface waters can be divided into shelf, front, and trough processes. Processes operating on the shelf are the mixing of ice-melt and Arctic Water to form "mixed meltwater", and radiative heating of Arctic and mixed meltwater. Frontal processes include mixing of Polar Front Water with Arctic or mixed meltwater, radiative heating of Polar Front Water, and mixing of Atlantic Water with Arctic, Polar Front, or mixed meltwater. Processes operating in the trough are the mixing of Atlantic and mixed meltwater and radiative heating of Atlantic Water. Shelf or front waters are involved in all of the above mechanisms except the final one. Apparently, except for warmed Atlantic Water, a fresh source located in the polar front region or over Spitzbergen Bank must be involved in forming the unclassified waters.

Consistent with a fresh water source on Spitzbergen Bank, the salinity of the unclassified surface waters increases with distance from the bank (Figure 2.10). The unclassified surface waters presented in this figure have been divided into three types, based solely on their salinity. Type 1 ( $<<34.3 \mathrm{psu})$ contains unclassified surface water with salinity fresher 

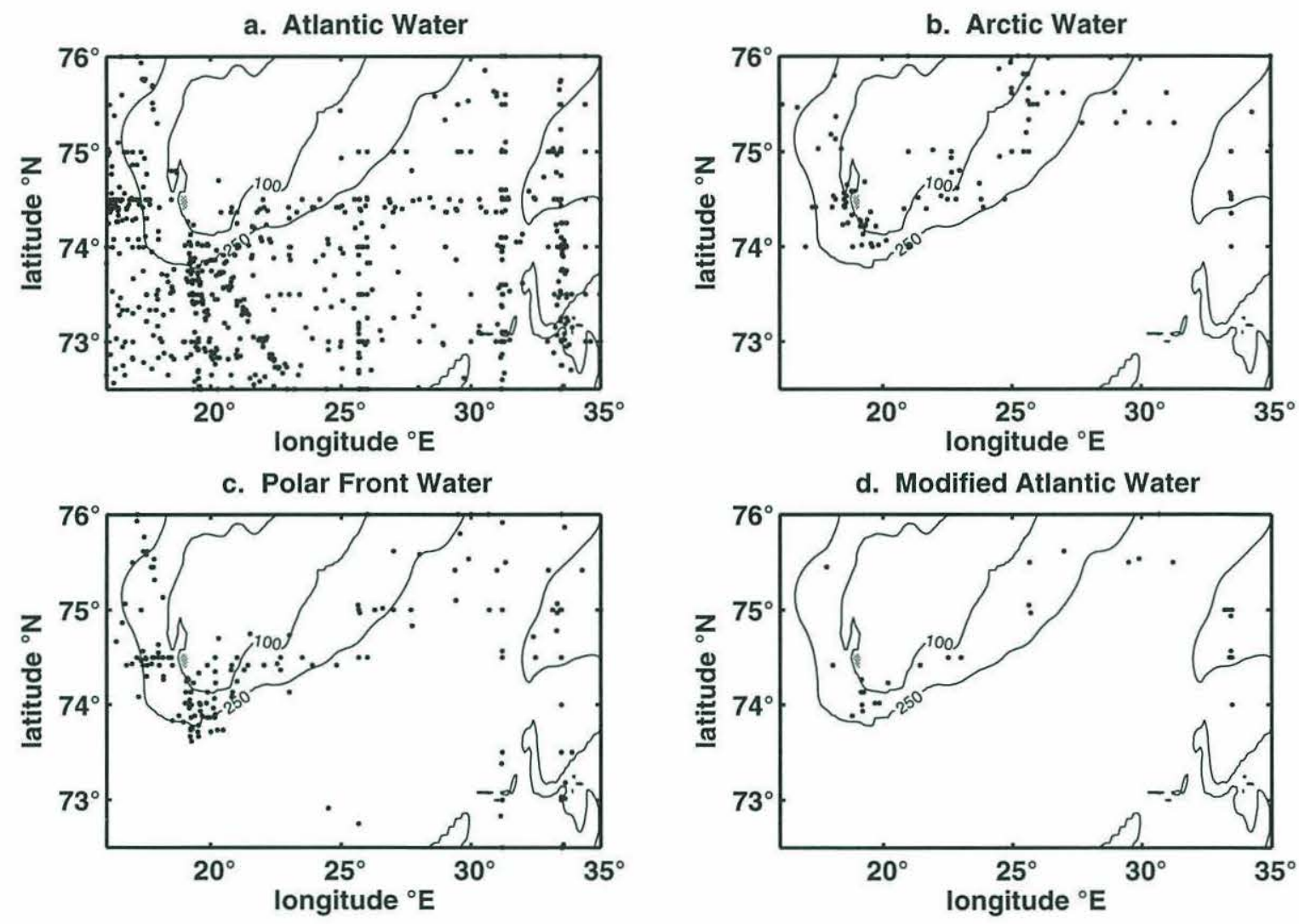

Figure 2.9: Geographic distributions of surface (0-50 m) (a) Atlantic Water, (b) Arctic Water, (c) Polar Front Water and (d) Modified Atlantic Water. Topography is the same as Figure 2.4. Water mass definitions are the same as Table 2.1. 

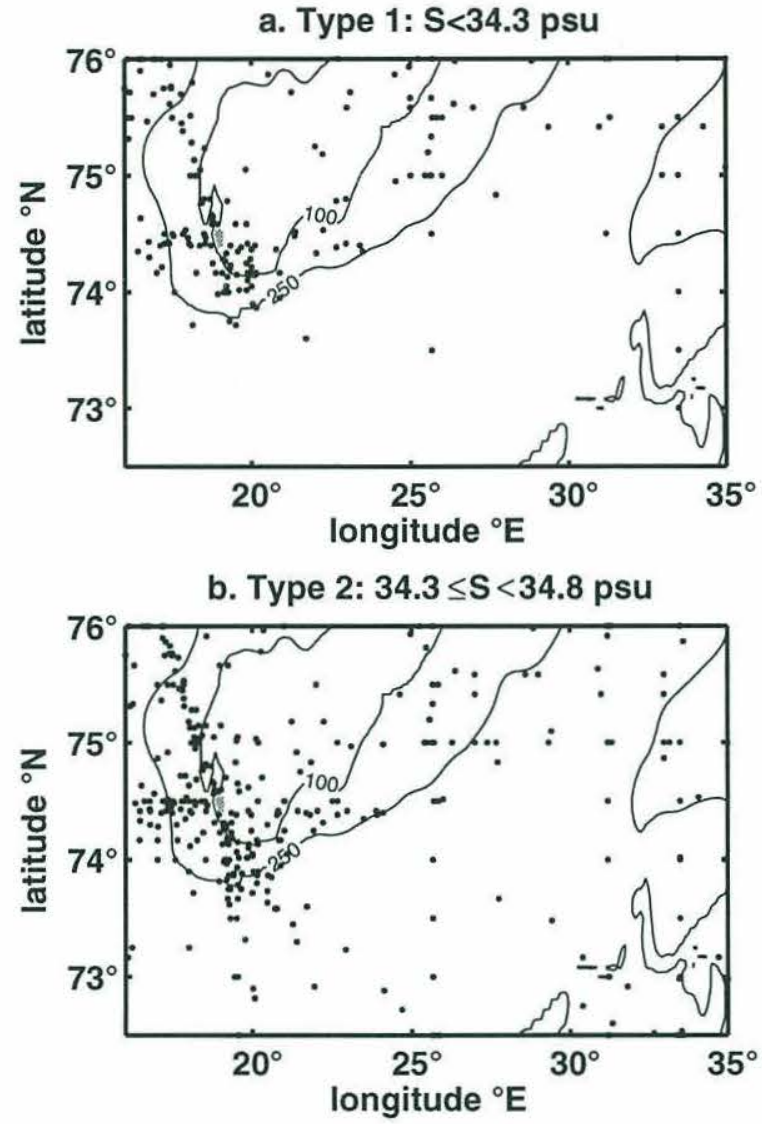

c. Type $3: 34.8 \leq \mathrm{S}<35.0 \mathrm{psu}$

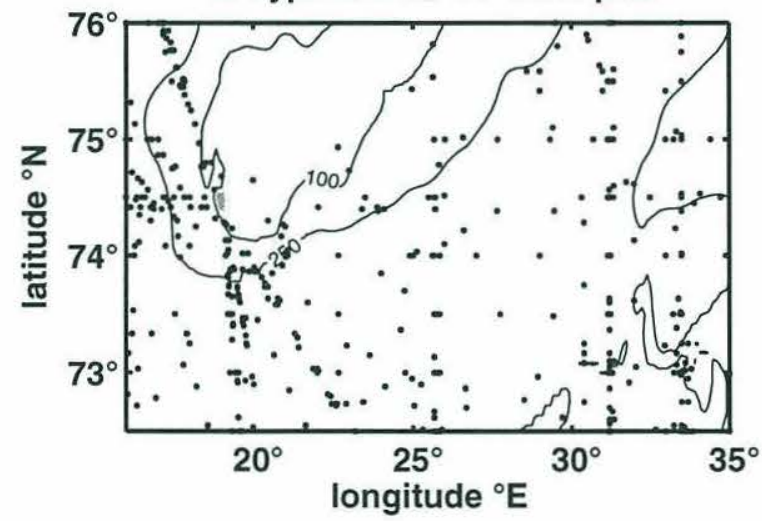

Figure 2.10: Geographic distribution of unclassified surface waters ordered from fresh to salty with (a) Type 1: $\mathrm{S}<34.3$ psu (b) Type 2: $34.3 \leq \mathrm{S}<34.8$ psu and (c) Type 3: $34.8 \leq \mathrm{S}<35.0 \mathrm{psu}$. See also Figure 2.8. Topography is the same as Figure 2.4. 
than Arctic Water. Type 1 waters are mainly located over Spitzbergen Bank (Figure 2.10a). Type $2(34.3 \leq \mathrm{S}<34.8 \mathrm{psu})$ contains unclassified surface water with the same salinity range as Arctic Water. Type 2 waters are scattered about both Spitzbergen Bank and Bear Island Trough (Figure $2.10 \mathrm{~b})$. Type $3(34.8 \leq \mathrm{S}<35.0 \mathrm{psu})$ contains unclassified surface water with the same salinity range as Polar Front Water. Type 3 waters are located mainly in Bear Island Trough.

The winter and summer geographic distributions of unclassified surface waters are shown in Figure 2.11. Only observations with salinity less than 35.0 psu are included in this figure; warmed Atlantic Water is not shown. While less than $20 \%$ of the winter (DecemberApril) surface observations are unclassified, over $50 \%$ of the summer (May-November) surface observations are unclassified, thus the winter distribution (Figure 2.11a) contains far fewer observations of the unclassified water than the summer distribution (Figure 2.11b). This seasonal difference indicates that unclassified surface water formation mechanisms are much more active in the summer. Further, it is remarkable that although the fresh source required to form the unclassified surface water is located at or north of the polar front, the unclassified water itself is observed throughout the southwestern Barents Sea. This result indicates that significant amounts of fresh surface water from Spitzbergen Bank must cross into the Atlantic Water region in the summer. The possibility of river runoff contributing significant fresh water to the unclassified waters is addressed in Section 2.4.

\subsubsection{Frontal structure and temporal variability}

The analysis of the surface layer shows that there must be processes which allow shelf water to cross the polar front. In fact, it is well-known from the literature that a summertime surface pool of meltwater has been observed across the frontal region [Loeng, 1991]. In the topographic control theory, however, the polar front appears as a vertical wall between the barotropic Atlantic and Arctic waters. It is reasonable to inquire how appropriate such a theory is in the surface layer given that observations show significant vertical stratification. Vertical and horizontal differences in the temperature, salinity, and density fields are examined to quantify the structure of the frontal region. Because the surface obser- 


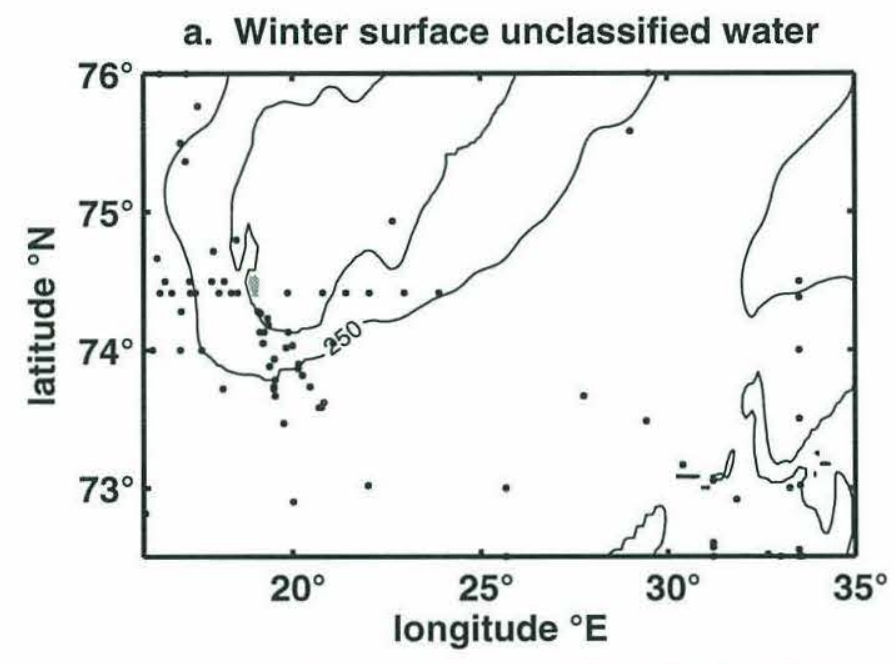

b. Summer surface unclassified water

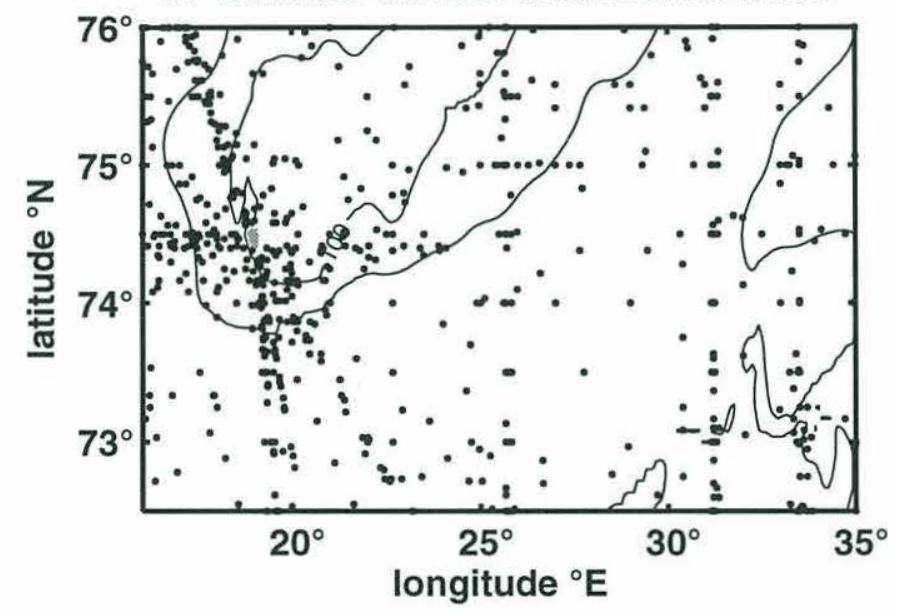

Figure 2.11: Geographic distribution of surface $(0-50 \mathrm{~m})$ unclassified water during (a) winter (December-April) and (b) summer (May-November). See also Figure 2.8. Topography is the same as Figure 2.4. 


\begin{tabular}{cccccccccccc}
\hline \hline Jan & Feb & Mar & Apr & May & Jun & Jul & Aug & Sep & Oct & Nov & Dec \\
\hline 0 & 1 & 2 & 2 & 3 & 6 & 0 & 2 & 6 & 3 & 2 & 2 \\
\hline
\end{tabular}

Table 2.2: Number of NODC-B cross-front transects by month. Each transect contains a minimum of 3 casts.

vations indicate seasonal variation in the $\mathrm{T} / \mathrm{S}$ characteristics with much greater variability in summer than in winter, the mean vertical changes are presented as a function of month and their variability is discussed. The results show that in the winter, little or no vertical thermohaline structure is present in the frontal region while in the summer, there is greater vertical structure and greater variability in that structure. Horizontal gradients show that the largest geostrophic shear in the region is associated with the meltwater pool and not with the polar front itself.

\section{Vertical structure}

Vertical changes in temperature and salinity are shown in Figure 2.12. These differences were calculated between $0 \mathrm{~m}$ and $100 \mathrm{~m}$; the lower depth of $100 \mathrm{~m}$ was selected to always include the maximum vertical gradient, which was between $50 \mathrm{~m}$ and $100 \mathrm{~m}$ depth for a number of the NODC-B transects. Vertical differences were calculated for each profile in the NODC-B data set. The results therefore represent the entire frontal region rather than just the polar front itself. The differences were averaged according to month and the number of NODC-B cross-frontal transects is shown in Table 2.2 .

From December through June the salinity field is constant vertically and there is no halocline (Figure 2.12a). The low variability indicates that the fresh surface pool never forms during these months. This result is consistent with Loeng [1991] who found that the maximum sea-ice coverage occurs between March and May, thus the fresh water is locked in sea-ice during these months. Alternatively, the fresh water may be vertically mixed. Loeng [1991] also reported that sea-ice melting begins in late April or early May, although the NODC-B data show a somewhat later release, after June. From August to November the 


\section{a. Salinity}

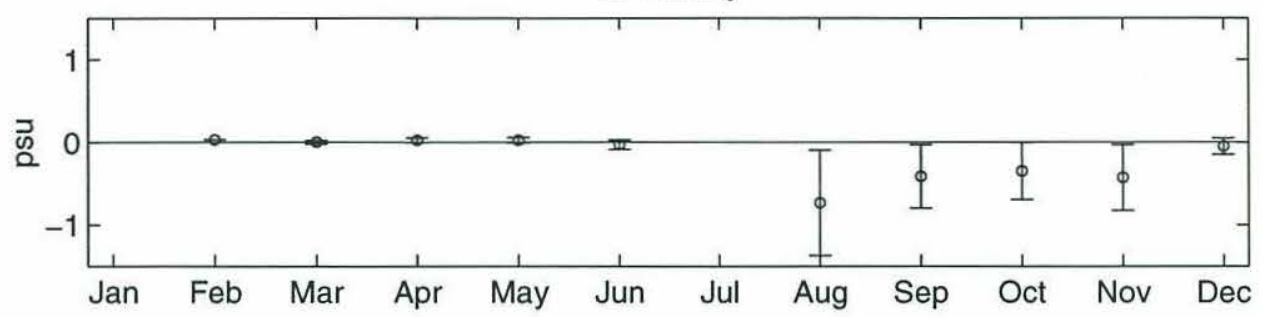

b. Temperature

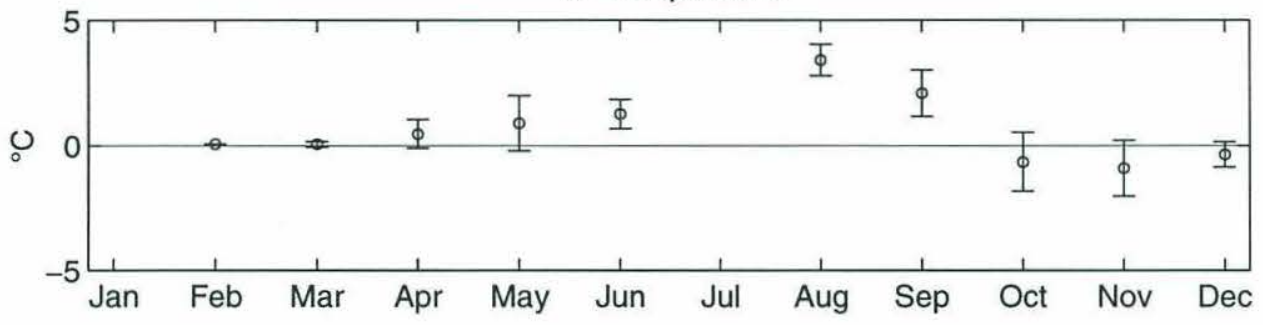

Figure 2.12: Frontal region vertical contrasts from NODC-B data of (a) salinity and (b) temperature between $0 \mathrm{~m}$ and $100 \mathrm{~m}$ depth. Means from all casts are shown with circles; the bars represent one standard deviation. A negative salinity change indicates fresh water at $0 \mathrm{~m}$ compared to $100 \mathrm{~m}$ and a negative temperature change indicates cold water at $0 \mathrm{~m}$ compared to $100 \mathrm{~m}$.

typical summertime salinity difference over the top $100 \mathrm{~m}$ of the water column is $-0.5 \mathrm{psu}$, indicating that fresh water has overriden saltier water. The much larger variability during these months reflects the varying strength and horizontal extent of the meltwater pool. The vertical density changes, not shown, closely follow the salinity changes.

The vertical temperature changes (Figure 2.12b) reflect vertical structure in the temperature field earlier in the year than the salinity field. The water column is nearly isothermal from December to March with little variability. Effects of surface warming typically appear in April and continue through September. During October and November, a fresh cold pool is sometimes observed at the surface. The incoming solar radiation has more or less halted by this time and these observations are remnants of the summertime meltwater pool, which remains buoyant due to its low salinity but is no longer being warmed by the sun. The annual insolation cycle is presented in Appendix A, Figure A.1. An interpretation of the full seasonal cycle based on the NODC data is presented in Section 2.4. 
The gradients from the NODC-B transects are now compared with those from the August BSPFX data. Over the same spatial scales, the BSPFX data show mean vertical changes in $(\mathrm{T}, \mathrm{S})$ of $\left(4.5^{\circ} \mathrm{C},-0.5 \mathrm{psu}\right)$ over the top $100 \mathrm{~m}$. Compared with the historical NODC-B data, the BSPFX data indicate average vertical salinity stratification and slightly higher than average vertical temperature stratification. By this measure, the BSPFX data represent typical August conditions at the polar front.

From the analysis of the vertical structure we conclude that the frontal region is always vertically well-mixed during the winter months, but that in the summer, a seasonal thermocline and halocline are present. The temperature, salinity and density fields show large vertical variability during the summer and almost no vertical variability in the winter. This seasonal variability decreases with depth, becoming essentially nonexistent below $100 \mathrm{~m}$ depth (not shown). Finally, the signs of the differences indicate that while meltwater may cross the front from the north into the Atlantic Water region, there is no complementary penetration across the front from the south by an Atlantic Water surface layer.

\section{Horizontal structure}

Horizontal contrasts in temperature, salinity and density are examined. The near-surface temperature and salinity contrasts are compared for summer and winter, showing that the salinity contrast across the region is stronger in summer but the temperature contrast is stronger in winter. A comparison of BSPFX and NODC-B temperature and salinity contrasts across the frontal region shows that observations are consistent with the assumption that seasonal changes are mainly confined to the surface layer. Analysis (not shown) of the location of the maximum horizontal density gradient in the frontal region demonstrates that, in the summer, the offshore location of maximum horizontal gradients in the surface layer does not align with the location of the polar front as determined by water mass classification. Instead, the location of the maximum horizontal density gradient, hence the maximum geostrophic shear, is determined by the meltwater pool. The dynamics governing the offshore location of the meltwater pool are beyond the scope of this work. 


\begin{tabular}{lrlclr} 
Source & Depth $(\mathrm{m})$ & Period & Distance $(\mathrm{km})$ & $\mathrm{T}\left({ }^{\circ} \mathbf{C}\right)$ & $\mathrm{S}(\mathrm{psu})$ \\
\hline & & & & & \\
NODC-B & 10 & August-November & 70 & $-3.8 \pm 1.6$ & $-0.8 \pm 0.3$ \\
NODC-B & 10 & February-June & 60 & $-4.9 \pm 1.0$ & $-0.4 \pm 0.2$ \\
BSPFX & 8 & August & 70 & -3.0 & -1.4 \\
BSPFX & 80 & August & 70 & -4.0 & -0.6 \\
\hline
\end{tabular}

Table 2.3: Horizontal temperature and salinity contrasts across the polar front region for NODC-B and BSPFX data. NODC-B values are mean contrasts \pm one standard deviation. The values reported for the BSPFX data are from single realizations calculated from Grid 1 data (see Parsons et al. [1996]).

Temperature and salinity contrasts representative of the entire frontal region were calculated by subtracting the values at the southernmost station from those at the northernmost station for each transect across the frontal region. The contrasts were calculated at a depth of $10 \mathrm{~m}$ and the results were averaged by season. The distance between the stations varied from one transect to another, and, for ease of comparison, the distances reported below approximate the exact mean distances. Horizontal density contrasts were also calculated at a depth of $10 \mathrm{~m}$, but, in order to determine the maximum geostrophic shear in the region, these differences were reported for all pairs of neighboring stations in each cross-front transect.

The NODC-B results demonstrate that the temperature contrast across the frontal region is about $1^{\circ} \mathrm{C}$ lower in summer (August-November) than in winter (February-June) (Table 2.3). The opposite trend is observed for the salinity contrast, with the summertime salinity contrast about twice that observed in winter. The BSPFX temperature contrast at $8 \mathrm{~m}$ depth across the frontal region is comparable to the summertime historical data, however, the BSPFX salinity contrast at $8 \mathrm{~m}$ depth is much stronger than the summertime NODC-B mean.

A direct evaluation of the consistency of the subsurface BSPFX T/S contrasts with the NODC-B data cannot be made due to the fact that the summertime surface layer often extends to the bottom over the shallow shelf region where the NODC-B data were collected. 
The typical shelf depth is $50 \mathrm{~m}$ in the NODC-B region, compared to $100 \mathrm{~m}$ in the BSPFX region.

Despite the inability to directly compare the subsurface data, it is interesting to note that the BSPFX subsurface contrasts are consistent with the NODC-B wintertime surface contrasts. The BSPFX temperature contrast is higher at depth than at the surface and the salinity contrast is lower. Likewise, the NODC-B temperature contrast is higher in winter than in summer and the salinity contrast is lower. This correspondence between the subsurface and the wintertime data would be expected in a region that is barotropic in winter with seasonal changes confined to the surface layer. That is, with little or no advective or directly forced seasonal changes at depth, the seasonal surface changes can be thought of as fluctuations imposed on the wintertime depth-constant conditions. Although the surface conditions may vary in the summer, the "wintertime conditions" are always present at depth, even in the summer.

Geostrophic velocities are now estimated for the surface layer. Using a horizontal density change of $-0.025 \mathrm{~kg} / \mathrm{m}^{3}$ per $\mathrm{km}$, a horizontal distance of $20 \mathrm{~km}$, a vertical distance of $50 \mathrm{~m}$, and with the Coriolis parameter $\mathrm{f}=1 \times 10^{4} \mathrm{~s}^{-1}$, the geostrophic shear is calculated to be approximately $-12 \mathrm{~cm} / \mathrm{s}$ (westward flow). This horizontal stratification is one of the strongest examples in the NODC-B data so it is anticipated that other calculations of geostrophic velocities on the same scales would have the magnitude of $0-15 \mathrm{~cm} / \mathrm{s}$. Note that the competing effects of temperature and salt create density differences such that the shear does not always have the same sign; the expected range of the geostrophic velocity is -15 to $+5 \mathrm{~cm} / \mathrm{s}$. Finer horizontal resolution may show higher, more localized geostrophic shear.

The geostrophic shear in the BSPFX observations of the meltwater pool had a maximum of $-5 \mathrm{~cm} / \mathrm{s}$ [Parsons et al., 1996]. When the geostrophic shear is calculated in the region of maximum gradient (the edge of the meltwater pool) with length scales identical to those used with the NODC-B data (20 km horizontally and $50 \mathrm{~m}$ vertically), the shear is about $-2 \mathrm{~cm} / \mathrm{s}$, well within the historical data range. 


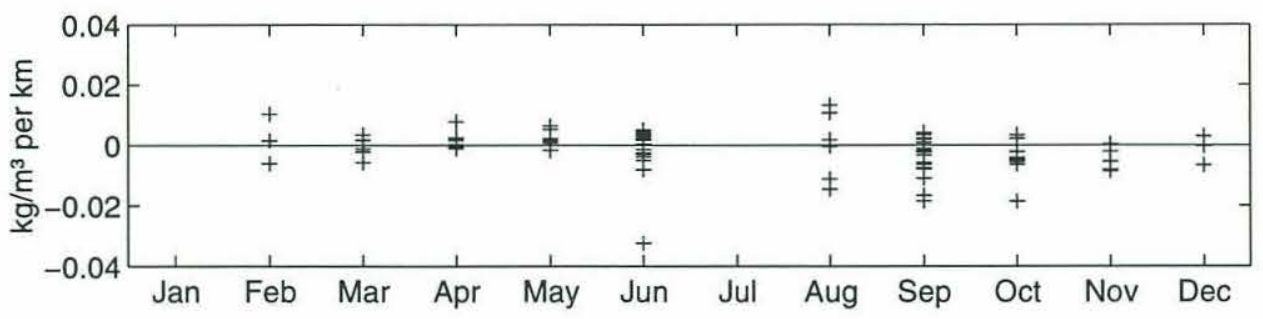

Figure 2.13: NODC-B horizontal density constrasts at $10 \mathrm{~m}$ depth across the polar front region shown as a function of month. A negative value indicates less dense water to the north.

\subsection{Discussion}

\subsubsection{Water mass definitions}

The definition of water masses led to the principle result that the hydrographic observations were consistent with the topographic control theory. Water mass definitions and the conclusions drawn from them are now discussed in greater detail. First, the sensitivity of the results to the water mass definitions is discussed. While the discussion shows that altering definitions could change the results somewhat, none of the available information presents a compelling case for revising these definitions, which were chosen based on historical precedent, fit to the observations, and categorization of water masses by formation processes. Northern Barents water mass definitions from previous studies are discussed with the conclusion that the northern Barents definitions also support the topographic control theory because they do not show the core of Atlantic Water one would expect if Atlantic Water from the southwestern Barents could flow over the edge of Hopen Trench into the northern part of the sea. Next, the disagreement between the isobath of the 35.0 psu contour and the $250 \mathrm{~m}$ isobath in individual representations of the cross-front salinity field from the NODC-B data set is attributed to the lack of resolution in the observations about the critical $250 \mathrm{~m}$ isobath. Finally, it is speculated that some of the scatter of Atlantic Water over isobaths shallower than $250 \mathrm{~m}$ deep is related to eddy activity.

Given a particular set of water mass definitions, the historical data have been shown to be consistent with the topographic control of Atlantic Water. The question may be 
raised, however, whether the results depend on the particular water mass definitions defined here. Water mass definitions in Table 2.1 follow Loeng [1991] with the exception that the definition of Atlantic Water was extended to include slightly cooler water and the Polar Front Water definition was altered to permit the addition of the Modified Atlantic water mass. Different water mass definitions could have been used. A literature search shows that nearly all water mass classifications for the Barents Sea define Arctic Water with $\mathrm{T} \leq 0^{\circ} \mathrm{C}$ and Atlantic Water with $\mathrm{S} \geq 35.00$ psu. Considering the substantial historical precedent, it does not seem compelling to alter either the Atlantic Water salinity boundary or the Arctic Water temperature boundary. Accepting these restrictions, a number of modifications from the definitions presented in Table 2.1 could still be made. Examining the BSPFX T/S distributions (Figure 2.2) shows that inflection points in the T/S curves basically support the definitions in Table 2.1. One might be tempted to classify slightly fresher water as Polar Front Water and also to freshen the Arctic Water range somewhat, however, only the former change could alter the geographic distributions, and, in fact, allowing Polar Front Water to have a lower salinity $(34.7 \leq \mathrm{S}$ instead of $34.8 \leq \mathrm{S})$ does not substantially change the geographic distributions (not shown). From examining the NODC T/S distributions (Figure 2.3), one may wish to include saltier water as Arctic Water, colder water as Atlantic Water, or alter or possibly remove the Modified Atlantic Water definition. Including saltier water as Arctic Water would, in fact, change its geographic distribution by allowing Arctic Water to appear over deeper isobaths because of the incorporation of some waters currently defined as Polar Front Water or Modified Atlantic Water. Likewise, lowering the Atlantic Water temperature boundary would change its geographic distribution by incorporating some of the Modified Atlantic Water into the Atlantic Water definition, resulting in Atlantic Water appearing over shallower isobaths. To some extent then, the results do depend on the definitions. In support of the current definitions, the following three points are presented. First, the current Polar Front Water definition fits the high resolution BSPFX data remarkably well despite the fact that it was chosen for an entirely different data set [Loeng, 1991]. Second, the use of the Modified Atlantic Water definition is defended because waters with these $\mathrm{T} / \mathrm{S}$ characteristics have been linked with a particular modification process, convective mixing. Third, it is felt that the water mass definitions 
should not be arbitrarily shifted away from previously established definitions, and the results presented here seem to show no justification for further modifying the definitions. Therefore, the definitions in Table 2.1, which rely on standards of historical precedent, fit to the data, and categorization of water masses by formation processes, lead to results in support of the topographic control theory.

Previous water mass definitions from a separate region, the northern Barents, also support the topographic control theory. As mentioned above, nearly all water mass classifications for the Barents Sea use an Atlantic Water definition with $\mathrm{S} \geq 35.00 \mathrm{psu}$. The few exceptions are studies in the northern Barents which use a lower salinity range [Pfirman, 1985; Steele et al., 1995; Pfirman et al., 1994]. This northern Atlantic water definition presents no contradiction with our results since the Atlantic Waters in the northern Barents and the Bear Island Trough should be separate according to the topographic control theory. The Atlantic Water in the northern Barents flows around Spitzbergen via Fram Strait to enter the Barents along its northern boundary. If the Atlantic Water topographic control in Bear Island Trough were to break down so that Atlantic Water originating from the Nordkapp Current could flow past Stor Bank into the northern Barents, then one would expect to find two types of Atlantic Water in the northwest Barents. One type would show T/S characteristics modified from passage around the north side of Spitzbergen and the other would show T/S characteristics modified from passing over the edge of Hopen Trench. A literature search has found no such double mode of Atlantic Water distribution. The lack of a double mode in the northern Barents Sea suggests the existence of a barrier to Atlantic Water flow between the northwest and southwest Barents, which is in support of the topographic control theory.

The mean cross-slope water mass distributions in Figures 2.6 and 2.7 are consistent with topographic control of Atlantic Water bounded by the $250 \mathrm{~m}$ isobath. Nonetheless, a number of individual realizations of the salinity field across the frontal region do not show the Atlantic Water boundary (the 35.0 psu contour) aligned with the $250 \mathrm{~m}$ depth contour. For example, of the two cross-slope salinity transects shown in Figure 2.14, Figure 2.14b shows the boundary exactly where predicted, but Figure 2.14a shows the boundary over 

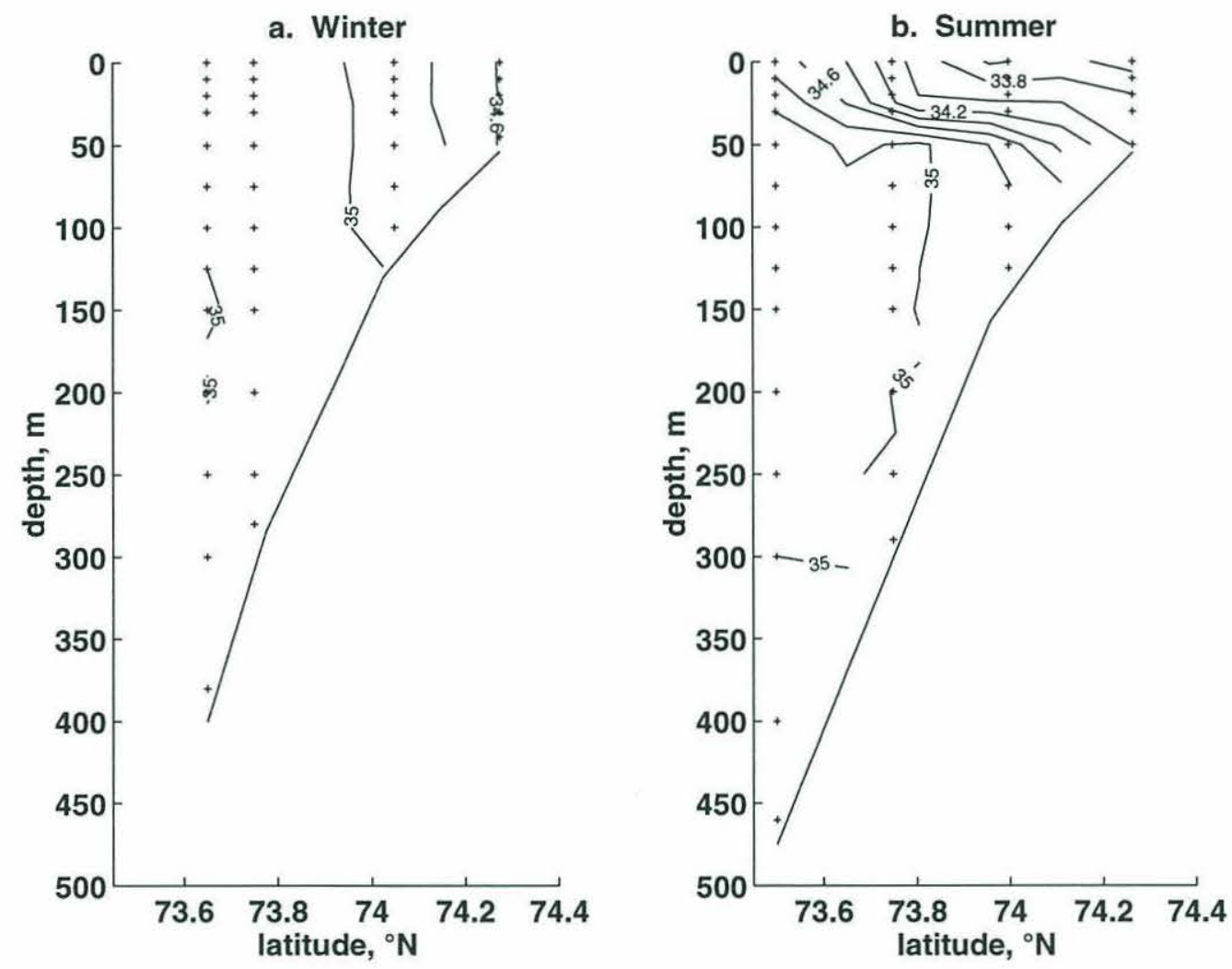

Figure 2.14: Vertical salinity structure from two NODC-B transects across the frontal region showing individual realizations of (a) winter (March) and (b) summer (September) conditions. The contour interval is $0.2 \mathrm{psu}$. The bathymetry is gridded from the depth of the bottom reported with each cast. 
somewhat shallower depths. It is likely that much of this problem can be attributed to the coarse sampling in the cross-bank direction. For instance, in Figure 2.14a there are no stations located between the $130 \mathrm{~m}$ and $300 \mathrm{~m}$ isobaths. Surveys with finer resolution about the critical $250 \mathrm{~m}$ isobath would eliminate this aspect of the problem.

Finally, the geographic distributions (Figure 2.4a) shows some scattered points where Atlantic Water is shallower than the $250 \mathrm{~m}$ isobath. These observations are probably due to the strong eddying motions reported in this region [Blindheim, 1989; Poulain et al., submitted]. Eddy activity may be enhanced along the western edge of the region by the proximity to the West Spitzbergen Current, and it may also be enhanced by the canyon apparent in the $100 \mathrm{~m}$ isobath near $22^{\circ} \mathrm{E}$.

\subsubsection{Local water mass formation}

The formation processes and the geographic distributions of locally formed Polar Front Water and Modified Atlantic Water are discussed. Polar Front Water is assumed to be formed via isopycnal mixing between Atlantic and Arctic water masses and the scatter in its geographic distribution is mainly attributed to eddy processes with some contribution from a misidentified mixture of ice-melt and Atlantic Water. The distinction between Polar Front Water and Cold Halocline Water [Steele et al., 1995] is noted. Convection is proposed as the process responsible for the formation of Modified Atlantic Water. Estimates of the surface heat flux and available fresh water are shown to be consistent with the heating and freshening required to form the cold, slightly fresh Modified Atlantic Water. Based on formation processes, a distinction is drawn between the Modified Atlantic Water and other dense waters previously observed in the region. While all the dense water classes are convectively formed, the Modified Atlantic Water, produced each year, has low salinity from mixing with the surface meltwater or from contact with sea-ice and the other dense waters, produced infrequently, have increased salinity due to brine rejection during sea-ice formation. 
Parsons et al. [1996] demonstrated the formation of Polar Front Water through isopycnal mixing of Atlantic and Arctic waters. Only the scatter in the Polar Front Water geographic distribution is discussed here since the existing data do not permit further testing of this formation mechanism. As previously mentioned, the distribution of Polar Front Water shows larger than anticipated scatter (Figure 2.5a). Polar Front Water is occasionally found deeper than $250 \mathrm{~m}$ in the Hopen Trench, shown in the upper right corner of Figure 2.5. These data are most likely the result of eddy activity along the polar front or else a misidentified mixture of Atlantic Water and ice-melt from the sea-ice that can cover the Hopen Trench in winter [Midttun, 1989]. The scatter in the center of Bear Island Trough around $73^{\circ} \mathrm{N} 20^{\circ} \mathrm{E}$ is believed to be the result of strong eddying motions which have been observed in this part of the Bear Island Trough [Blindheim, 1989; Poulain et al., submitted]. There is a large quantity of Polar Front Water appearing on the western flank of Spitzbergen Bank, which might result from local formation related to the West Spitzbergen Current or may be related to the transport of Polar Front Water from the Barents Sea into the Norwegian Sea. Despite this scatter, the majority of the Polar Front Water in Figures 2.5a, 2.6, and 2.9c occurs between the Arctic Water and Atlantic Water distributions, a result which supports the topographic control theory.

It is noted that the Polar Front Water is not the same water mass class as the locally formed Cold Halocline Water [Steele et al., 1995]. The Cold Halocline Water has colder, fresher $\mathrm{T} / \mathrm{S}$ characteristics $\left(\mathrm{T}<-0.5^{\circ} \mathrm{C} ; 34.0<\mathrm{S}<34.5 \mathrm{psu}\right)$ and the two water masses are not even adjacent in T/S space. Cold Halocline Water is formed to the north of the Polar Front from the Atlantic Water, previously mentioned, which enters the Barents Sea from the north [Steele et al., 1995].

The amount of Modified Atlantic Water observed in the study region is rather small but the low temperature of this water mass, the salinity slightly fresher than Atlantic Water, and the distribution of the water mass on the northern side of Bear Island Trough and Hopen Trench, all suggest that the Modified Atlantic Water is convectively formed where meltwater overlies Atlantic Water. Water column stability is low around the front at the end of the winter, as shown in Figure 2.14a. To form the Modified Atlantic Water, 
convective mixing of Atlantic Water is driven by the strong wintertime surface heat flux in the region [Häkkinen and Cavalieri, 1989], while the surface meltwater layer, or possibly contact with the ice edge, causes the slight freshening (see Figure 2.3).

The following calculation shows the feasibility of this transformation. In the Atlantic Water region near Bear Island, Häkkinen and Cavalieri [1989] show a net surface heat loss from October-April and a net heat gain from June-August (see Table A.1 in Appendix A). May and September show little or no net heat exchange in this region. During the seven months of net heat loss, the average heat flux per month is $Q=270 \mathrm{~W} / \mathrm{m}^{2}$. This heat flux is related to a water column temperature loss by

$$
\rho c_{p} \Delta T \Delta z=\int Q d t,
$$

where $\rho$ is the density of seawater, $c_{p}$ is the specific heat of seawater, $\Delta z$ is the depth of convective penetration, $\Delta T$ is the mean change in temperature over $\Delta z$, and $Q$ is the heat flux. Assuming that the heat loss is due to one-dimensional convection which penetrates the entire water column $(\Delta z=300 \mathrm{~m})$, then with $c_{p}=3986 \mathrm{~J} / \mathrm{kg} /{ }^{\circ} \mathrm{K}$ and density $\rho=1025 \mathrm{~kg} / \mathrm{m}^{3}$, a heat flux of $270 \mathrm{~W} / \mathrm{m}^{2}$ causes a depth-averaged temperature change of $4^{\circ} \mathrm{C}$ after 7 months. For comparison with observations, a profile containing Modified Atlantic Water from the Atlantic Water region during September and a second profile from April, near the end of the convecting season, is shown in Figure 2.15. The April salinity profile is entirely homogeneous, presumably the result of surface to bottom convection. The depth-averaged temperature change between these two profiles is $3.7^{\circ} \mathrm{C}$, consistent with the hypothesis that Modified Atlantic Water is formed from Atlantic Water through the surface heat flux estimates of Häkkinen and Cavalieri [1989].

Also consistent with this hypothesis are results (not shown) which indicate that in the NODC-A data set the Modified Atlantic Water tends to be observed throughout the water column in the spring at the end of the convective season, but generally deeper in the water column $(>200 \mathrm{~m}$ ) later in the year, when surface heating has warmed the top layer.

Finally, a simple salt budget illustrates the possibility that the freshening required to form the Modified Atlantic Water could come from the meltwater layer or contact with the sea-ice edge. While the surface layer shows a wide range of salinities (Figure 2.8), 
the NODC-B cross-bank transects verify that a $30 \mathrm{~m}$ thick surface layer with a salinity of $34.5 \mathrm{psu}$ is a reasonable approximation for a meltwater layer (see Figure B.4 in Appendix B). In a water column $300 \mathrm{~m}$ deep, a $30 \mathrm{~m}$ deep meltwater layer with salinity of 34.5 psu that is entirely mixed with a $270 \mathrm{~m}$ thick layer of 35.0 psu Atlantic Water, will form water with a salinity of $34.95 \mathrm{psu}$, the lower bound for the Modified Atlantic Water. It is equally possible that the freshening can come from contact between Atlantic Water and the ice-edge. Atlantic Water directly at the polar front with a water column depth of $250 \mathrm{~m}$ and a salinity of $35.0 \mathrm{psu}$ would need to melt $0.4 \mathrm{~m}$ of sea-ice $(\mathrm{S}=5.0 \mathrm{psu}$ ) to freshen to $34.95 \mathrm{psu}$, the lower salinity bound for the Modified Atlantic Water. This sea-ice thickness is consistent with the observations reported by [Vinje, 1985]. The results presented here show that Atlantic Water could be freshened to form Modified Atlantic Water through convective mixing with a freshwater source from the meltwater layer or from contact with sea-ice. Although the results do not support the predominance of one freshwater source over another, they do indicate the importance of Spitzbergen Bank as a freshwater source in the formation of Modified Atlantic Water.

Note that river runoff from Norway might also freshen the surface waters in the domain, particularly along its southeastern side (see Figure 1.1). The major rivers entering the Barents, the Pechora and the Severnaya Dvina, contribute about $240 \mathrm{~km}^{3} /$ year of fresh water to the Barents [Aagaard and Carmack, 1989]. For comparison, a sea-ice thickness of $1 \mathrm{~m}$ [Vinje, 1985] covering the region $75^{\circ} \mathrm{N}-80^{\circ} \mathrm{N}, 20^{\circ} \mathrm{E}-35^{\circ} \mathrm{E}$ results in a sea-ice freshwater source of about $200 \mathrm{~km}^{3} /$ year. These rivers are located in the eastern Barents, and, due to the surface circulation patterns, it is not expected that their runoff would directly contribute to the surface layer in the western Barents. Further, a freshwater contribution from river runoff would not be expected to produce the surface salinity gradient shown by the unclassified waters in Figure 2.10. Further clarification of the contribution of river runoff to the surface unclassified water cannot be determined with the available data.

Observations of dense water reported in the literature are now considered. The names of the main water masses are fairly constant throughout the Barents literature with the notable exception of the densest water class in any particular study. Various names 

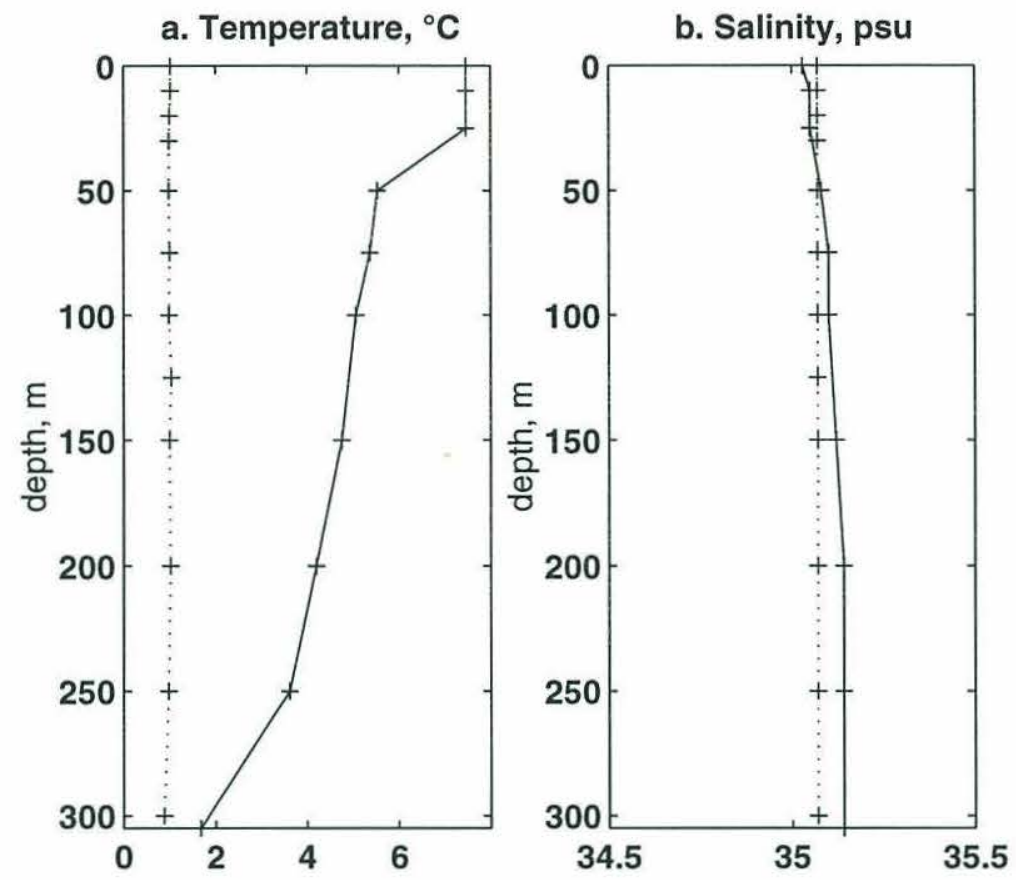

Figure 2.15: A September Atlantic Water profile (solid line) is contrasted with an April Modified Atlantic Water profile (dotted line). Panel (a) shows the temperature profile and (b) the salinity profile. Profiles are NODC observations.

and definitions have been used and the outcome is confusing. To clarify matters somewhat, the proposal is made to divide the densest water mass definitions into two groups based on formation processes; such a distinction has previously been made by Sarynina [1969]. The first group of dense waters is typified by the Modified Atlantic Water, which appears synonymous with Blindheim and Loeng [1981] Barents Sea Bottom Water, Blindheim [1989] Station III, and Sarynina [1969] bottom water. Although a previous study described the formation of this class of water through the mixture of other dense water types [Blindheim, 1989], it is suggested here that these waters form convectively from cooled Atlantic Water and are freshened through mixing with the meltwater pool or the ice edge. Analysis has shown that the Modified Atlantic Water is not necessarily a bottom water mass, but occurs throughout the water column at the end of the convecting season. It is believed that the heat and salt fluxes required to create this water mass are consistent with formation of Modified Atlantic Water every year on the slope of Spitzbergen Bank. The second group of dense waters is represented by Midttun [1985] dense bottom water, Blindheim [1989] Stations I, 
II and Loeng [1991] Bottom Water. These waters are saltier and often colder than the Modified Atlantic Water. While the initial step in the formation of these densest waters is also convection, the high salinity indicates that brine rejection from sea-ice formation is necessary to create these waters. Locations of these denser waters indicate scattered sources, including Spitzbergen Bank [Midttun, 1985] and Sentral Bank [Blindheim, 1989]. It is conceivable that in exceptionally cold years, the sea-ice formation and brine rejection necessary to form these waters could also occur in the Atlantic waters along the ice edge in the Bear Island Trough and Hopen Trench, however, mainly due to the lack of observations of these densest waters in the NODC data sets, it is believed that this formation process does not occur annually in the region studied here.

\subsubsection{Seasonal frontal structure}

The seasonal evolution of the front, believed to account for the dominant variability in the polar front region, is qualitatively described using the results from Section 2.3.3 and individual realizations of transects across the frontal region. One result of this seasonal cycle, which affects regional fresh water budgets, is that the sea-ice is mainly formed from the fresh meltwater layer and not from the saltier Arctic Water. A second result is that surface properties and water mass modifications in the Atlantic Water region are affected by the excursions of the seasonal meltwater pool across the polar front.

The thermohaline structure of the front was presented in Section 2.3.3. The data from the front show its structure switching between two dominant modes, one in winter, when temperature and salinity are vertically well-mixed (e.g., Figure 2.14a) and the other in summer, when the surface layer variability is dominated by the effects of the meltwater pool (e.g., Figure 2.14b). These results agree with previous work (e.g., Loeng [1991]). While our data are too sparse to fully resolve the seasonal cycle, the results presented in Section 2.3.3 represent the first time seasonal changes have been quantified. These results, combined with individual representations of the frontal region, suggest the following seasonal cycle. During winter (January-March), the ice pack is in place at the front and the front is wellmixed vertically, forced by surface heat loss and wind mixing. There is no solar heating 
for most of the winter period. In the spring (April-June), the ice pack is generally still in place north of the front although solar warming is apparent in the surface layer south of the front. In the summer (July-September), the ice edge has receded from the front and the fresh meltwater is released. This meltwater is warmed by the sun so it appears fresh, but not cold. On occasion, the meltwater pool crosses the polar front and the stratification introduced by the fresh water and surface warming is strong enough to create a seasonal thermocline, halocline and pycnocline with an associated near-surface geostrophic current. In the fall (October-December), the influx of meltwater continues from the north, but it receives little insolation and is observed as a fresh, cold pool. Fall cooling and mixing reduces the seasonal stratification. Eventually, the sea-ice pack reforms, representing full wintertime conditions.

The suggested seasonal cycle has implications for the heat and salt budgets of the Barents. For example, our results suggest that fresh meltwater is present at the polar front up until the time the sea-ice is formed locally. In other words, it must be this fresh layer which is frozen as the sea-ice is formed. This result agrees with Midttun [1985] who states that the summer surface layer is refrozen the following winter, thereafter perhaps forming more ice. The relevent implication for budgeting purposes is that the majority of the ice locally formed each year in the Barents Sea must be from this fresh surface layer and not from the saltier Arctic Water.

\subsection{Summary}

Atlantic Water topographic control in the surface layer is disrupted during the summer. The breakdown of the front in the surface layer allows the meltwater pool to cross the polar front and contribute a fresh, cool surface layer to the Atlantic Water region. This surface layer then affects water mass modifications in the southwest Barents, including the formation of Modified Atlantic Water, a dense water mass whose T/S characteristics can be distinguished from Arctic Halocline Water and from high salinity bottom water formed from brine rejection during sea-ice formation. The water mass modification paths in $\mathrm{T} / \mathrm{S}$ space 


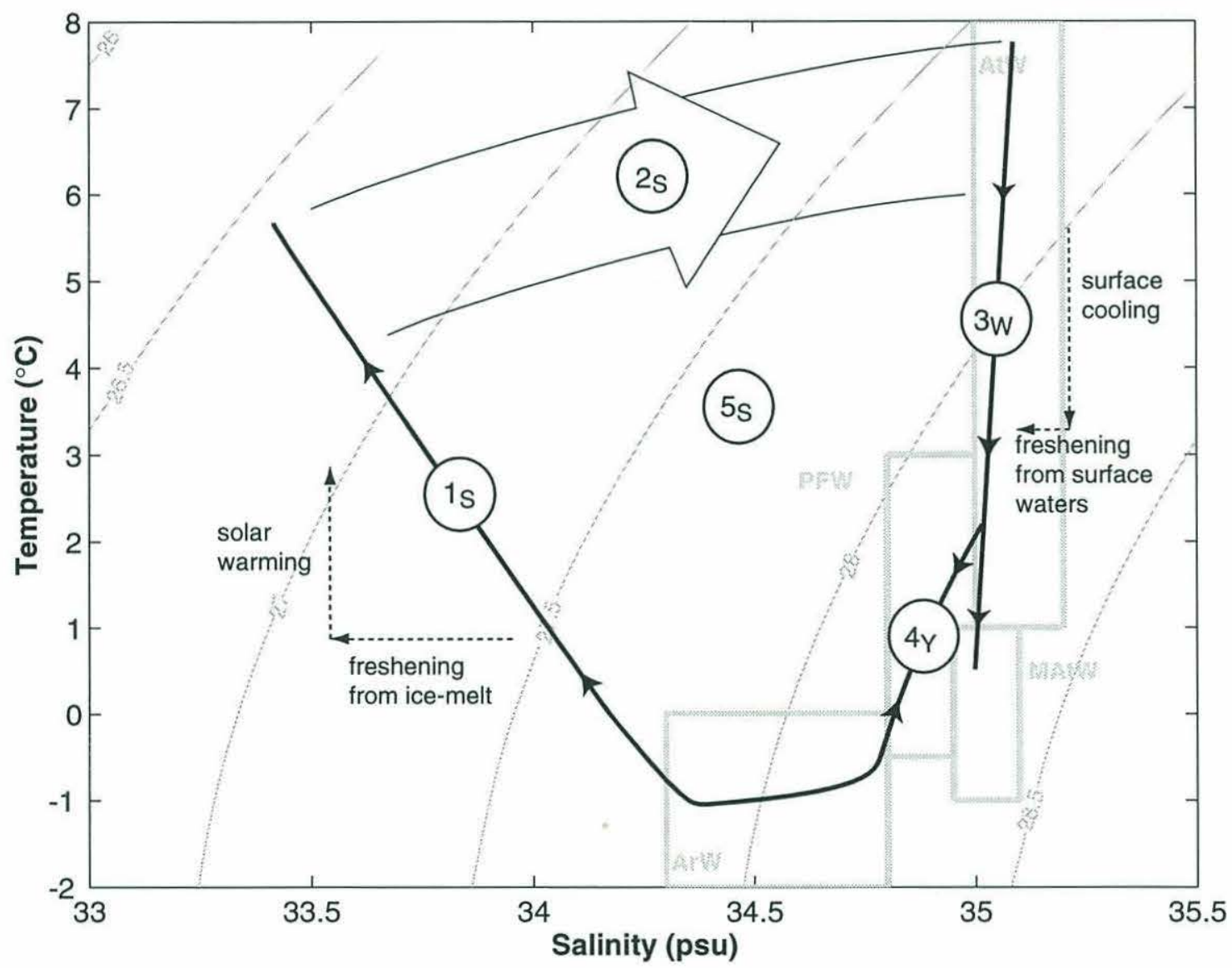

Figure 2.16: A schematic T/S diagram illustrates the water mass modifications which occur in the southwestern Barents Sea. The path numbers are referred to in the text. The path subscripts (S, W, Y) refer to the season during which the path is traversed (summer, winter, year round). Paths 1, 2, 3 illustrate a seasonal progression from Arctic Water to Modified Atlantic Water. Path 4 illustrates the isopycnal formation of Polar Front Water. Region 5 shows a summertime diapycnal/isopycnal mixing region. Water mass definitions shown in grey are identical to Table 2.1. See Section 2.5 for more details. 
are shown schematically in Figure 2.16. Arctic Water can be transformed into Modified Atlantic Water by traversing, in order, paths 1, 2, and 3. The summertime warming and freshening of Arctic Water from the diapycnal mixing with fresh ice-melt is shown as path 1. The resulting fresh warm layer is called the "surface mixed meltwater" and it comprises the pool which can override the polar front. Once the surface mixed meltwater has crossed the polar front to the Atlantic region, it is diapycnally mixed with Atlantic Water, presumably driven by wind stress (shown by path 2). The wintertime cooling and freshening, which occurs in the Atlantic region as fresher surface waters are convectively mixed with the core of the Atlantic Water, is labelled path 3. This convective mixing, driven by a surface heat loss, forms Modified Atlantic Water. Isopycnal formation of Polar Front Water occurs throughout the year; in this diagram it is labelled path 4 . The T/S region containing summertime waters formed through diapycnal and/or isopycnal mixing of water originating along paths 1, 2, 3, and 4 is labelled 5. This region also contains Arctic and Polar Front waters warmed from the surface heat flux. Mixing across this region allows water mass modification shortcuts from Arctic Water to Modified Atlantic Water primarily by mixing between slightly cooler and saltier waters than required by the circuit defined by paths 1 , 2 , and 3 .

\subsection{Conclusions}

Results from subsurface geographical water mass distributions and averaged transects across the slope of Spitzbergen Bank were consistent with the topographic control of Atlantic Water in the southwestern Barents Sea. The wide temporal and spatial coverage of the NODC data allowed evaluation of the topographic control theory over broad time and space scales, however, the large interannual thermohaline variability, possible eddy variability and the low spatial resolution of the data compared to the steep topography of Spitzbergen Bank detracted from the ability of the geographic distributions to determine the exact Atlantic water mass boundary. Although results of both the geographic subsurface water mass distributions and the cross-slope transects were consistent with a shelfward boundary of Atlantic Water between the $150 \mathrm{~m}$ and the $300 \mathrm{~m}$ isobaths, no further narrowing of that 
range was warranted by the NODC results presented here. The BSPFX cross-slope results, also consistent with the topographic control theory, added support for the hypothesis that the Nordkapp Bank-Sentral Bank sill depth, approximately $250 \mathrm{~m}$, defines the shelfward boundary of the topographically controlled Atlantic Water.

The geographical distribution of the defined water masses in the surface layer were quite similar to those at depth and were consistent with the topographic control theory. This result held despite the wide range of thermohaline conditions found at the surface due to seasonal buoyancy forcing. Scatter in T/S characteristics removed nearly half of the surface observations from the defined water mass boxes.

The seasonal existence of a low salinity, low density, surface meltwater pool is the most significant condition under which the topographic control of Atlantic Water appeared to break down in the surface layer. While radiative heating initially created the fresh water from sea-ice, it had little direct effect on the density of the meltwater pool and surface freshening alone was sufficient to cause the low density observed when the melt pool capped the front. Although the pool was observed to cross the polar front from the Arctic region to the Atlantic region, no substantial evidence was found suggesting that surface water could cross from the Atlantic region to the north side of the polar front.

Water mass modifications which occurred in the polar front region were: diapycnal mixing, presumably forced by wind, of fresh ice-melt and Arctic Water to form the surface meltwater pool, isopycnal mixing of Atlantic Water and Arctic Water to form Polar Front Water, and convective mixing of the meltwater pool and Atlantic Water to form Modified Atlantic Water. No significant amount of dense water formed from brine rejection during sea-ice formation was observed in these data. While the formation of Polar Front Water was expected to occur throughout the year, the meltwater pool was formed in late spring and summer and Modified Atlantic Water was formed during late winter. The seasonal cycle therefore played an important role in water mass modification processes in the Barents Sea.

The summertime meltwater pool produced the largest horizontal density gradient in the polar front region. Geostrophic velocities in the meltwater pool were estimated 
to be between -15 to $+5 \mathrm{~cm} / \mathrm{s}$. While the melt pool originated on Spitzbergen Bank, results showed that the pool could cross the polar front and modify surface water properties throughout the southwestern Barents Sea. The ability of the meltwater pool to cross the frontal region was the basis for hypothesizing the connection between the melt pool and the formation of Modified Atlantic Water.

The results presented here support a conceptual scheme in which the most prominent dynamics at the polar front were determined by the topographic control of Atlantic water inflow and the most significant deviations from the theory were seasonally determined. Nevertheless, other than the summertime geostrophic flow in the surface meltwater layer, the results and discussion neglected the circulation of the Arctic water region. Although a number of authors have discussed an important, high velocity Bjørnøya Current which flows westward along the eastern slope of Spitzbergen Bank [Pfirman, 1985; Loeng, 1991; Pfirman et al., 1994], direct measurements of this current have not been found in the literature. Further, the direct current measurements from the BSPFX found no mean flow on the shelf in the Arctic water region and the modeling study of Gawarkiewicz and Plueddemann [1995] was able to replicate the temperature and salinity structure at the front with a quiescent body of Arctic water. One possibility is that the Bjørnøya Current might actually have been the recirculating Atlantic water. A better understanding of the circulation of Arctic water driven by large scale pressure gradients is needed to resolve this issue. 


\section{Bibliography}

Aagaard, K. and E. C. Carmack, The Role of Sea Ice and Other Fresh Water in the Arctic Circulation, J. Geophys. Res., 94(C10), 14485-14498, 1989.

Aagaard, K., J. H. Swift and E. C. Carmack, Thermohaline Circulation in the Arctic Mediterranean Seas, J. Geophys. Res., 90(C3), 4833-4846, 1985.

Aagaard, K., L. K. Coachman and E. Carmack, On the halocline of the Arctic Ocean, Deep Sea Res., 28A(6), 529-545, 1981.

Blindheim, J., Cascading of Barents Sea bottom water into the Norwegian Sea, Rapports et Proces-Verbaux des Réunions, Counseil International pour l'Exploration de la Mer, $188,49-58,1989$.

Blindheim, J. and H. Loeng, On the variability of Atlantic influence in the Norwegian and Barents Seas, FiskerDirektoratets Skrifter Serie HavUndersøkelser, 17(4), 161-189, 1981.

Candela, J., R. C. Beardsley and R. Limeburner, Separation of Tidal and Subtidal Currents in Ship-Mounted Acoustic Doppler Current Profiler Observations, J. Geophys. Res., 97(C1), 769-788, 1992.

Gawarkiewicz, G. G. and A. J. Plueddemann, Topographic control of thermohaline frontal structure in the Barents Sea Polar Front on the south flank of Spitsbergen Bank, J. Geophys. Res., 100(C3), 4509-4524, 1995.

Häkkinen, S. and D. J. Cavalieri, A Study of Oceanic Surface Heat Fluxes in the Greenland, Norwegian, and Barents Seas, J. Geophys. Res., 94(C5), 6145-6157, 1989. 
Harris, C. L., A. J. Plueddemann, R. H. Bourke, M. D. Stone and R. A. Pawlowicz, Collection and Processing of Shipboard ADCP velocities from the Barents Sea Polar Front Experiment, Woods Hole Oceanog. Inst. Tech. Rept, WHOI-95-03, 1995.

Johannessen, O. M. and L. A. Foster, A Note on the Topographically Controlled Oceanic Polar Front in the Barents Sea, J. Geophys. Res., 83(C9 ), 4567-4571, 1978.

Kowalik, Z. and A. Y. Proshutinsky, Topographic enhancement of tidal motion in the western Barents Sea, J. Geophys. Res., 100(C2), 2613-2637, 1995.

Levitus, S., Climatological Atlas of the World Ocean, U.S. Department of Commerce, NOAA, Professional Paper 13, 1982.

Loeng, H., Features of the physical oceanographic conditions of the Barents Sea, Polar Research, 10, 5-18, 1991.

Mauritzen, C., A Study of the Large Scale Circulation and Water Mass Formation in the Nordic Seas and Arctic Ocean, MIT/WHOI, PhD Thesis, WHOI-93-53, 1993.

Midttun, L., Formation of dense bottom water in the Barents Sea, Deep Sea Res., 32(10), 1233-1241, 1985.

Midttun, L., Climatic fluctuations in the Barents Sea, Rapports et Proces-Verbaux des Réunions, Counseil International pour l'Exploration de la Mer, 188, 12-35, 1989.

Nansen, F., Northern Waters: Captain Roald Amundsen's oceanographic observations in the Arctic seas in 1901, Videnskabs-Selskapets Skrifter 1. Matematisk-naturvidenskapelig Klasse, 3, 1906.

National Climatic Data Center, National Oceanic and Atmospheric Administration, U.S. Navy Regional Climatic Study of the Barents Sea and Adjacent Waters, NAVAIR 50-1C-558, 1990. 
National Oceanographic Data Center, National Oceanic and Atmospheric Administration, Global Ocean Temperature and Salinity Profiles, CDROM NODC-02, 1991.

National Oceanographic Data Center, National Oceanic and Atmospheric Administration, Oceanographic Station Profile Time Series, CDROM NODC-20, 1993.

Parsons, A. R., R. H. Bourke, A. J. Plueddemann, C-S. Chiu, J. F. Lynch, R. D. Muench, R. Pawlowicz and J. H. Miller, The Barents Sea Polar Front in Summer, J. Geophys. Res., accepted, 1996.

Pfirman, S. L., Modern Sedimentation in the Northern Barents Sea: Input, Dispersal and Deposition of Suspended Sediments from Glacial Meltwater, MIT/WHOI, PhD Thesis, WHOI-85-4, 1985.

Pfirman, S. L., D. Bauch and T. Gammelsrød, The Northern Barents Sea: Water Mass Distribution and Modification, in The Polar Oceans and Their Role in Shaping the Global Environment: The Nansen Centennial Volume, edited by R. D. Muench and J. E. Overland, Geophys. Monogr. Ser., 88, AGU, Washington, D.C., 1994.

Poulain, P. -M., A. Warn-Varnas and P. P. Niiler, Near Surface Circulation of the Nordic Seas as Measured by Lagrangian Drifters, J. Geophys. Res., submitted.

Sarynina, R. N., Conditions of Origin of Cold Deep-Sea Waters in the Bear Island Channel, International Council for the Exploration of the Sea, 28th Symposium, 1-8, 1969.

Slagstad, D., K. Støle-Hansen and L. Harald, Density driven currents in the Barents Sea calculated by a numerical model, Modeling, Identification and Control, 11(4 ), 181$190,1990$.

Steele, M., J. H. Morison and T. B. Curtin, Halocline Water Formation in the Barents Sea, J. Geophys. Res., 100(C1), 881-894, 1995.

Vinje, T., Sea ice conditions in the European sector of the marginal seas of the Arctic, 1966-1975, in Norsk Polarinstitutt Arbok, pp. 163-174, 1977. 
Vinje, T., Drift, composition, morphology and distribution of the sea ice fields in the Barents Sea, in Norsk Polarinstitutt Årbok, Skrifter 179C, pp. 3-26, 1985. 


\section{Appendix A}

\section{Supplementary information}

The information presented in this appendix is supplemental to the main text of this work. For the most part, it has already been presented elsewhere by various authors. It is included here with the intent of presenting a more complete background for this work.

\begin{tabular}{llllllllllll}
\hline \hline Dec & Jan & Feb & Mar & Apr & May & Jun & Jul & Aug & Sep & Oct & Nov \\
\hline & & & & & & & & & & & \\
-280 & -380 & -440 & -280 & -100 & -20 & 140 & 200 & 60 & -40 & -180 & -240 \\
\hline
\end{tabular}

Table A.1: Surface heat flux estimates in units of $\mathrm{W} / \mathrm{m}^{2}$ calculated by Häkkinen and Cavalieri, [1989] near Bjørnøya, $74^{\circ} \mathrm{N}, 20^{\circ} \mathrm{E}$. 


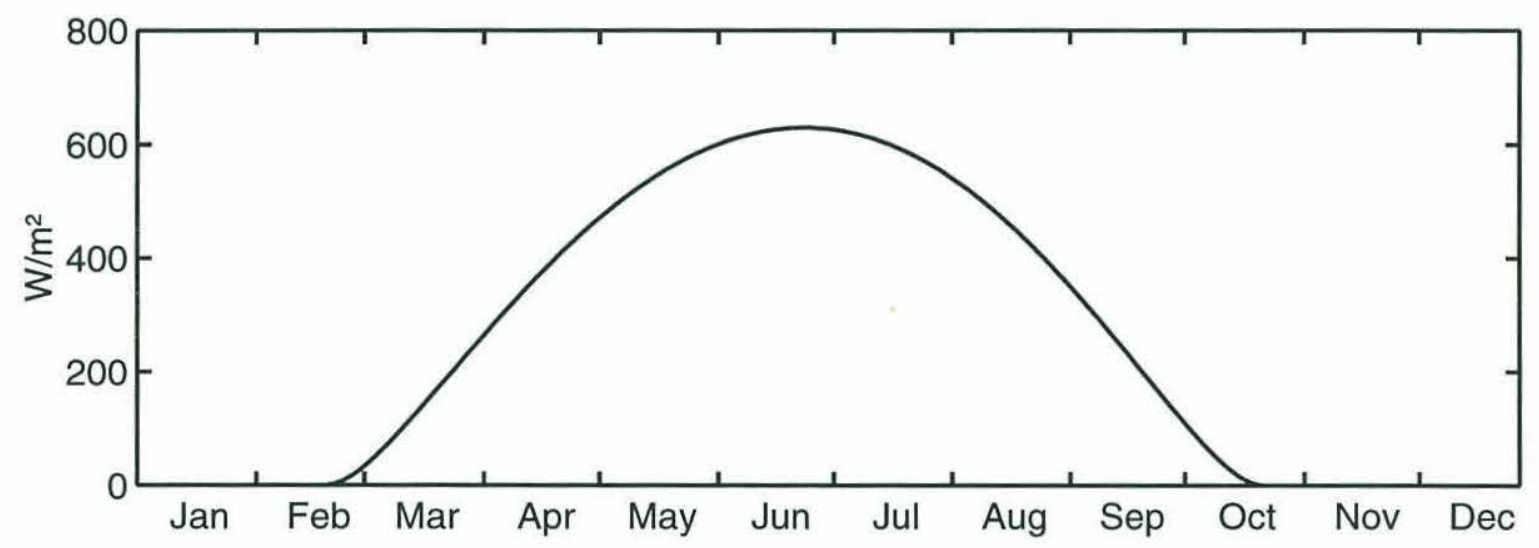

Figure A.1: Noontime incoming solar radiation at the surface near Bjørnøya $\left(74^{\circ} \mathrm{N}, 20^{\circ} \mathrm{E}\right)$ assuming an atmospheric transmission coefficient of 0.9 . 


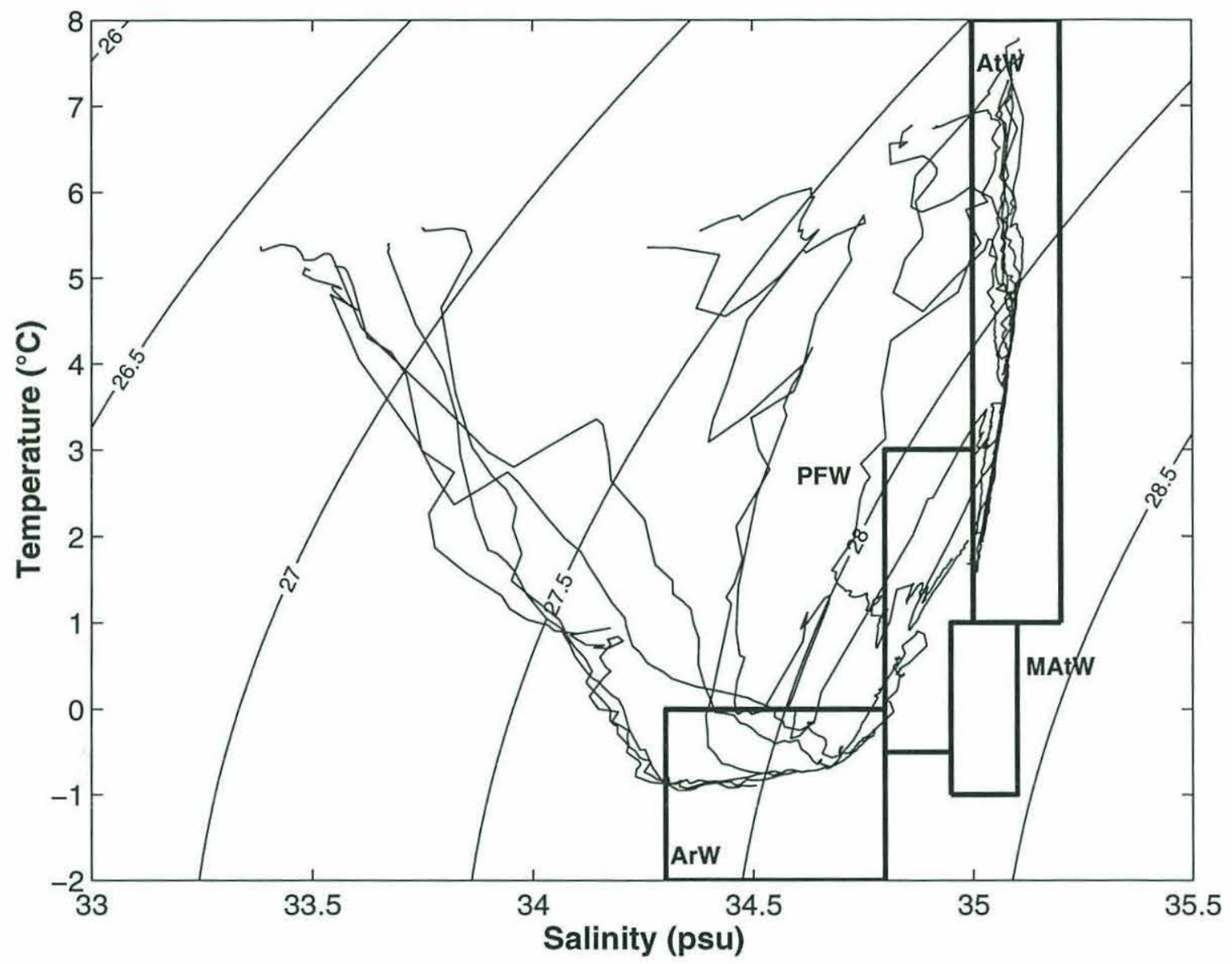

Figure A.2: T/S curves are shown for eight BSPFX CTD casts across the slope of Spitzbergen Bank at an approximate longitude of $22^{\circ} 48^{\prime} \mathrm{E}$. The points in each cast are connected by a line. The progression from fresh to salty water at the surface is shown. The interleaving of water masses is also visible, for example near a salinity of $34.5 \mathrm{psu}$, temperature of $4^{\circ} \mathrm{C}$. See Parsons et al. [1996] for more information regarding these data. 
a. $20 \mathrm{~m}$

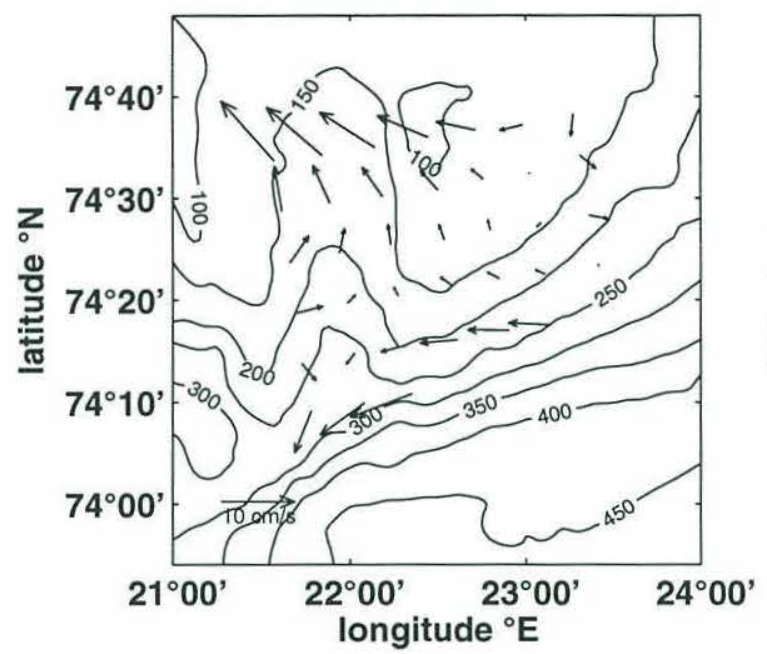

c. $80 \mathrm{~m}$

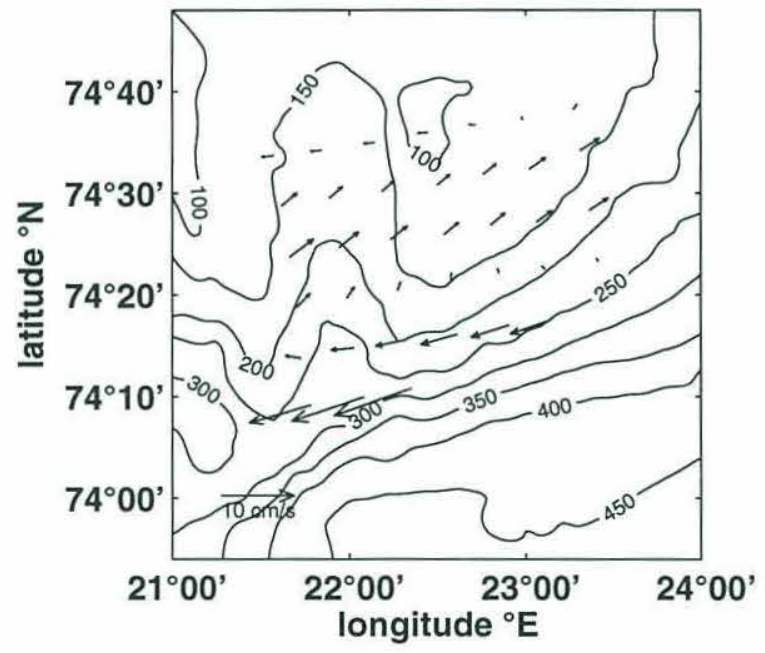

b. $50 \mathrm{~m}$

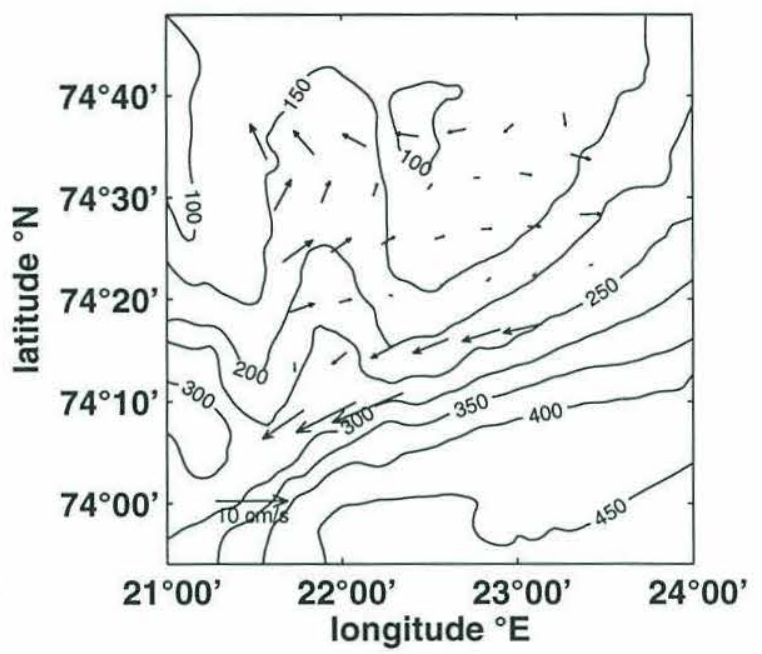

d. depth average

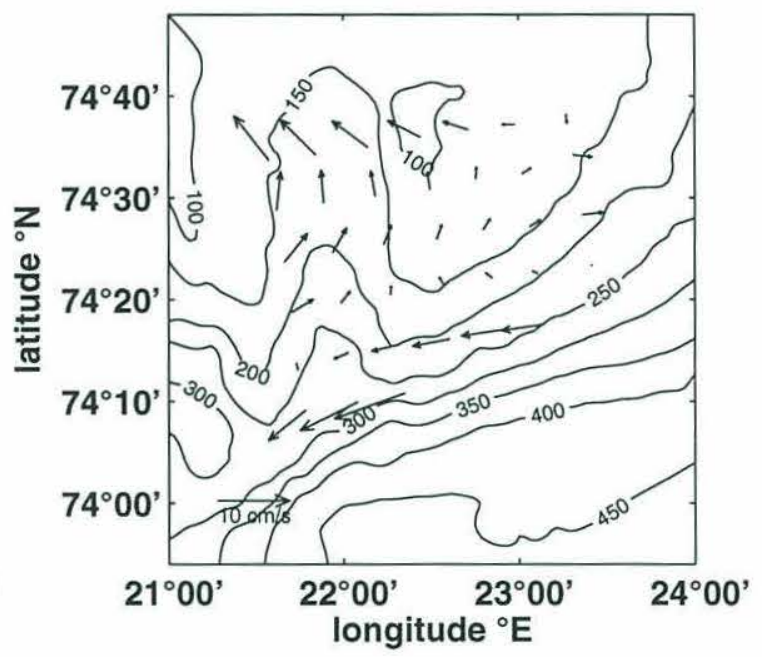

Figure A.3: BSPFX sub-tidal velocities are shown superimposed on a topographic map of the BSPFX region with bathymetric contours labeled in meters. To obtain these velocities, the $\mathrm{M}_{2}, \mathrm{~S}_{2}$, and $\mathrm{K}_{1}$ tides were removed from the ADCP and current meter data using the method of Candela et al. [1992]. Velocities were computed at depths of (a) $20 \mathrm{~m}$, (b) $50 \mathrm{~m}$, (c) $80 \mathrm{~m}$, and (d) the depth average. Velocities with magnitudes below (u, v) $=(3,2) \mathrm{cm} / \mathrm{s}$ are not significant. For further details on the detiding of the BSPFX data, see Harris et al. [1995]. 


\section{Appendix B}

\section{NODC-B cross-front transect data}

NODC-B cross-front sections of salinity, temperature, and density are displayed in this appendix. The location, country of origin, NODC cruise number, number of casts, and dates of each transect are shown in Figure B.3; see Figure B.1 for the key to this information. Salinity sections are shown in Figure B.4, temperature sections are shown in Figure B.5, and density $\left(\sigma_{t}\right)$ sections are shown in Figure B.6; see Figure B.2 for the key to these figures. The transects are ordered by month and, for ease of cross-reference, each section is labeled with its NODC cruise number, month, and year. 
a. YYMMDD1 YYMMDD2

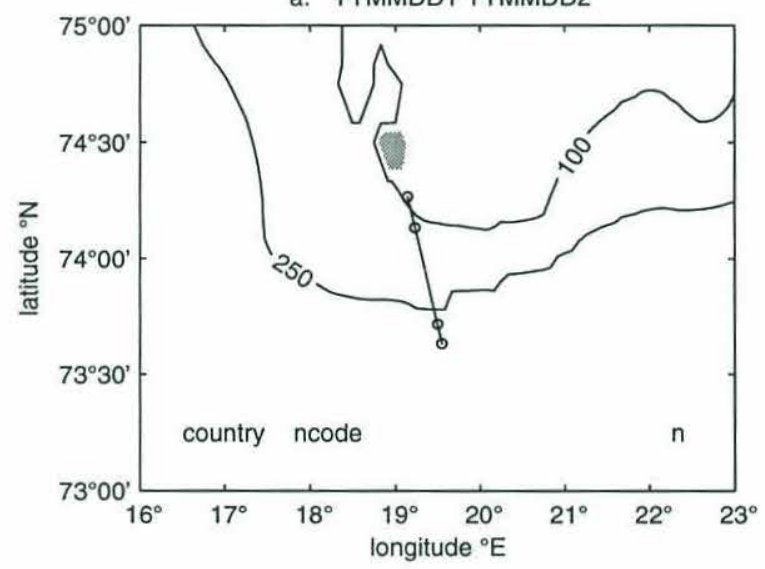

Figure B.1: The key for the locations of the NODC-B transects is shown. A topographic map of the region near Bear Island including the 100 and $250 \mathrm{~m}$ contours is shown. Bear Island is shaded. The bathymetry source is the ETOPO5 database. The position of each cast is shown by a small circle and the cast positions are connected to show the order they were occupied. The dates spanning the measurement of the profiles are shown at the top of the figure ( $Y Y M M D D 1-Y Y M M D D 2)$. The country of origin for the data (country) is shown in the lower left corner of the figure and the NODC cruise code (ncode) is displayed just to its right. The number of casts in the transect $(n)$ is shown in the lower right corner of the figure. The position data associated with this key are shown in Figure B.3. 


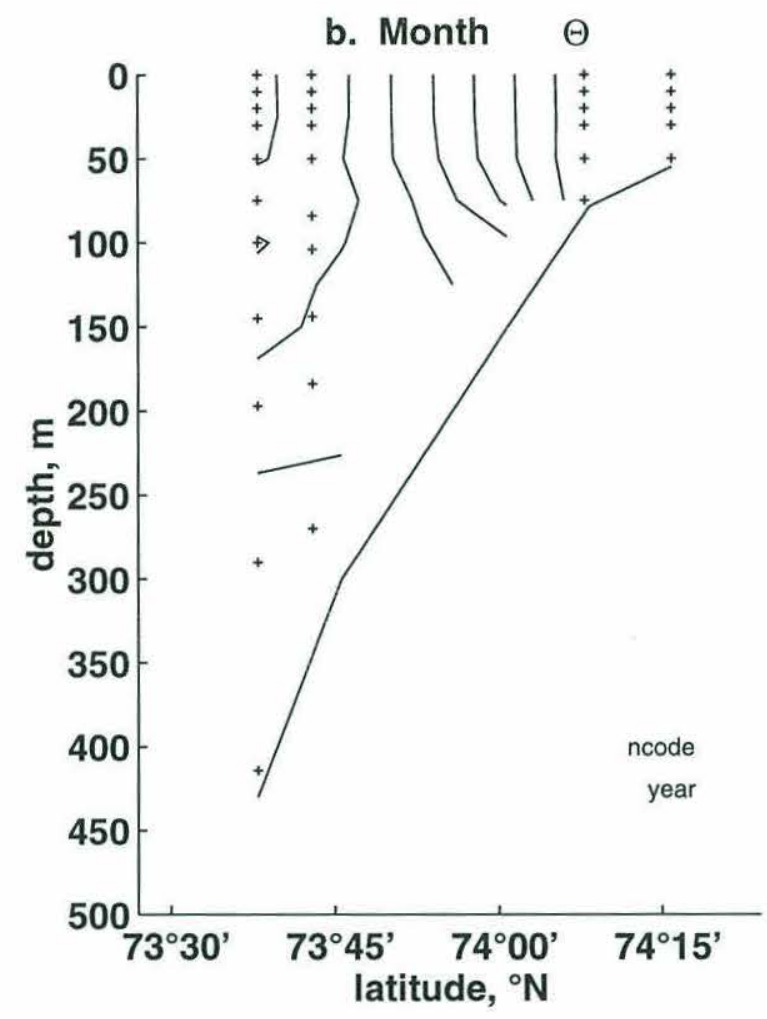

Figure B.2: The key for the NODC-B data sections is shown. The top of the figure is labeled with the month (Month) and the property shown $(\Theta)$, where $\Theta$ is either salinity $(S)$, temperature $(T)$, or density $\left(\sigma_{t}\right)$. The small crosses indicate the data positions. The bathymetry is gridded from information reported with each cast. The lower right corner of the figure is labeled with the NODC cruise code (ncode) and the year (year). The sections associated with this key are shown in Figures B.4-B.6. 

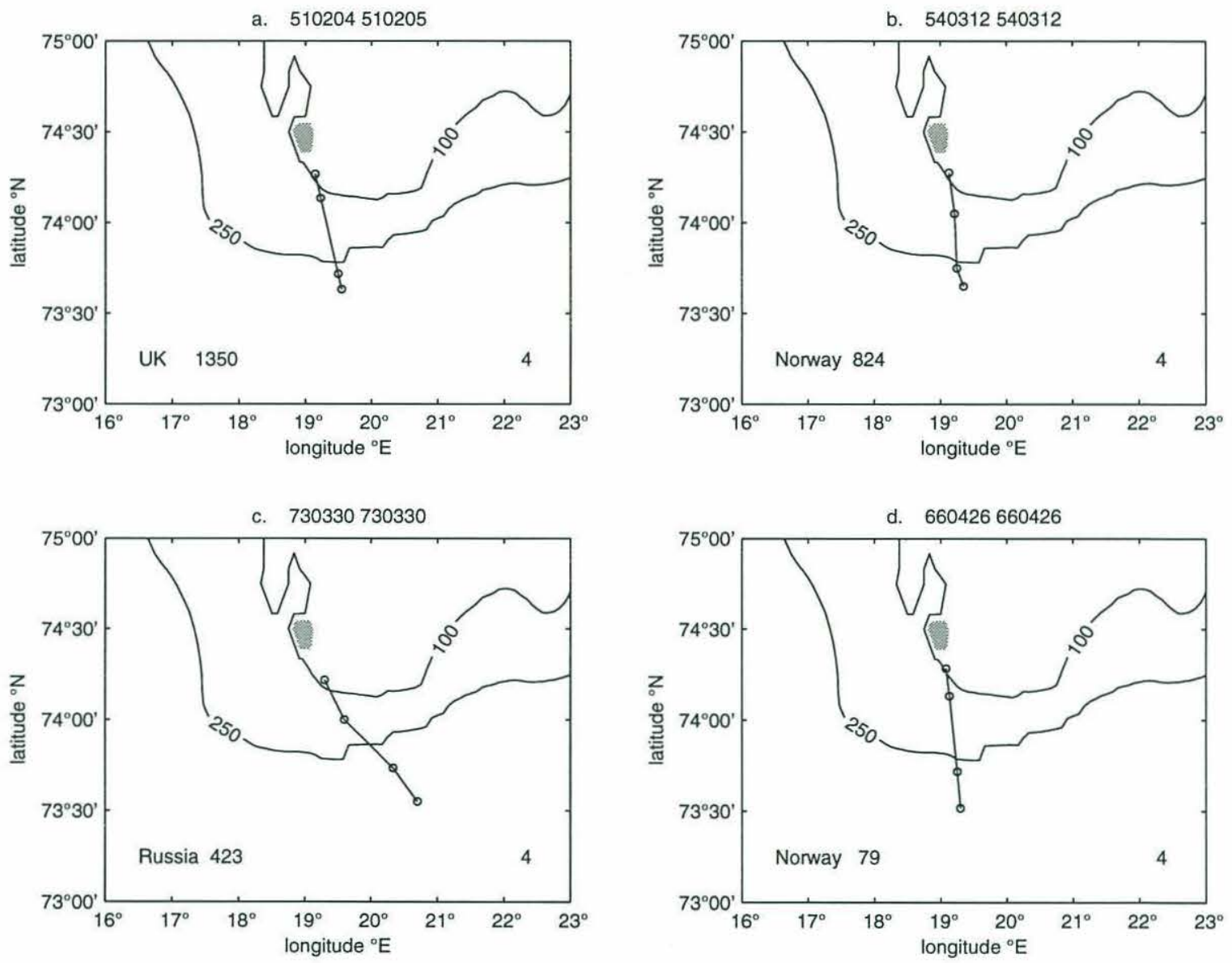

Figure B.3: NODC-B transect locations. Figure B.1 is the key for this figure. See Figures B.4, B.5, and B.6 for other transect data. 
e. 760415760416

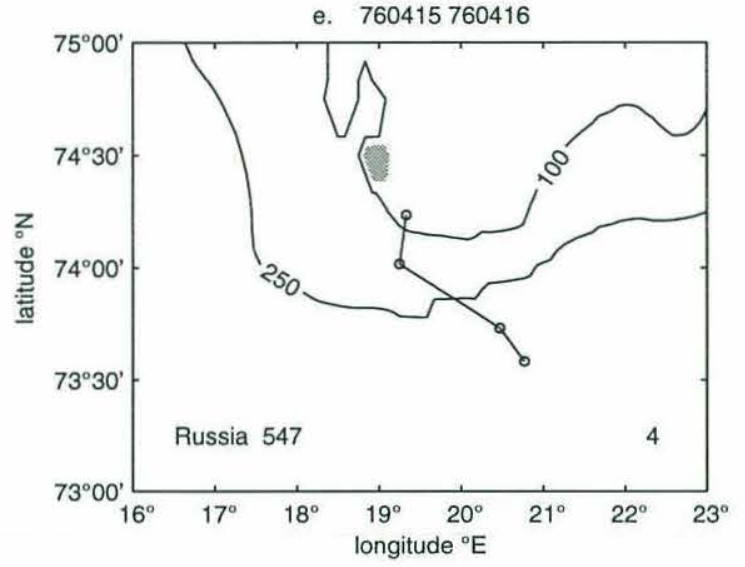

g. 560526560527

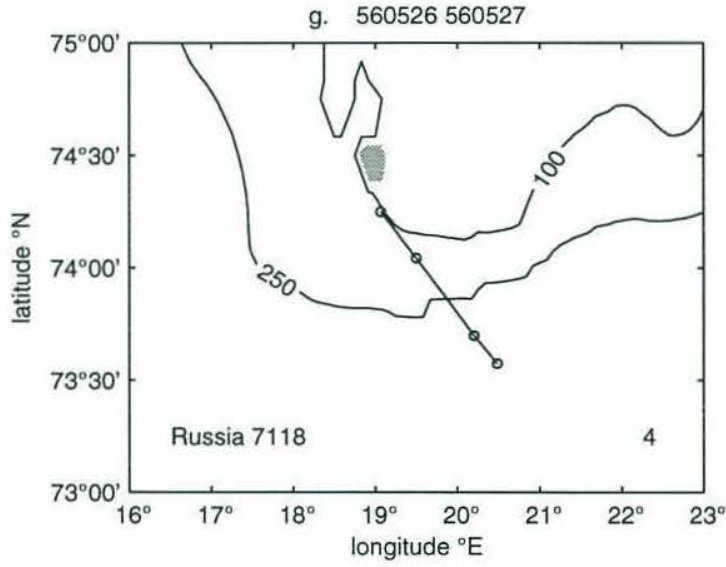

f. 550521550522

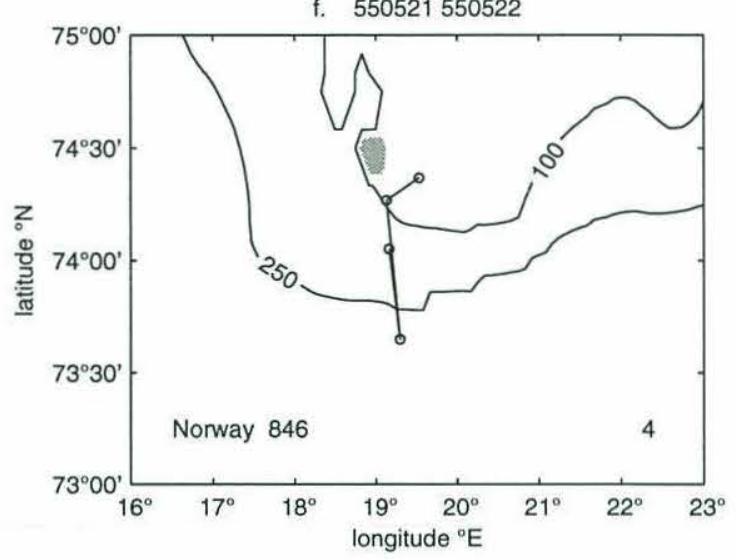

h. 570502570509

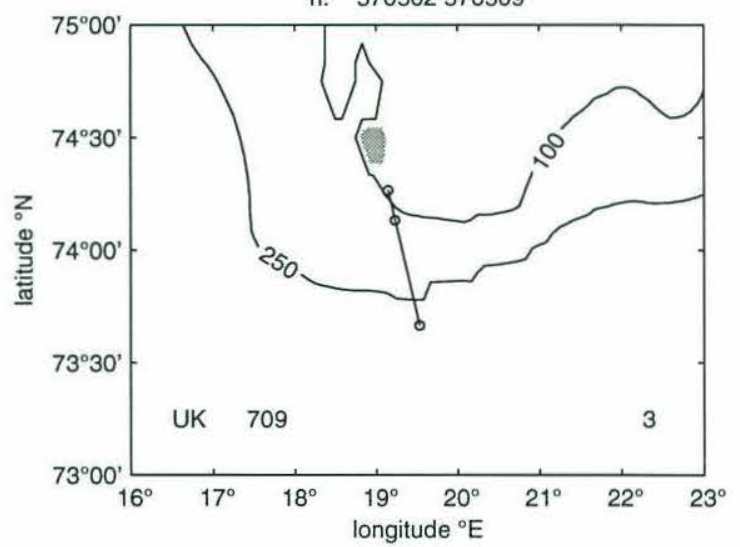

Figure B.3: continued. 

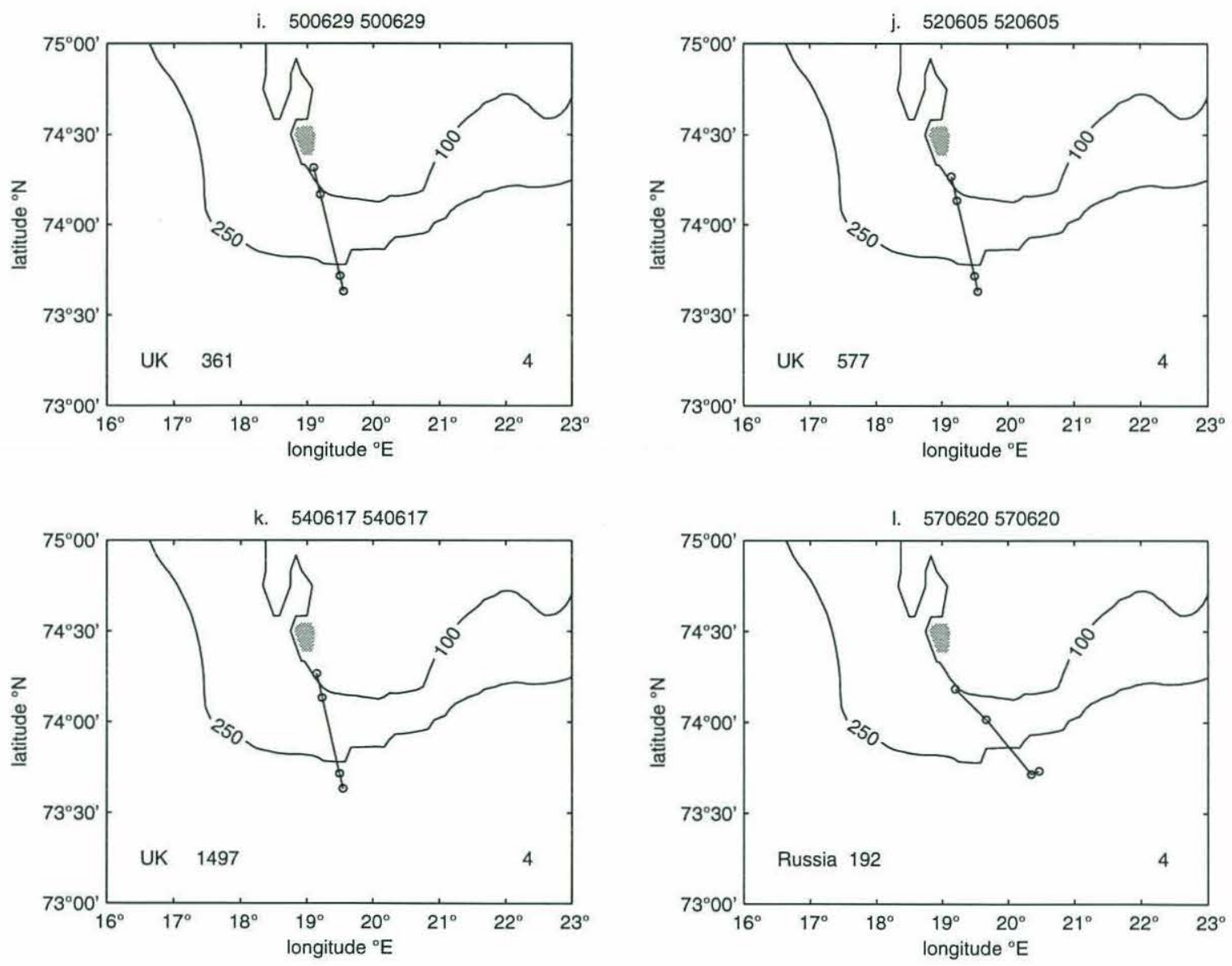

Figure B.3: continued. 

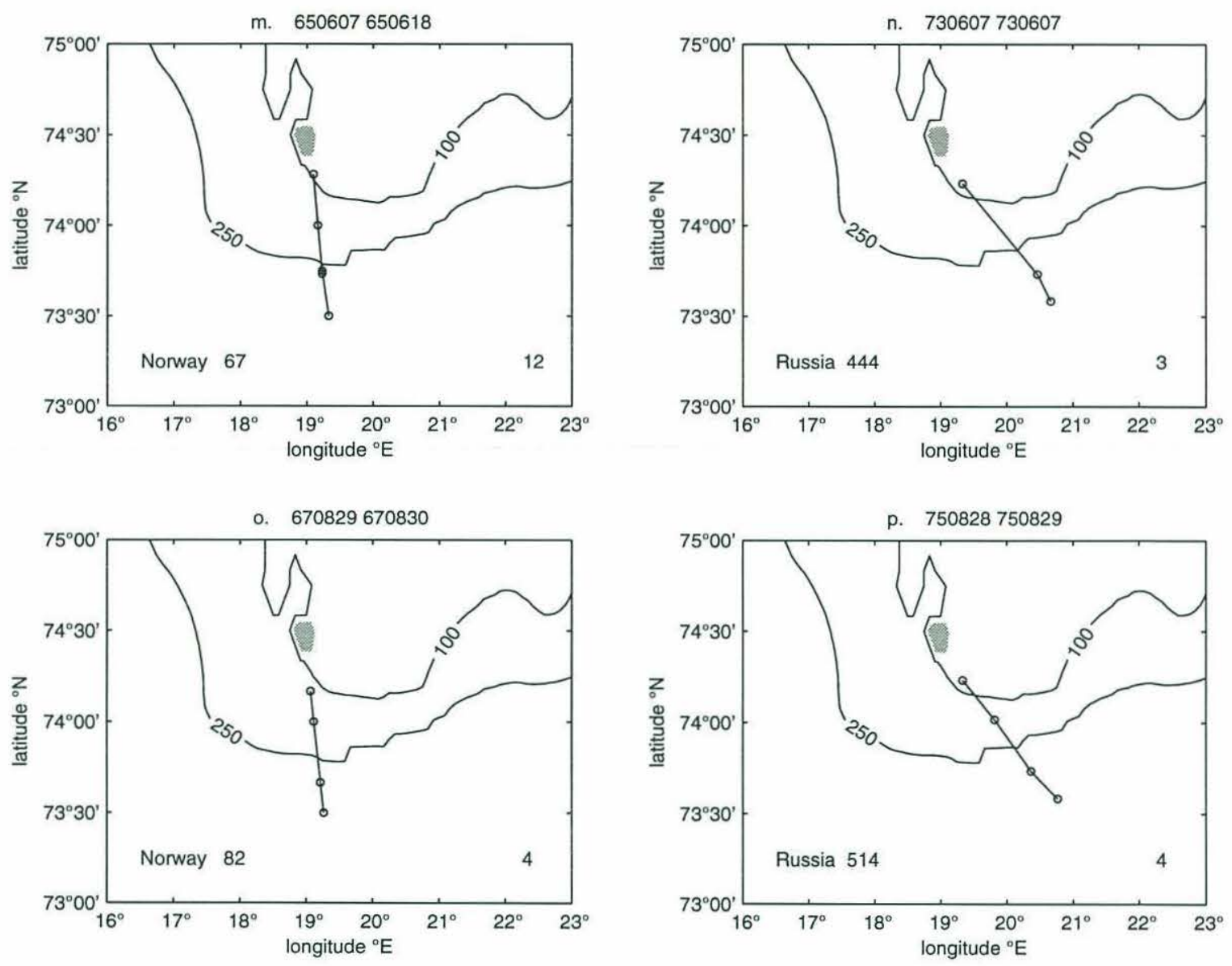

Figure B.3: continued. 

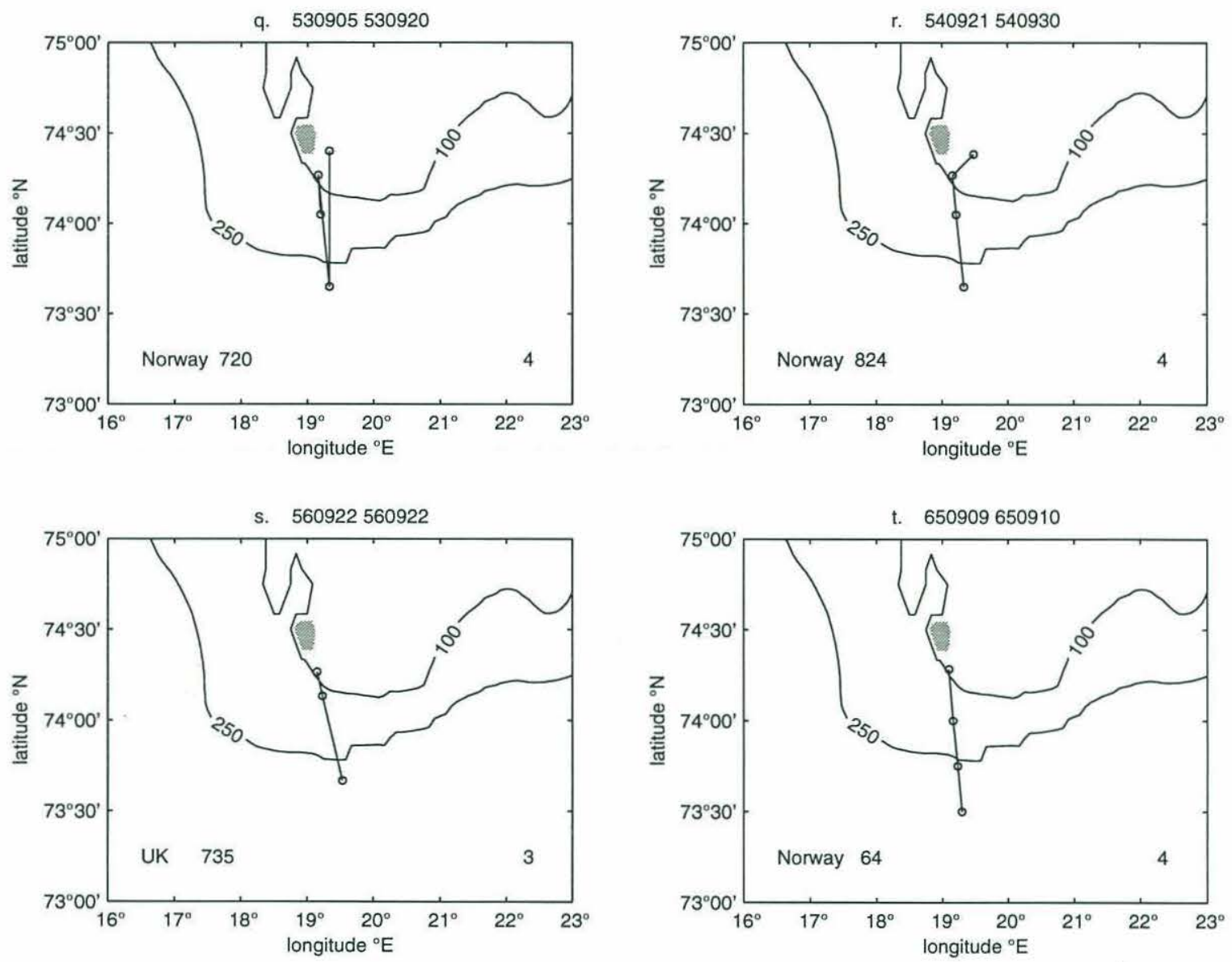

Figure B.3: continued. 

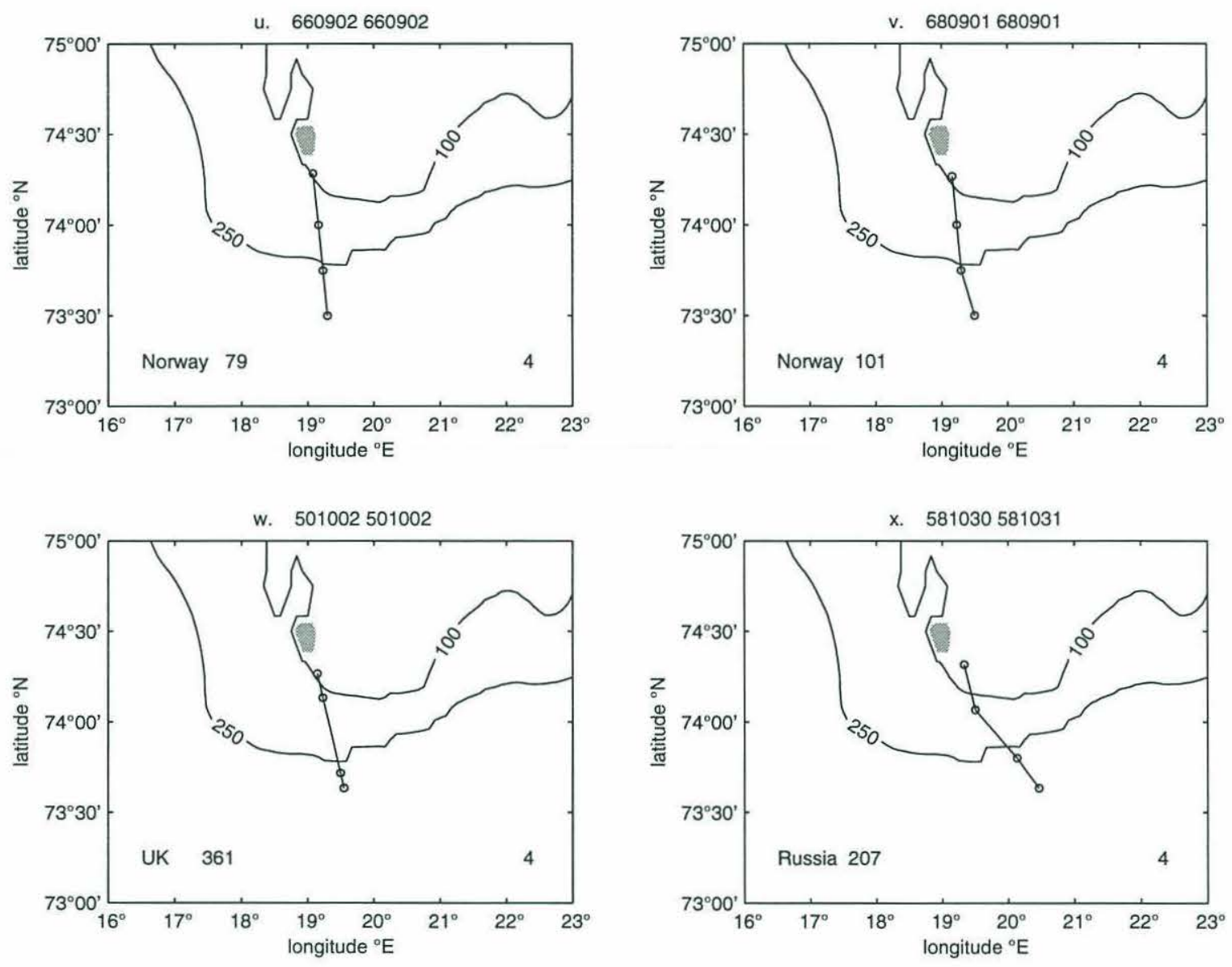

Figure B.3: continued. 

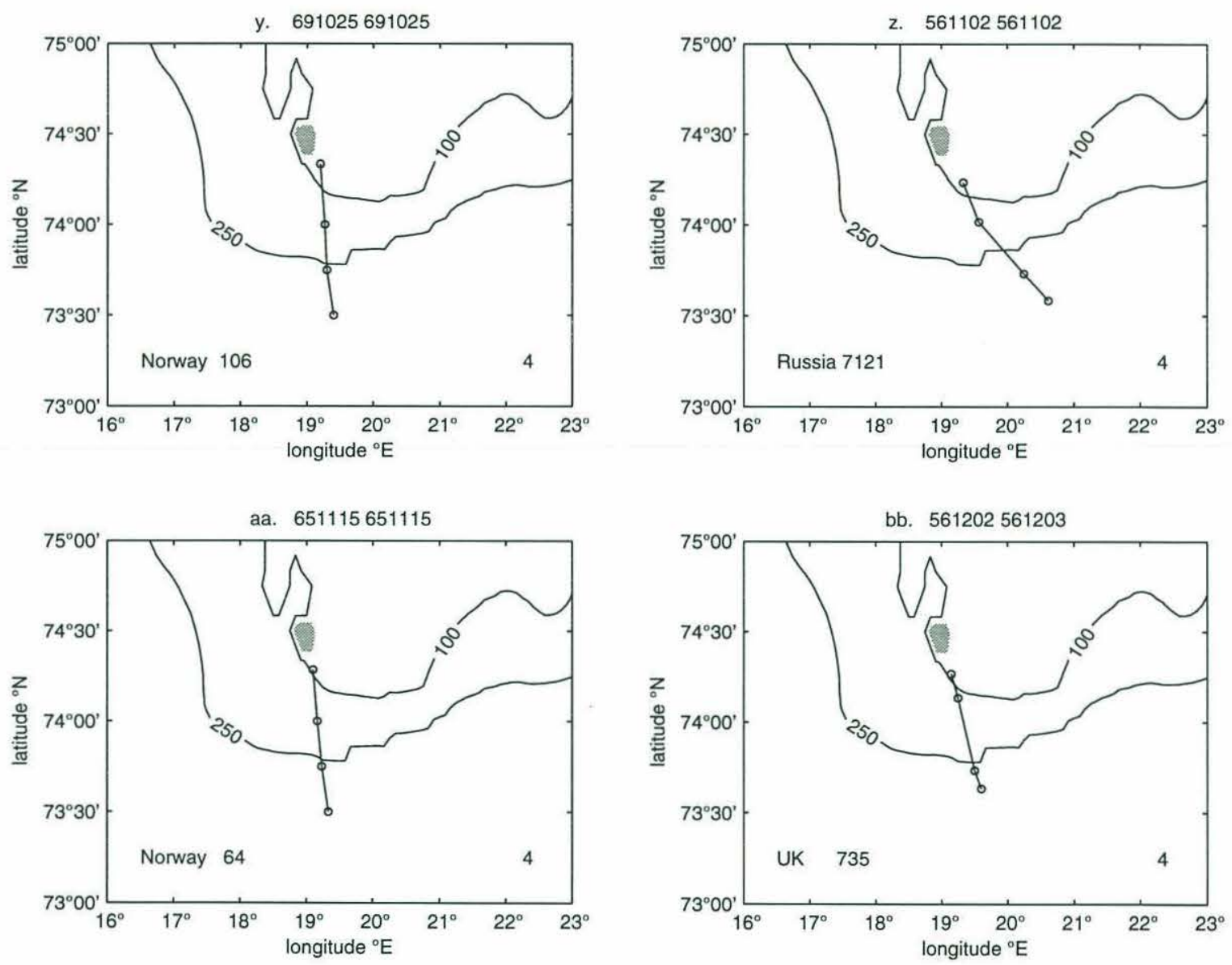

Figure B.3: continued. 


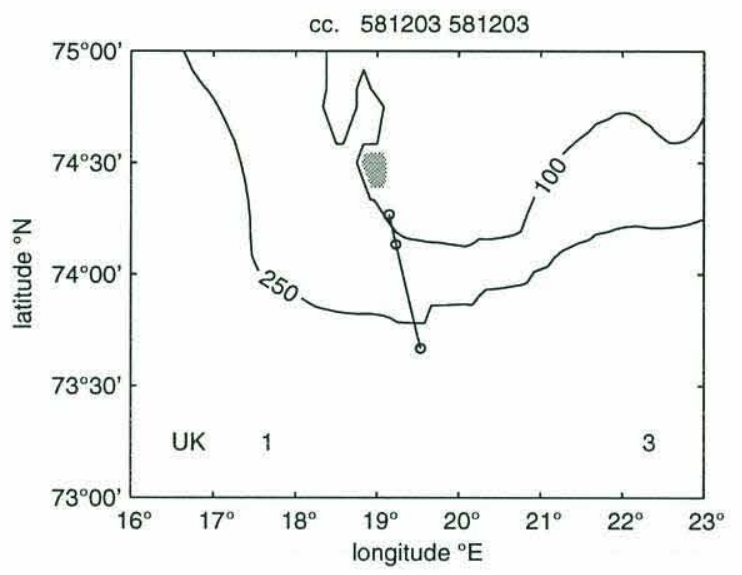

Figure B.3: continued. 

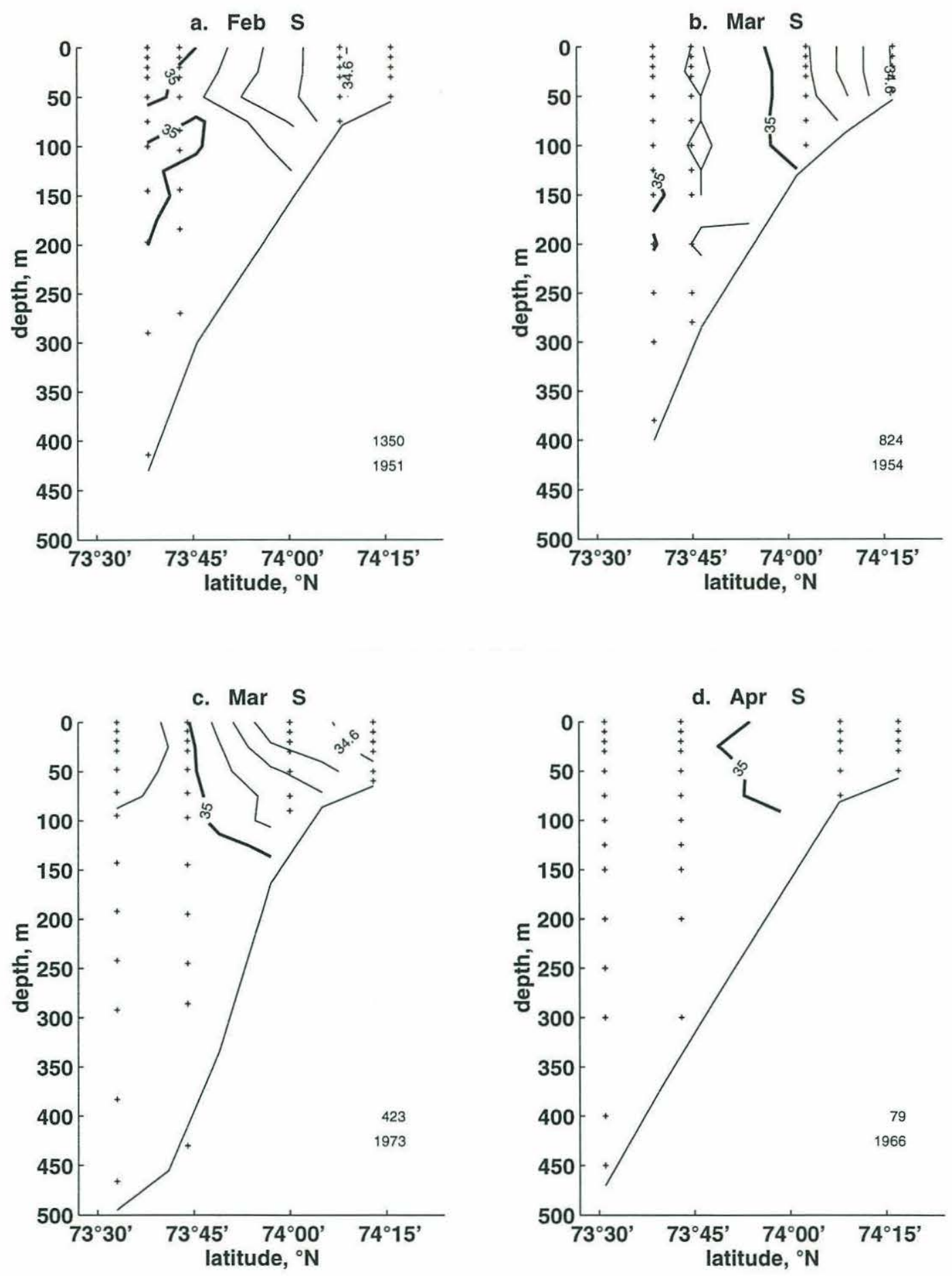

Figure B.4: NODC-B salinity sections. The contour interval is $0.1 \mathrm{psu}$. The $35.0 \mathrm{psu}$ contour is emphasized because it is a water mass boundary between subsurface Atlantic and Polar Front waters. Figure B.2 is the key for this figure. See Figures B.3, B.5, B.6 for other transect data. 

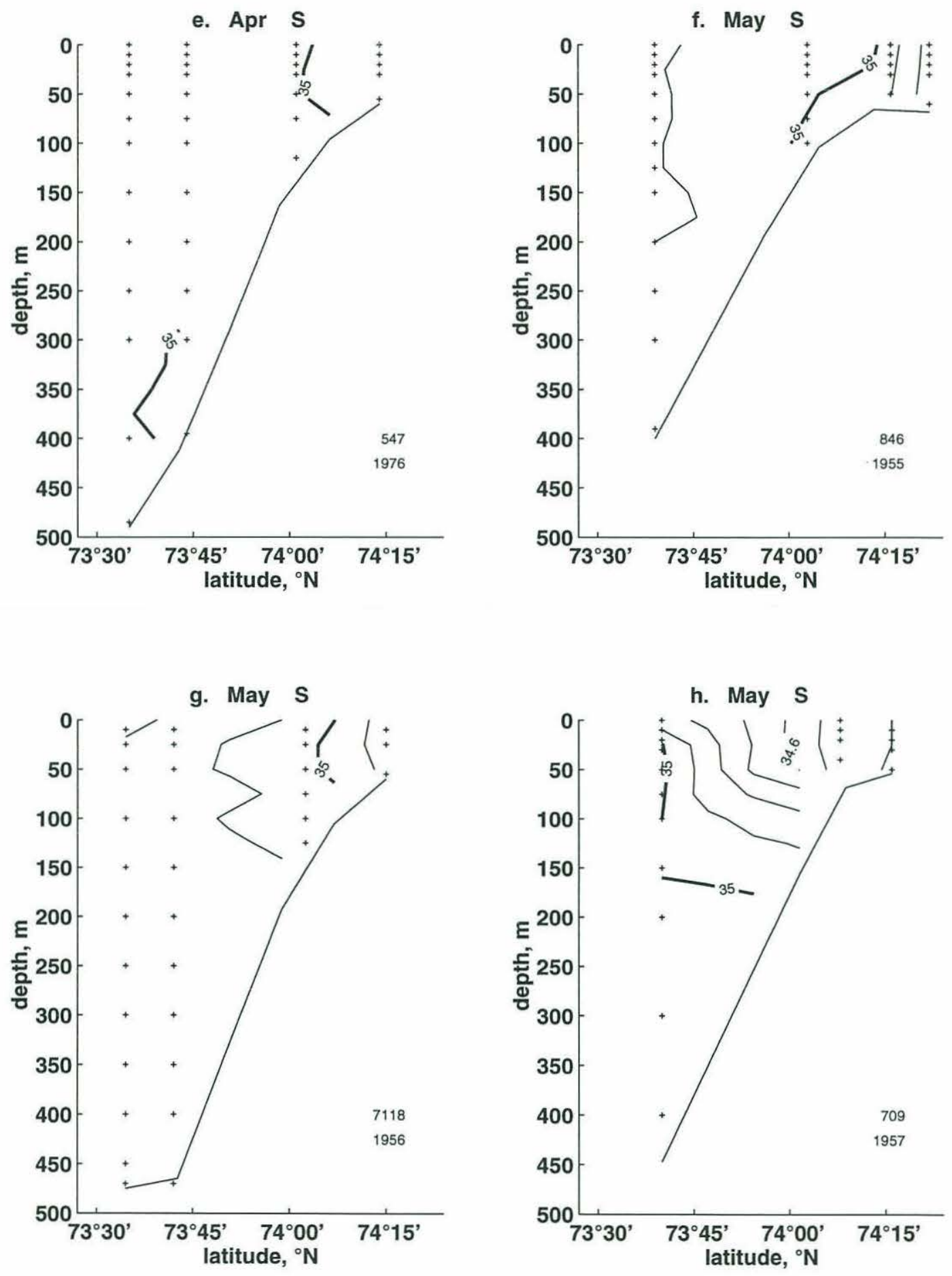

Figure B.4: continued. 

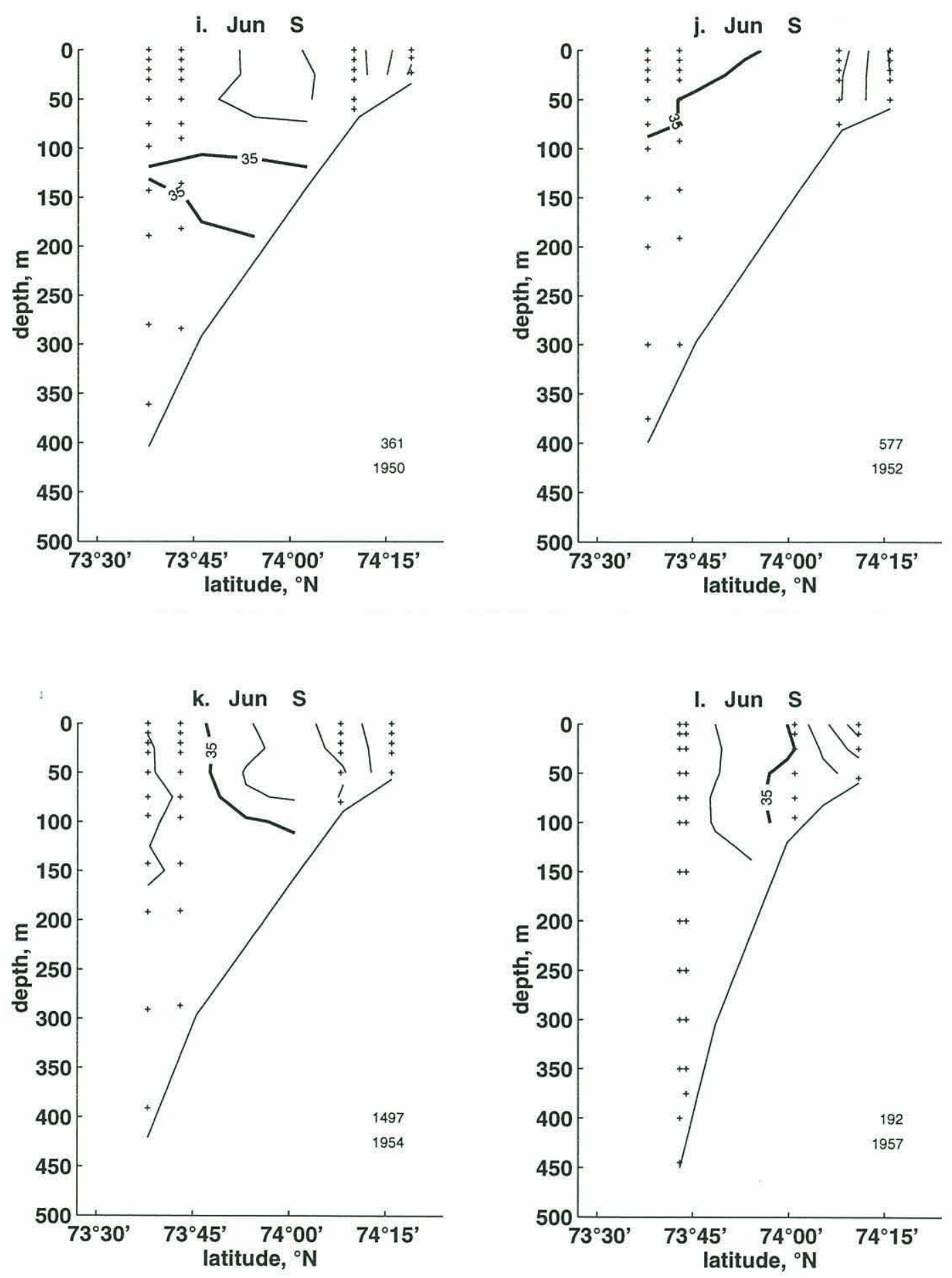

Figure B.4: continued. 

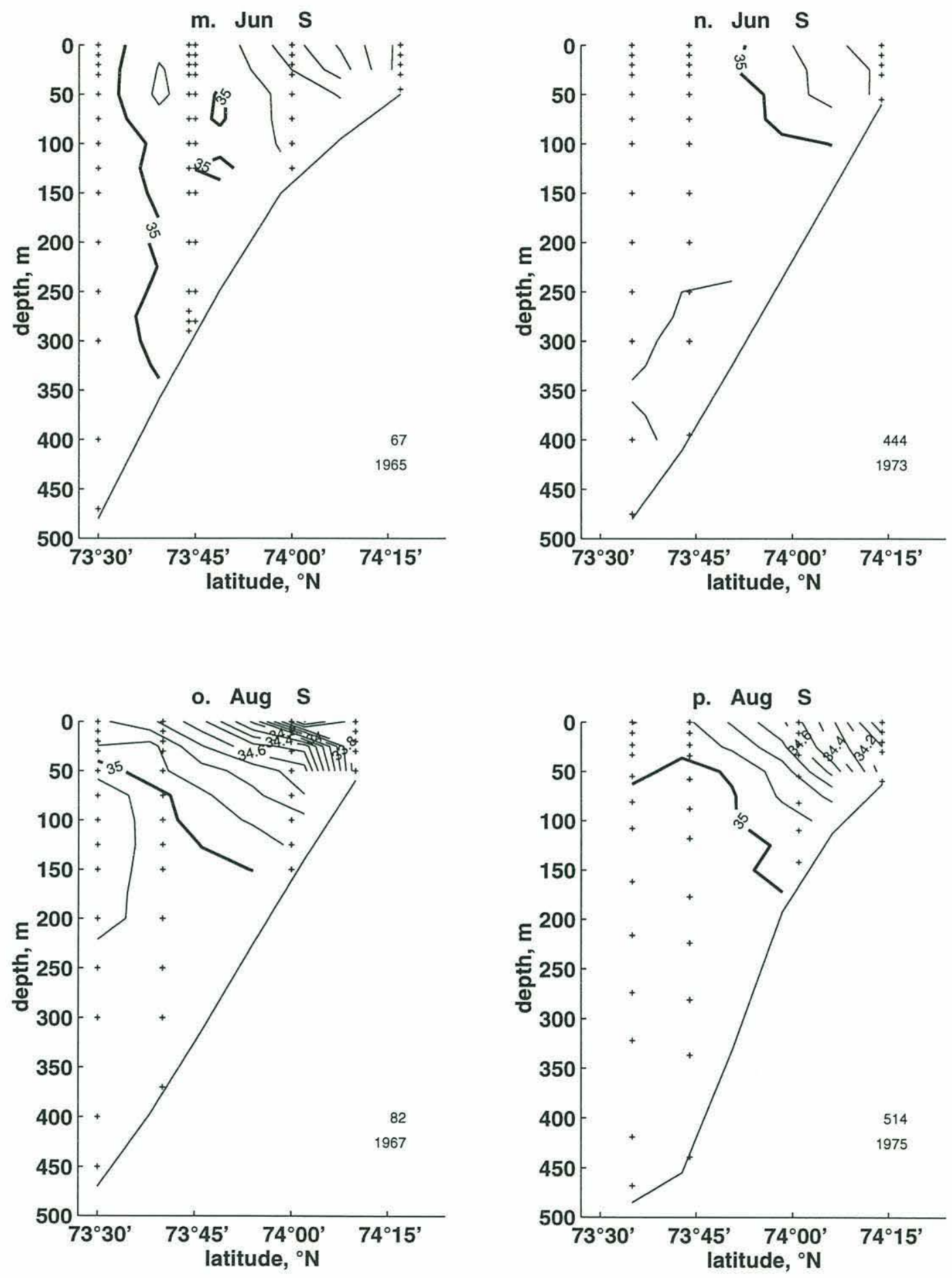

Figure B.4: continued. 

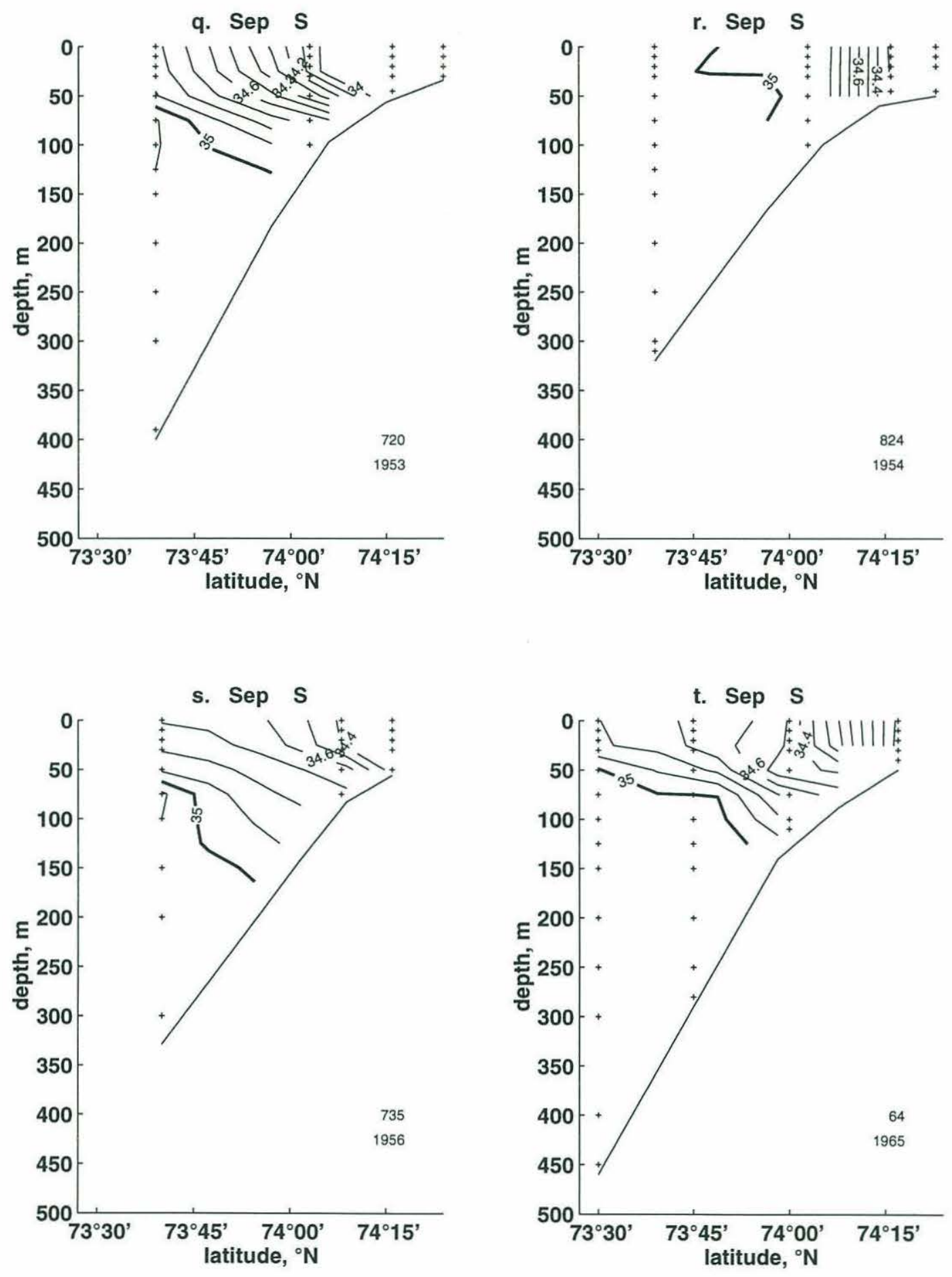

Figure B.4: continued. 

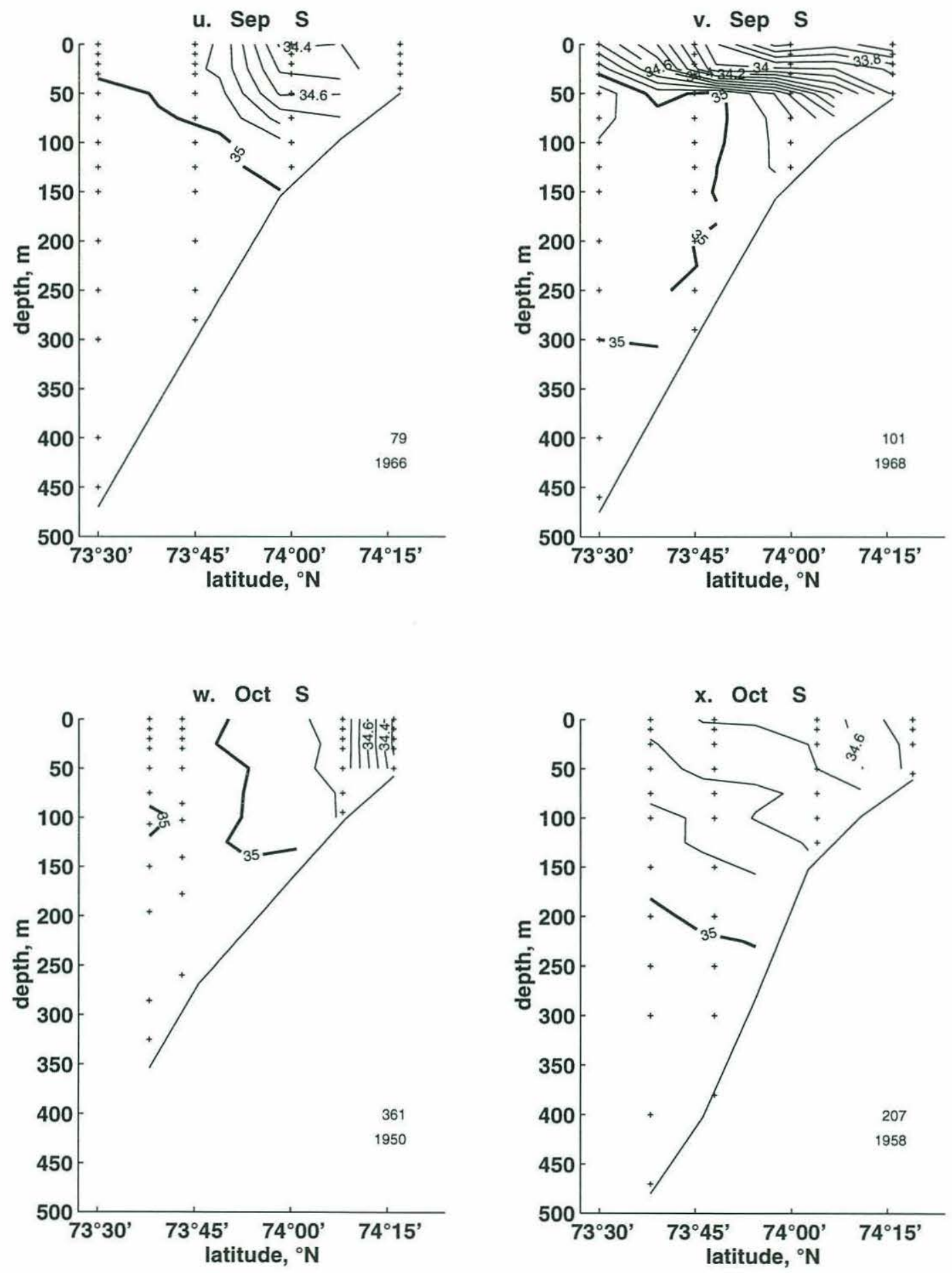

Figure B.4: continued. 

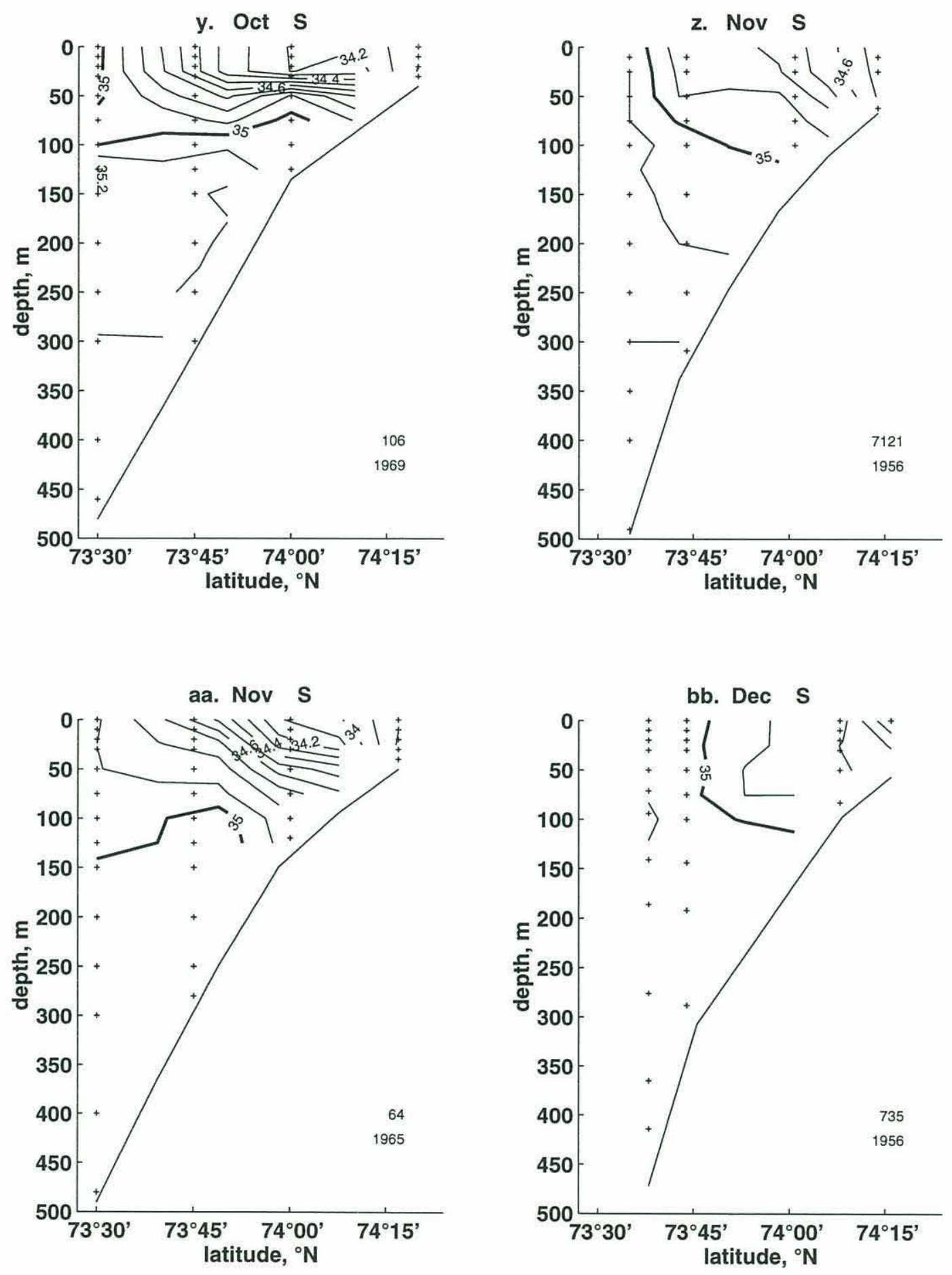

Figure B.4: continued. 


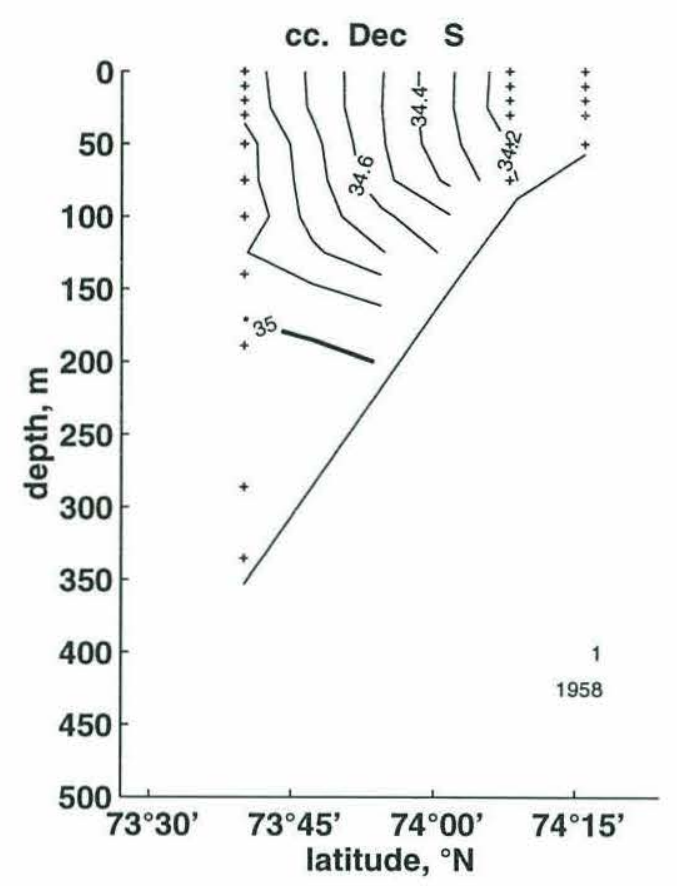

Figure B.4: continued. 

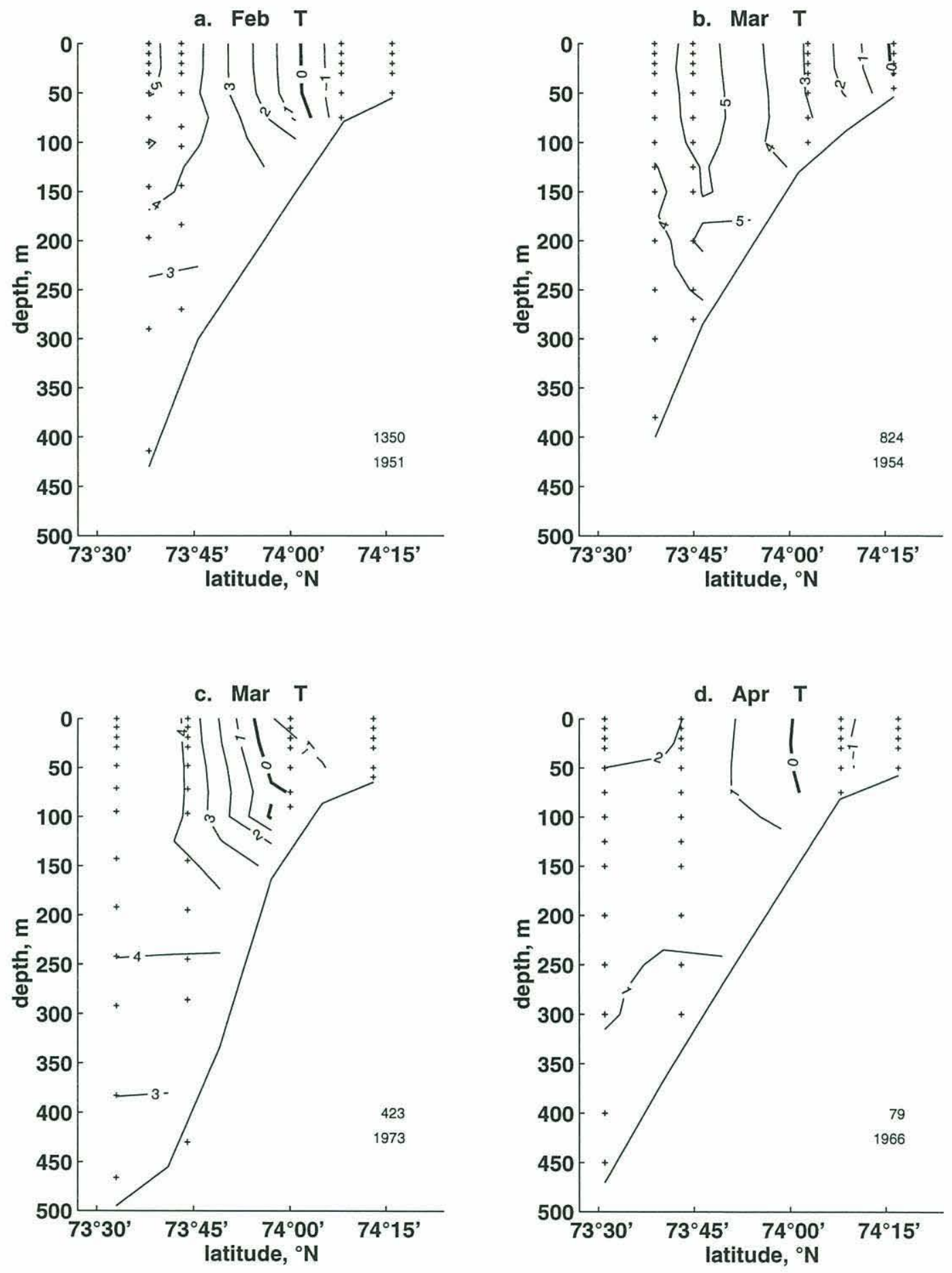

Figure B.5: NODC-B temperature sections. The contour interval is $1^{\circ} \mathrm{C}$. The $0^{\circ} \mathrm{C}$ isotherm is emphasized because it is a water mass boundary delimiting the subsurface Arctic Water. Figure B.2 is the key for this figure. See Figures B.3, B.4, B.6 for other transect data. 

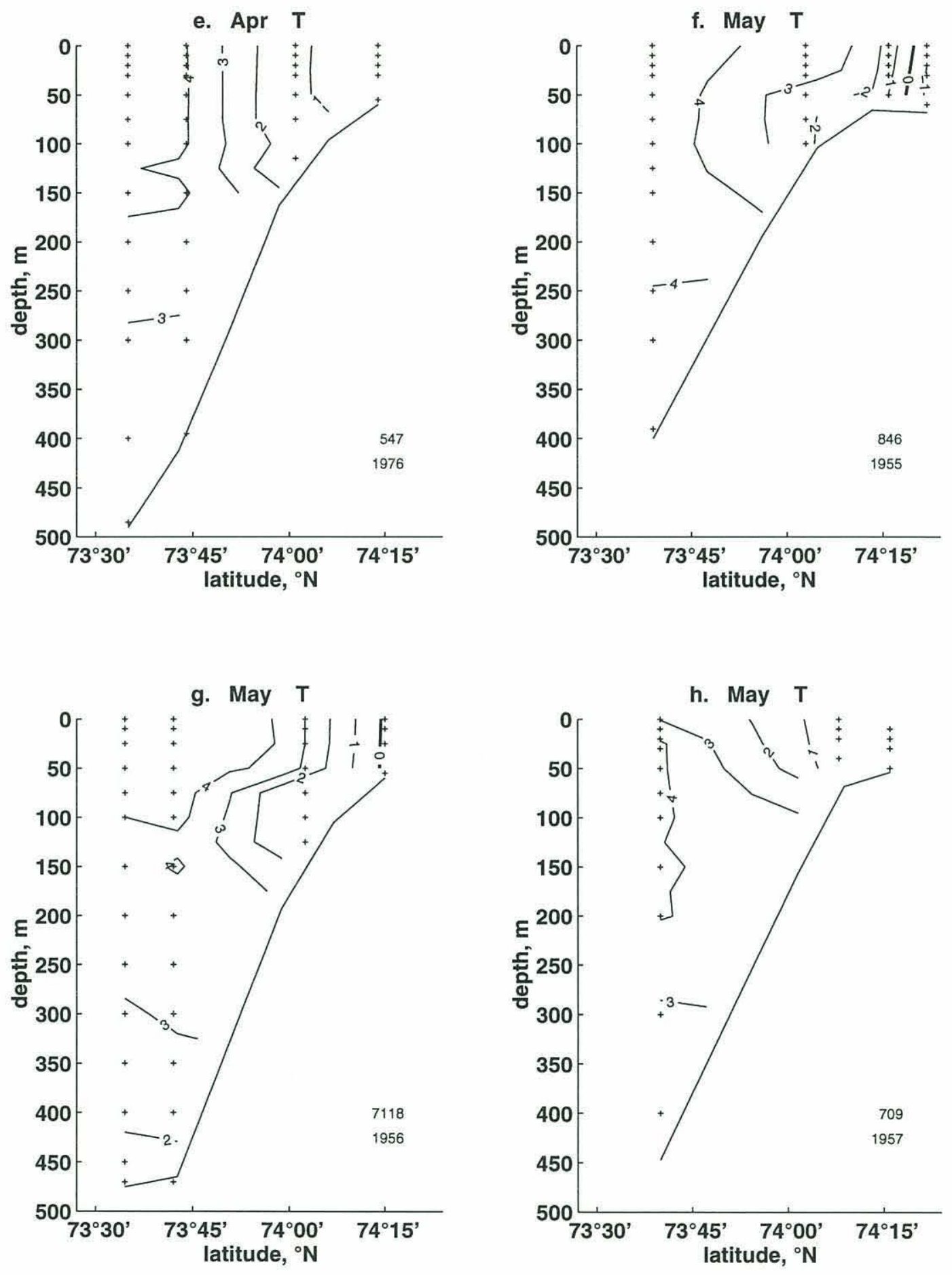

Figure B.5: continued. 

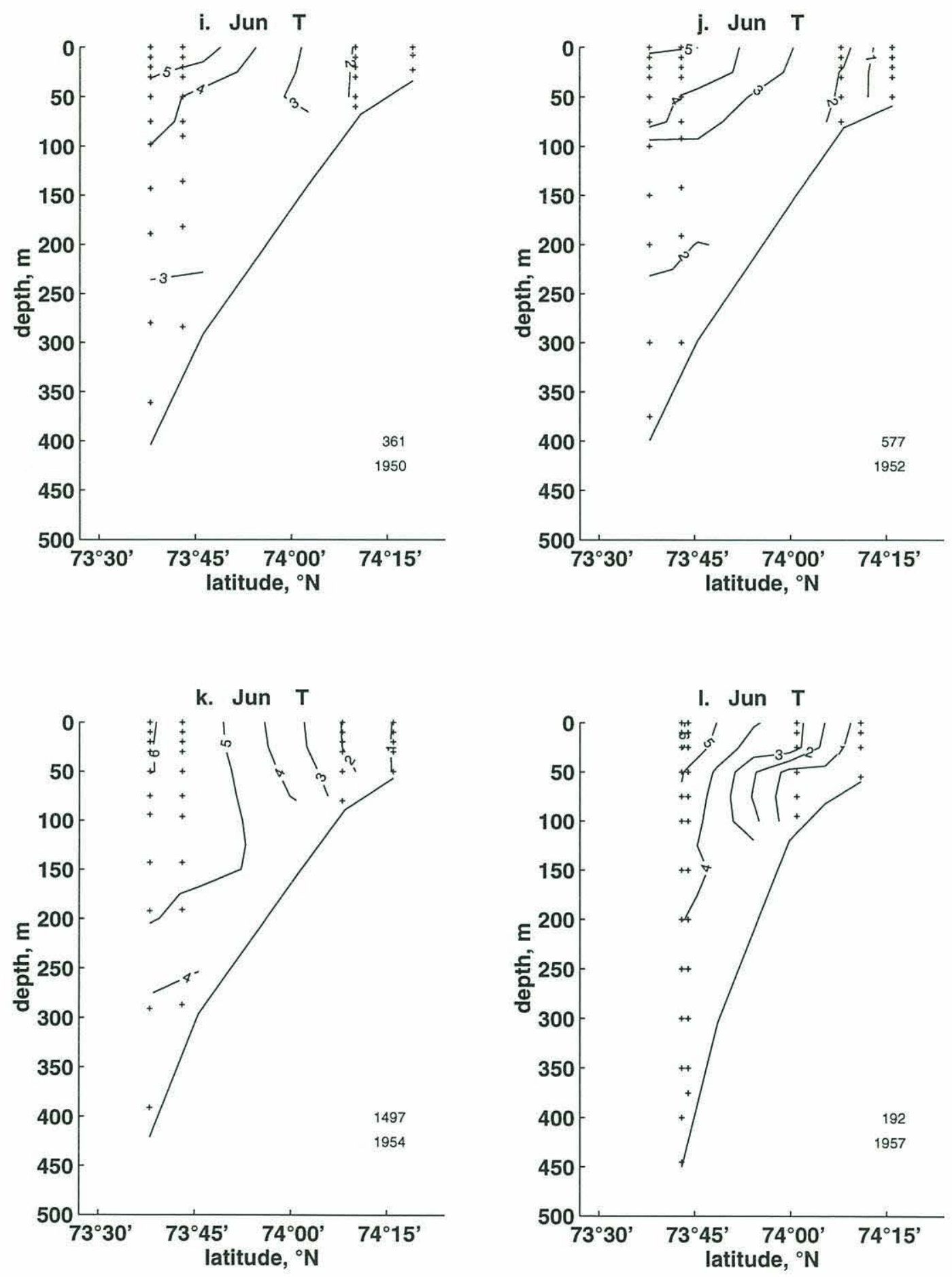

Figure B.5: continued. 

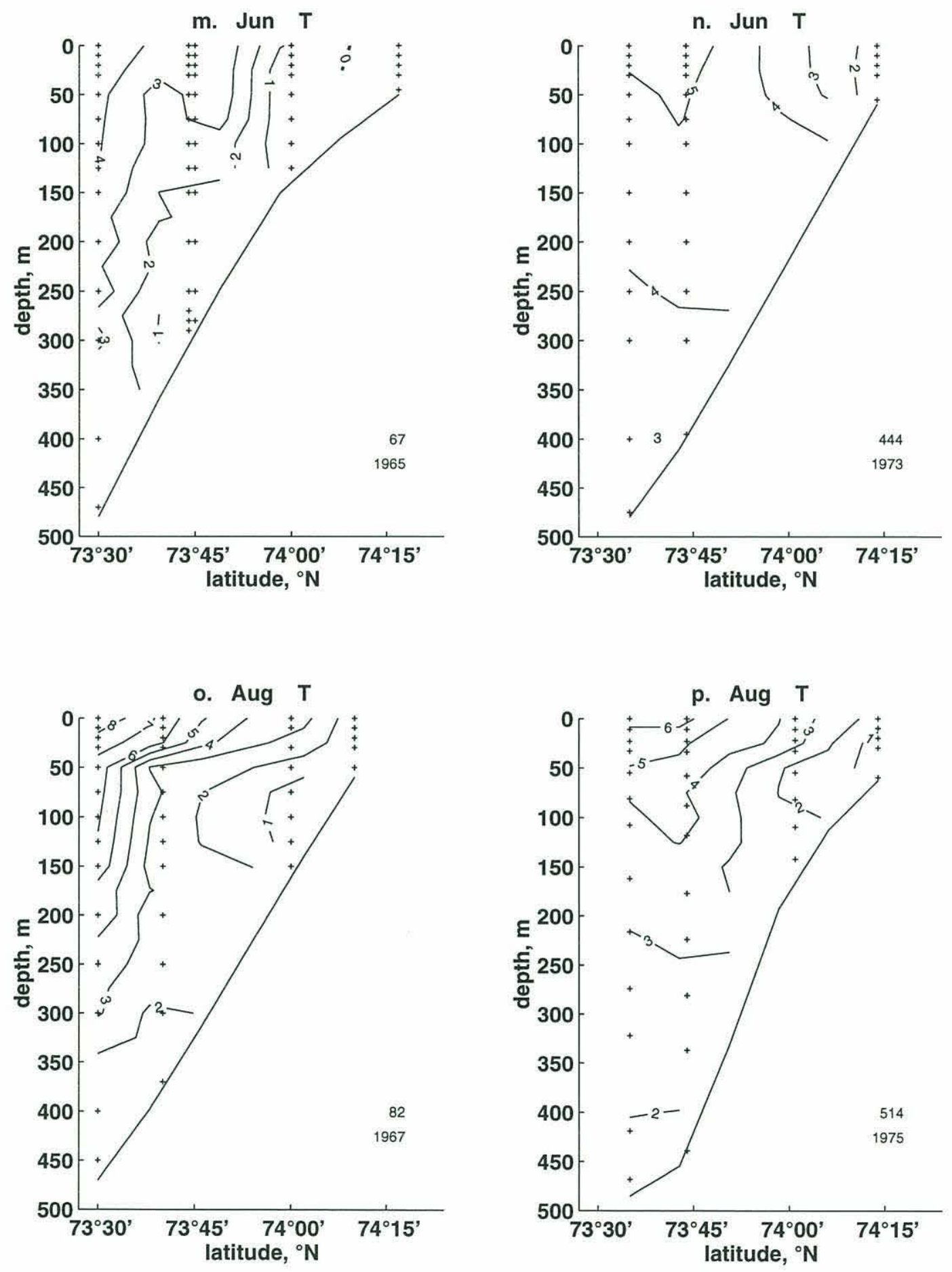

Figure B.5: continued. 

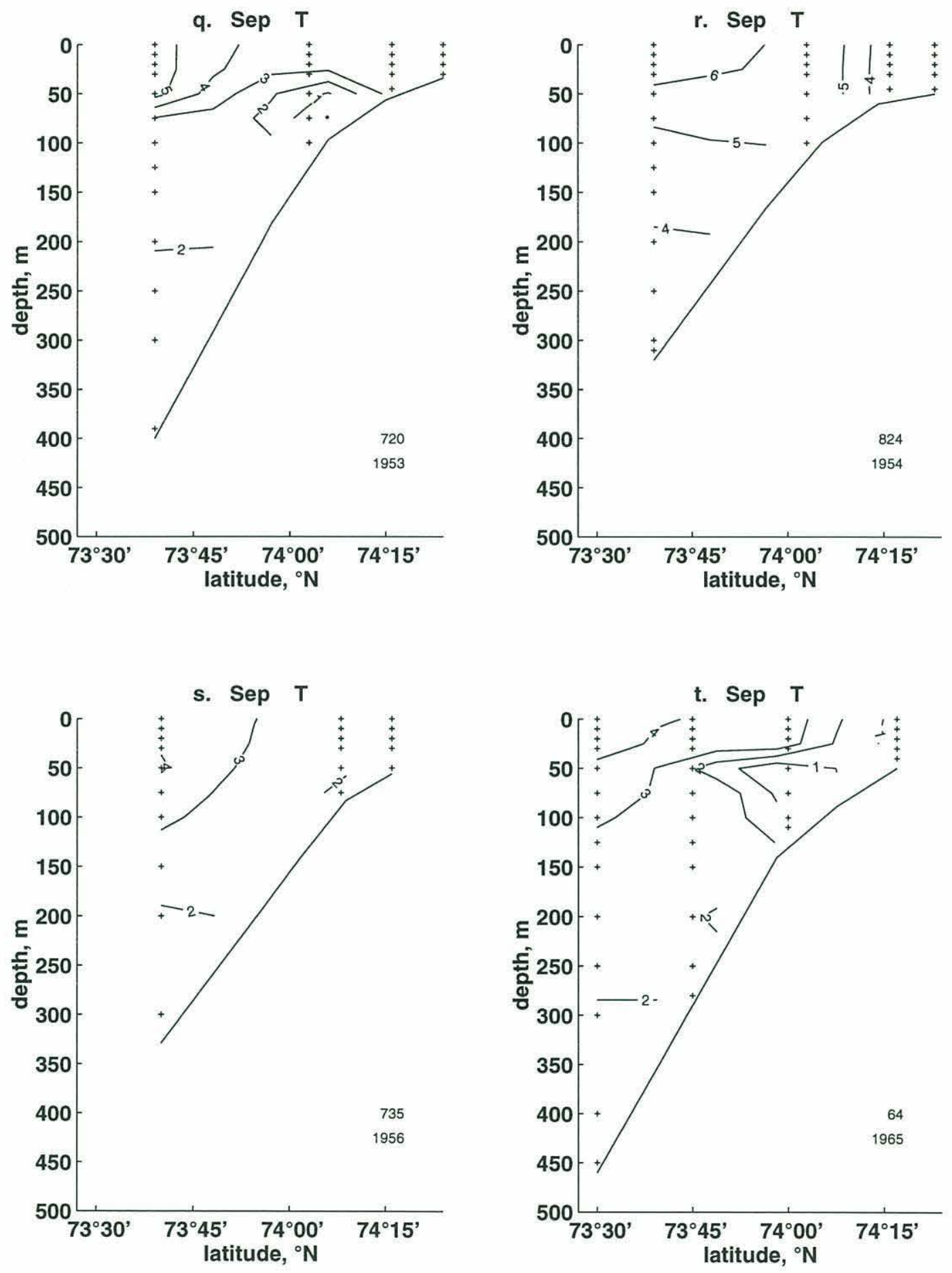

Figure B.5: continued. 

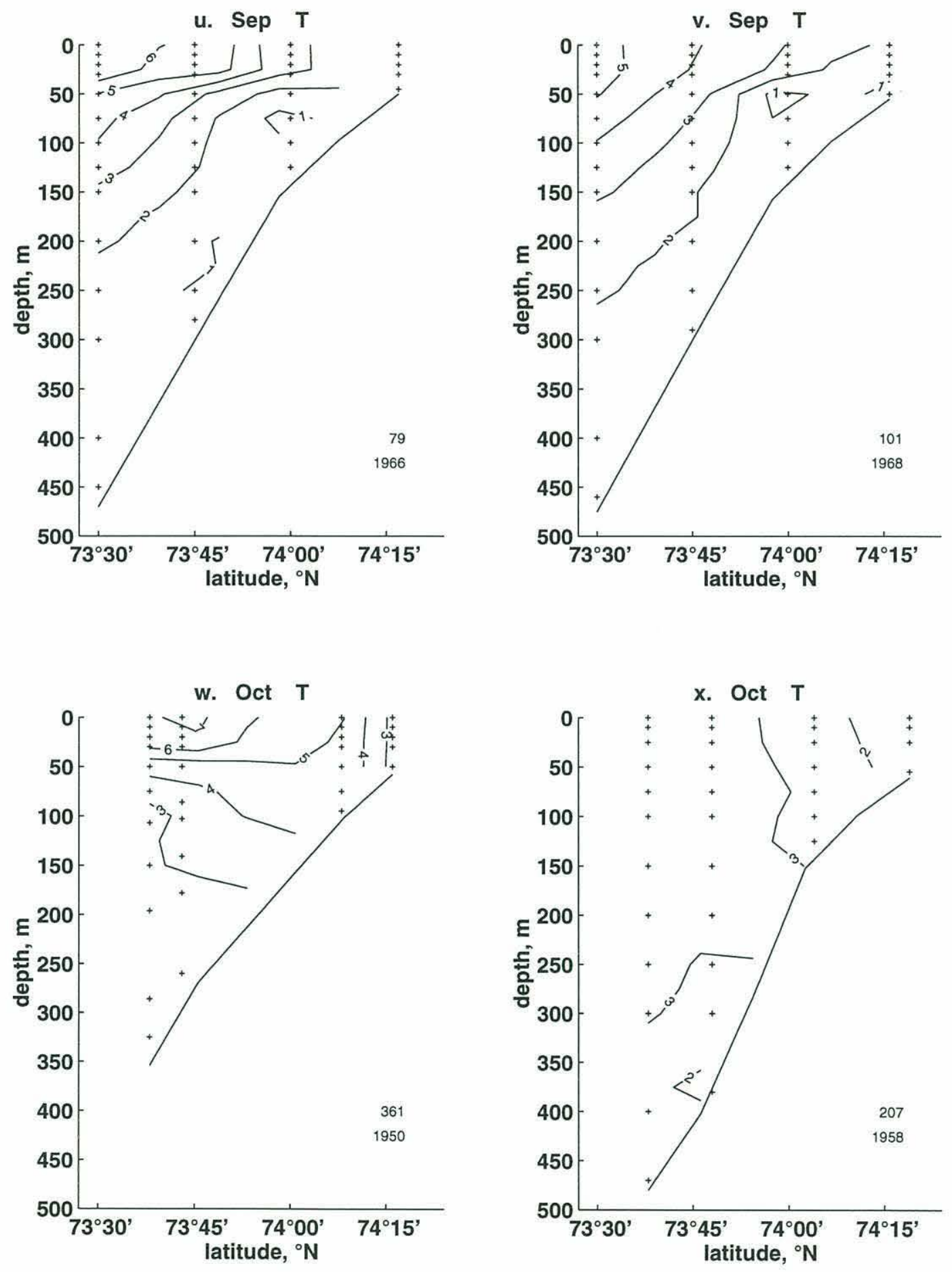

Figure B.5: continued. 

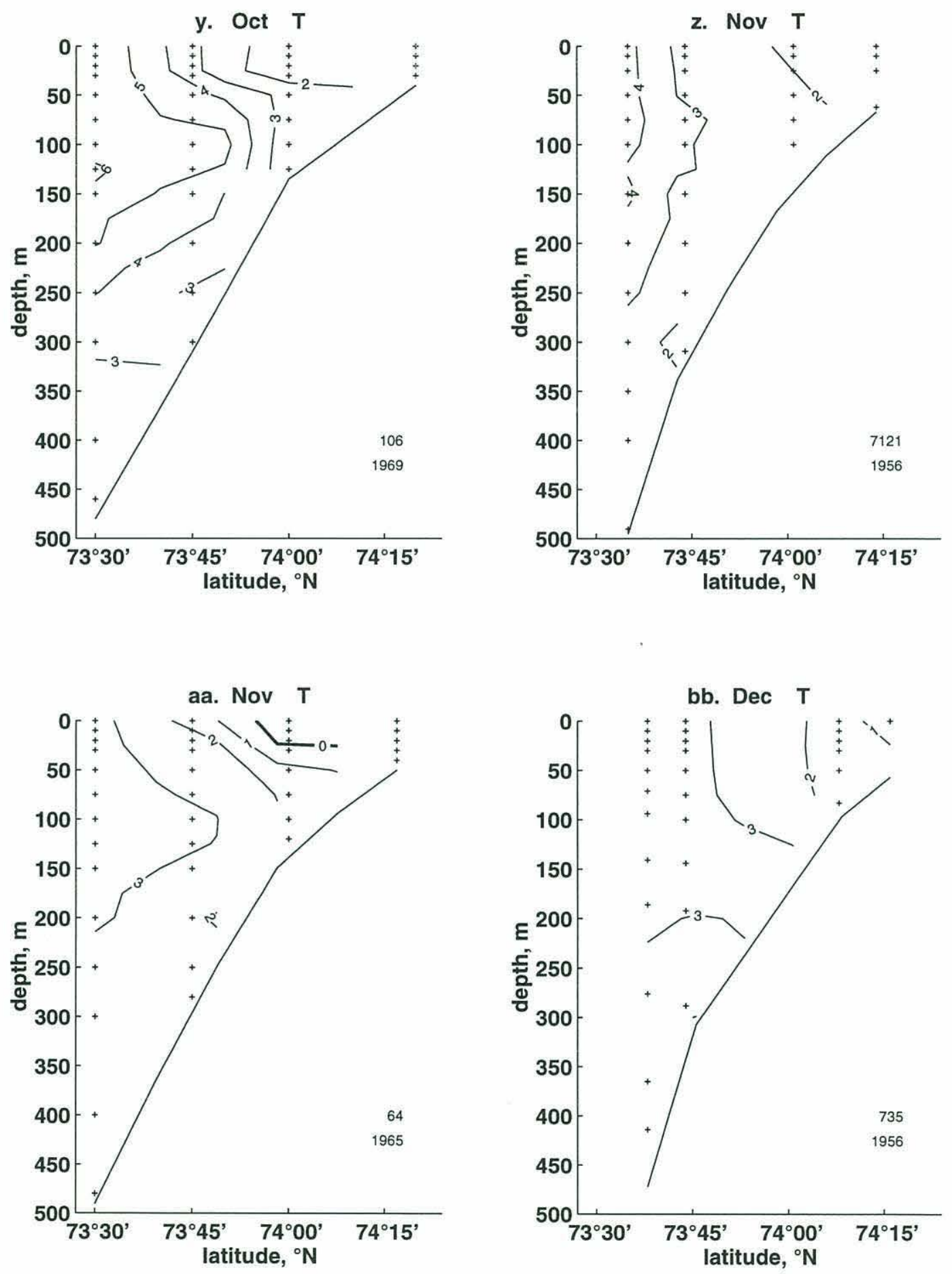

Figure B.5: continued. 


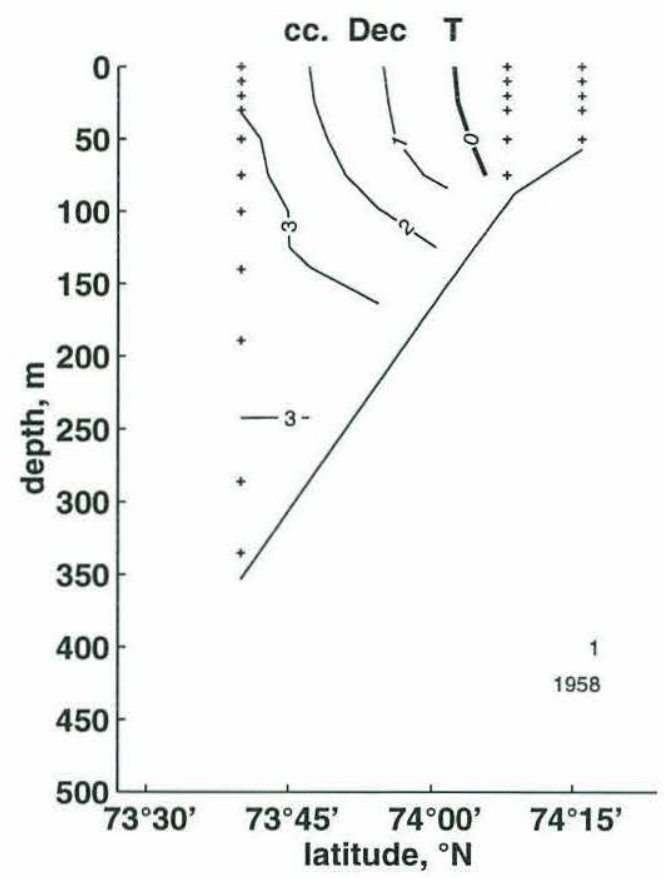

Figure B.5: continued. 

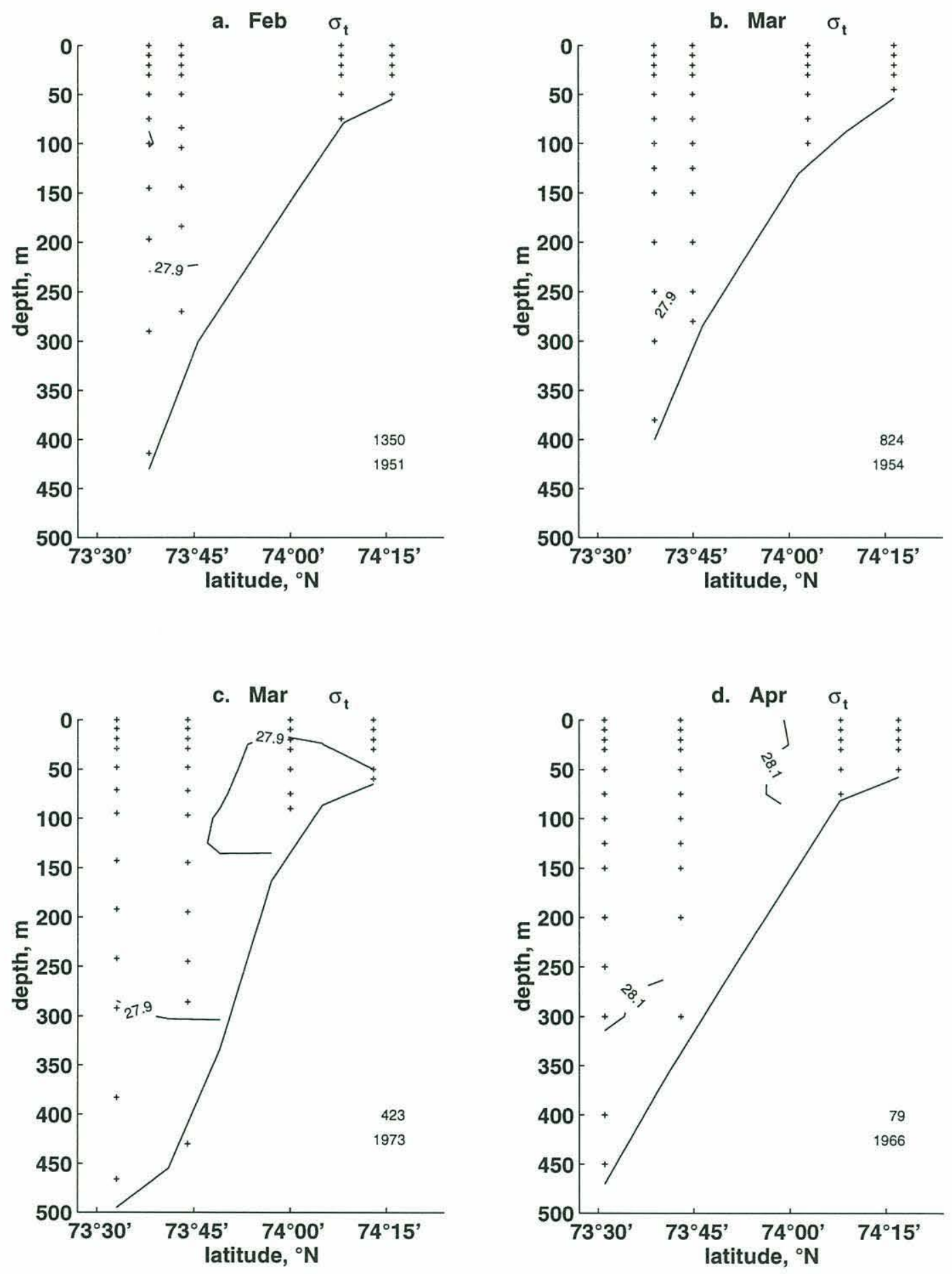

Figure B.6: NODC-B density $\left(\sigma_{t}\right)$ transects. The contour interval is $0.2 \mathrm{~kg} / \mathrm{m}^{3}$. Figure B.2 is the key for this figure. See Figures B.3, B.4, B.5 for other transect data. 

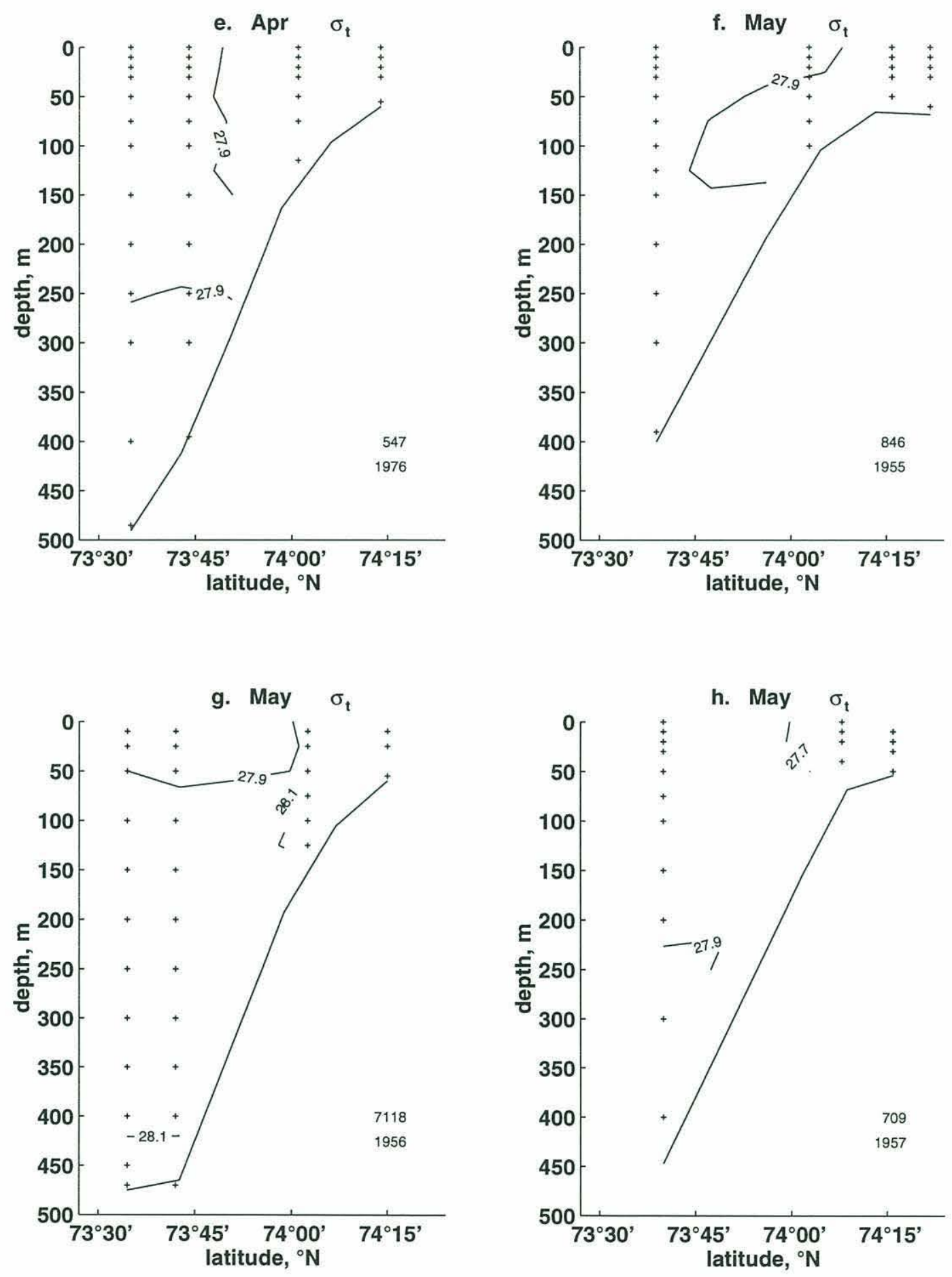

Figure B.6: continued. 

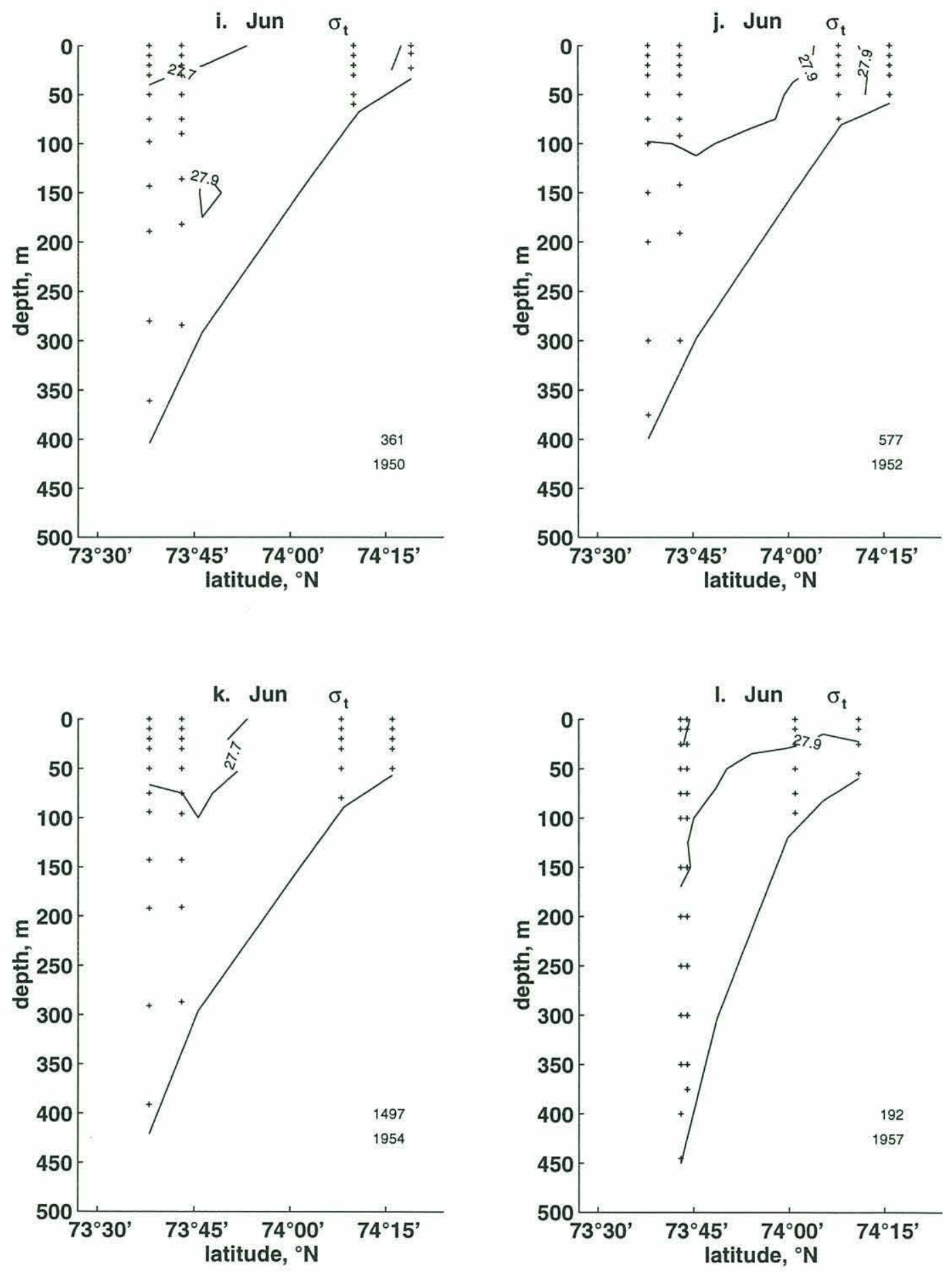

Figure B.6: continued. 

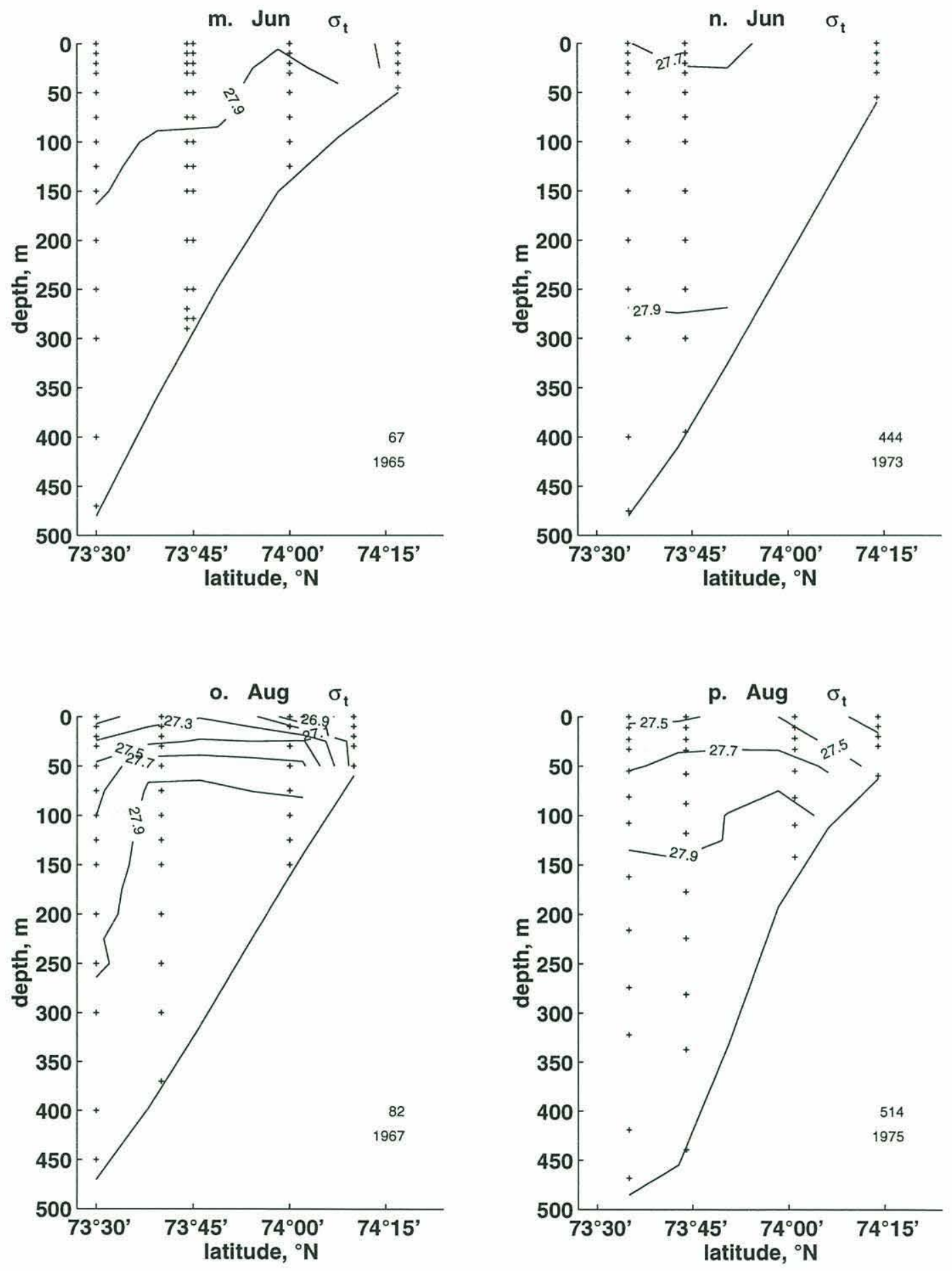

Figure B.6: continued. 

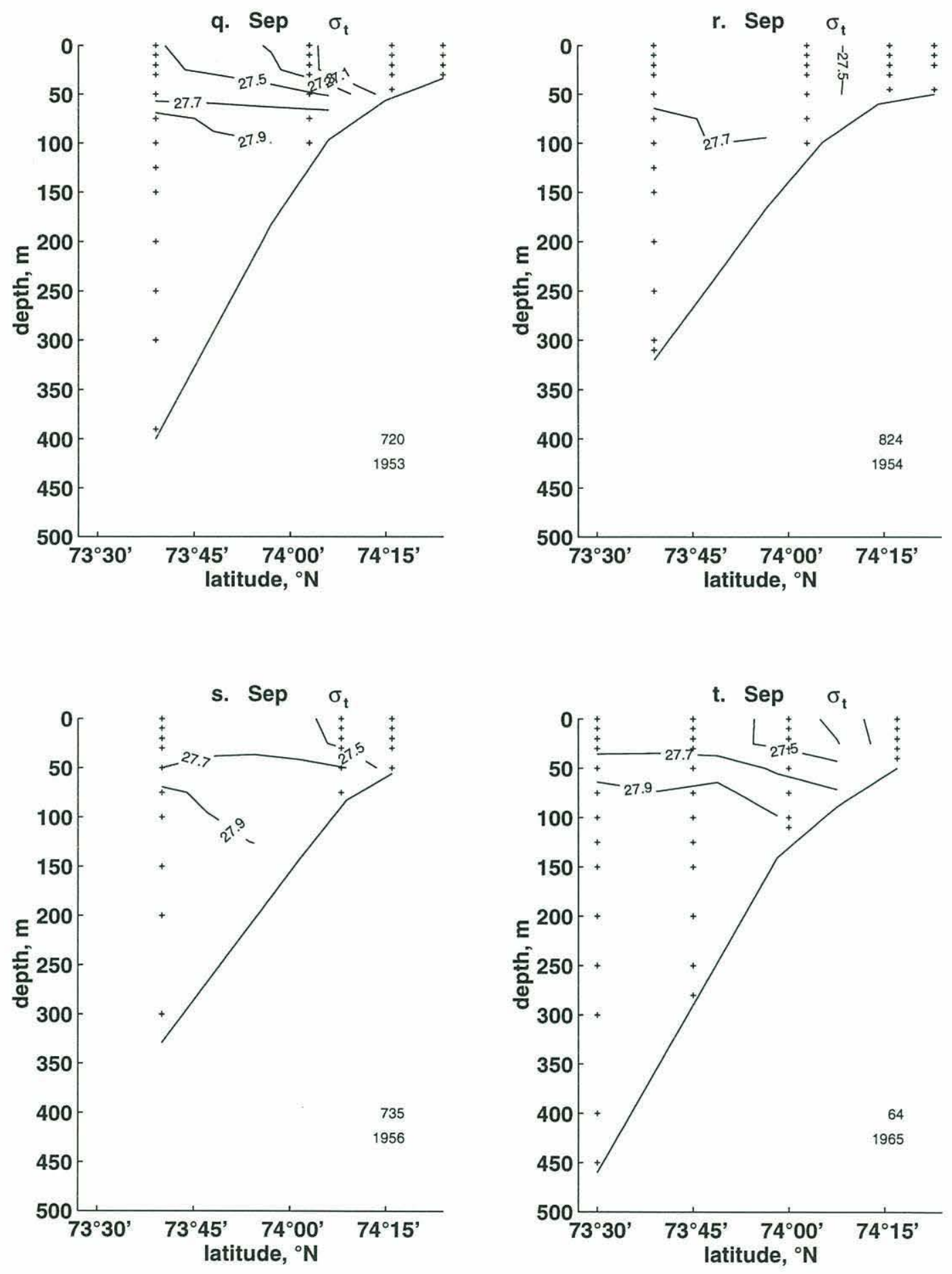

Figure B.6: continued. 

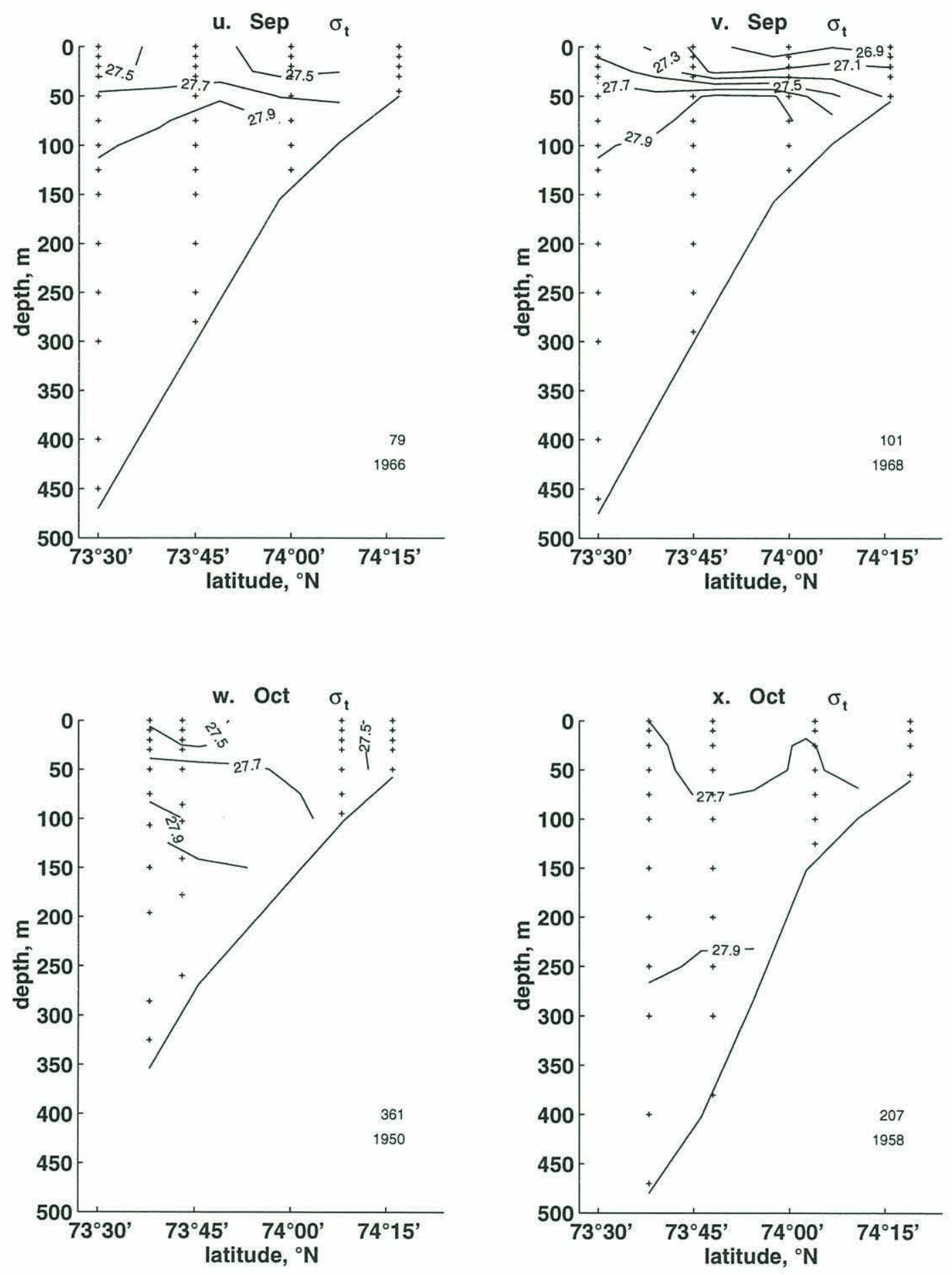

Figure B.6: continued. 

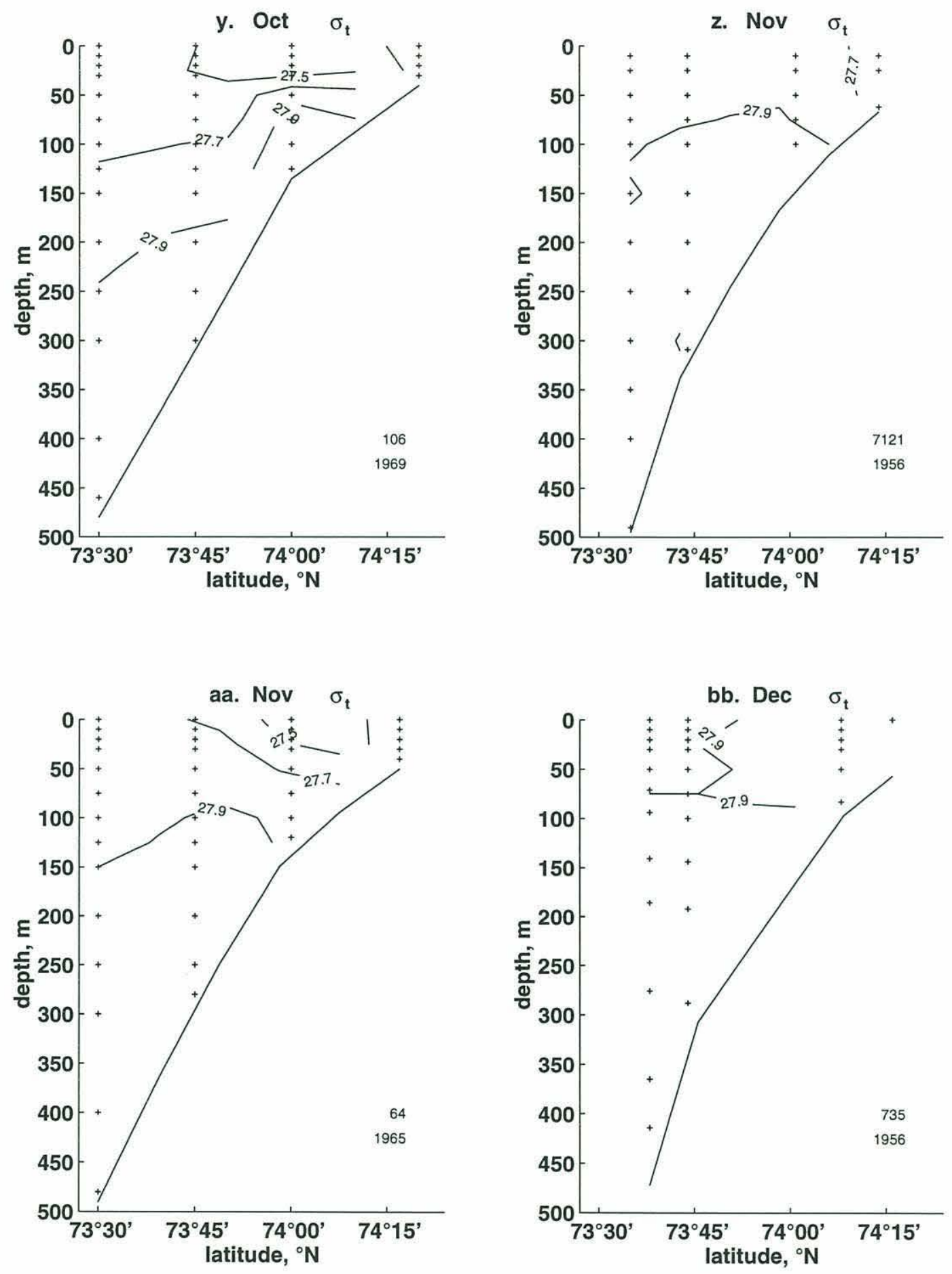

Figure B.6: continued. 


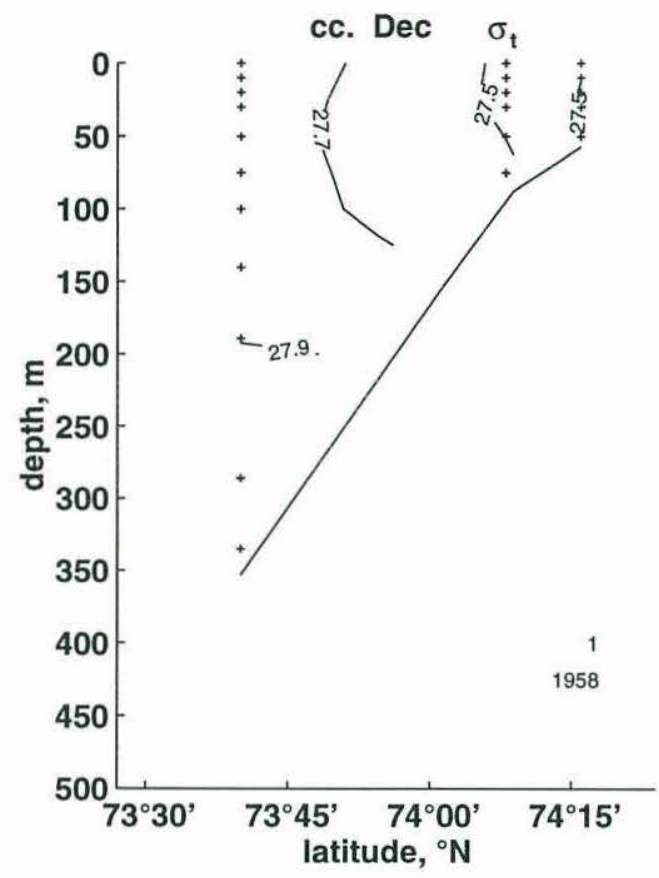

Figure B.6: continued. 